ELECTROCHEMICAL AND OPTICAL PROPERTIES OF SOLUTION PROCESSABLE BENZOTRIAZOLE AND BENZOTHIADIAZOLE CONTAINING COPOLYMERS

A THESIS SUBMITTED TO

THE GRADUATE SCHOOL OF NATURAL AND APPLIED SCIENCES $\mathrm{OF}$ MIDDLE EAST TECHNICAL UNIVERSITY

BY

MELIKKE KARAKUŞ

IN PARTIAL FULFILLMENT OF THE REQUIREMENTS

FOR

THE DEGREE OF MASTER OF SCIENCE

IN

CHEMISTRY

SEPTEMBER 2011 
Approval of the thesis:

\section{ELECTROCHEMICAL AND OPTICAL PROPERTIES OF SOLUTION PROCESSABLE BENZOTRIAZOLE AND BENZOTHIADIAZOLE CONTAINING COPOLYMERS}

submitted by MELIKE KARAKUŞ in partial fulfillment of the requirements for the degree of Master of Science in Chemistry Department, Middle East Technical University by,

Prof. Dr. Canan Özgen

Dean, Graduate School of Natural and Applied Sciences

Prof. Dr. İlker Özkan

Head of Department, Chemistry

Assist. Prof. Dr. Ali Çırpan

Supervisor, Chemistry Dept., METU

Prof. Dr. Levent Toppare

Co-advisor, Chemistry Dept., METU

Examining Committee Members:

Assoc. Dr. Metin Ak

Chemistry Dept., Pamukkale University

Assist. Prof. Dr. Ali Çırpan

Chemistry Dept., METU

Prof. Dr. Levent Toppare

Chemistry Dept., METU

Assoc. Dr. Yasemin Arslan Udum

Chemistry Dept., Gazi University

Dr. Bilge Emre

Elementary Educ., Inonu University

Date: 12.09 .2011 
I hereby declare that all information in this document has been obtained and presented in accordance with academic rules and ethical conduct. I also declare that, as required by these rules and conduct, I have fully cited and referenced all material and results that are not original to this work.

Name, Last name: MELIKKE KARAKUŞ

Signature:

iii 


\title{
ABSTRACT \\ ELECTROCHEMICAL AND OPTICAL PROPERTIES OF SOLUTION PROCESSABLE BENZOTRIAZOLE AND BENZOTHIADIAZOLE CONTAINING COPOLYMERS
}

\author{
Karakuş, Melike \\ M.Sc., Department of Chemistry \\ Supervisor: Assist. Prof. Dr. Ali Çırpan \\ Co-supervisor: Prof. Dr. Levent Toppare
}

September 2011, 87 Pages

2-Dodecyl benzotriazole (BTz) and benzothiadiazole (BTd) containing copolymers poly(4-(2-dodecyl-2H-benzo[d][1,2,3]triazol-4-yl)benzo[c][1,2,5]thiadiazole (P1), poly(4-(5-(2-dodecyl-7-(thiophen-2yl)-2H-benzo[d][1,2,3]triazol-4-yl)thiophen-2yl)benzo[c][1,2,5] thiadiazole (P2) and poly(4-(5-(2-dodecyl-7-(4-hexylthiophen-2yl)-2H-benzo[d] [1,2,3]triazol-4-yl) -3-hexylthiophen-2-yl) benzo[c][1,2,5] thiadiazole (P3) were synthesized via Suzuki polymerization. Electrochemical and optical properties of the polymers were analyzed. The fabrication of solar cells were carried out and current density-voltage ( $\mathrm{J}-\mathrm{V})$ and incident photon to charge carrier efficiency (IPCE) measurements were done to characterize the solar cells.

Keywords: Solar Cell, Electrochromism, Donor-Acceptor Theory, Suzuki Coupling. 


\title{
ÖZ
}

\section{BENZOTRİAZOL VE BENZOTHIDİAZOL İÇEREN KOPOLIMERLERIN ELEKTROKROMIKK VE FOTOVOLTAİK ÖZELLIKKLERİ}

\author{
Karakuş, Melike \\ Yüksek Lisans, Kimya Bölümü \\ Tez Yöneticisi: Yrd. Doç. Dr. Ali Çırpan \\ Ortak Tez Yöneticisi: Prof. Dr. Levent Toppare \\ Eylül 2011, 87 sayfa
}

2-Dodesil benzotriazol (BTz) ve benzothiadiazol (BTd) içeren poli(4-(2-dodesil2H-benzo[d][1,2,3]triazol-4-yl)benzo[c][1,2,5]thiadiazol (P1), poli(4-(5-(2-dodesil7-(thiophen-2yl)-2H-benzo[d][1,2,3]triazol-4-yl)thiophen-2-yl)benzo[c][1,2,5] thiadiazol (P2) ve poli(4-(5-(2-dodesil-7-(4-hexylthiophen-2-yl)-2Hbenzo[d][1,2,3]triazol-4-yl)-3-hexylthiophen-2-yl) benzo[c][1,2,5] thiadiazol (P3) kopolimerleri Suziki polimerleştirme metoduyla sentezlenmiştir. Bu polimerlerin elektrokimyasal ve optik özellikleri analiz edilmiştir. Bu polimerlerden güneş pili yapılmış ve akım yoğunluğu- potansiyel $(\mathrm{J}-\mathrm{V})$ ve gelen fotonun yük taşıma verimine oranı (IPCE) ölçümleriyle karakterize edilmiştir.

Anahtar Sözcükler: Güneş Pili, Elektrokromizm, Donör-Akseptör, Suziki Birleşmesi. 
To My Family 


\section{ACKNOWLEDGMENTS}

I would like to express my sincere thanks to my supervisor Assist. Prof. Dr. Ali Çırpan and my coadvisor Prof. Dr. Levent Toppare for their guidance, support, encouragement, patience, advice, criticism and for listening and helping me in many ways.

I would like to thank to Abidin Balan, Derya Baran and Doğukan Hazar Apaydın for their kind friendships and helps during the experiments.

I would like to thank to Emine Kaya, my close friend, for her friendship and cooperation beginning from our undergraduate years.

I would like to thank to all Toppare Research Group members for their friendship.

My deepest thanks to my family for believing in me and giving me endless support. 


\section{TABLE OF CONTENTS}

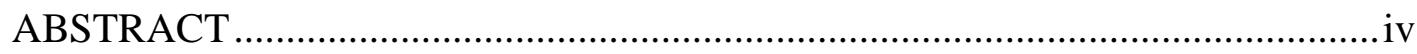

ÖZ

ACKNOWLEDGMENTS................................................................................

TABLE OF CONTENTS .................................................................................. vii

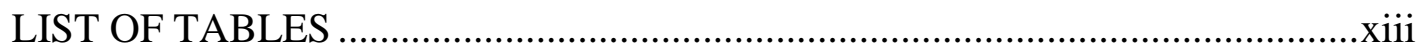

LIST OF FIGURES ..................................................................................

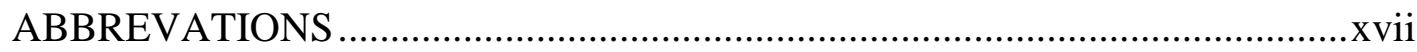

CHAPTERS

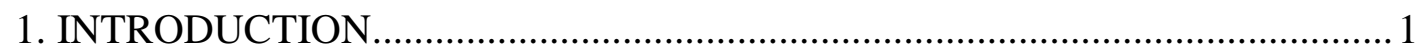

1.1 Conjugated Polymers ....................................................................................... 1

1.2 Band Theory

1.3 Conduction in $\pi$-Conjugated Organic Materials …….......................................

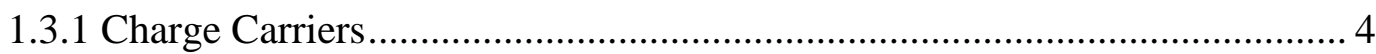

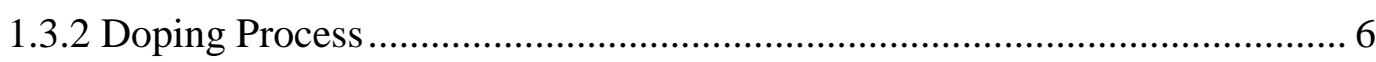

1.4 Polymerization Methods ............................................................................

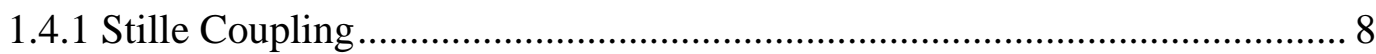

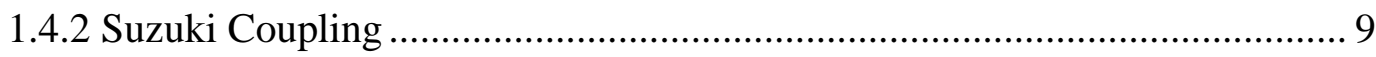

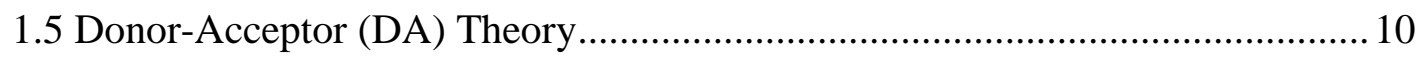

viii 


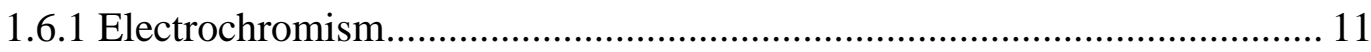

1.6.1.1 Advantages of Conjugated Polymers in Electrochromic Applications . 12

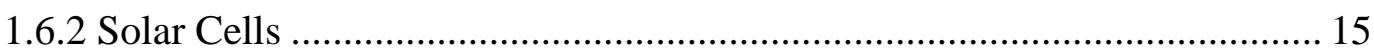

1.6.2.1 Advantages of Conjugated Polymers in Solar Cell Applications .......... 15

1.6.2.2 Bulk Heterojunction Organic Solar Cells ........................................... 16

1.6.2.3 Working Principle of BHJ Organic Solar Cells.................................. 17

1.6.2.4 Structure of BHJ Organic Solar Cell .................................................. 19

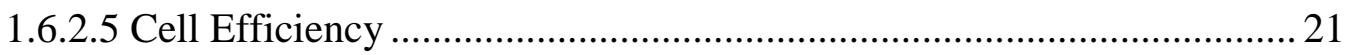

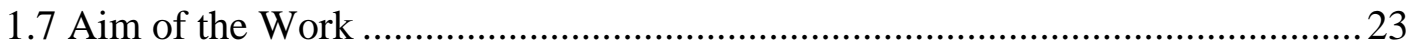

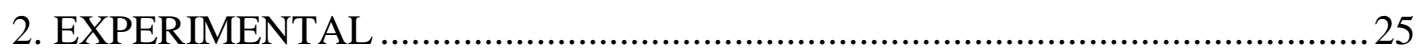

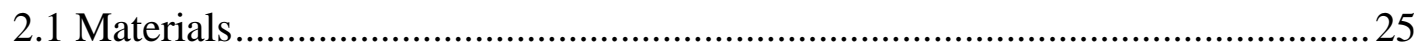

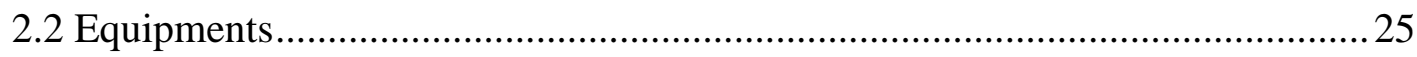

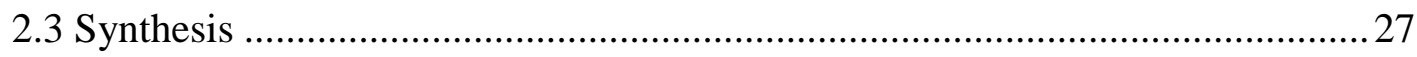

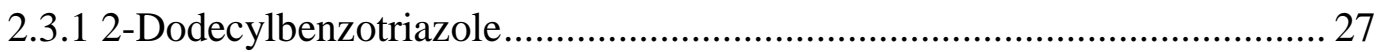

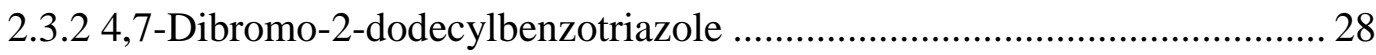

2.3.3 Tributyl(thiophen-2-yl)stannane and Tributyl(4-hexylthiophen-2 yl)stannane 28

2.3.4 2-Dodecyl-4,7-di(thiophen-2-yl)-2H-benzo[d][1,2,3]triazole (TBT) ......... 29

2.3.5 2-Dodecyl-4,7-bis(4-hexylthiophen-2-yl)-2Hbenzo[d][1,2,3]triazole (HTBT) 
2.4.1Poly(4-(2-dodecyl-2H-benzo[d][1,2,3]triazol-4 yl) benzo[c] [1,2,5 ] thiadiazole (P1) 32

2.4.2 Poly(4-(5-(2-dodecyl-7-(thiophen-2yl)-2H-benzo[d][1,2,3]triazol-4yl)thiophen-2-yl)benzo[c][1,2,5]thiadiazole (P2) 33

2.4.3 Poly(4-(5-(2-dodecyl-7-(4-hexylthiophen-2-yl)-2H-benzo[d][1,2,3] triazol4-yl)-3-hexylthiophen-2-yl)benzo[c][1,2,5] thiadiazole (P3) 33

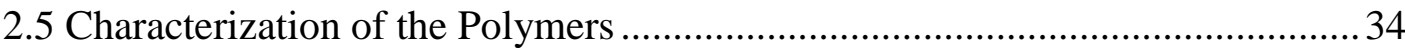

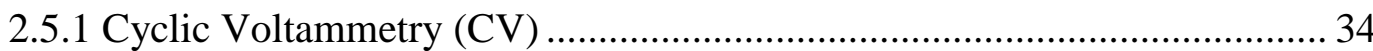

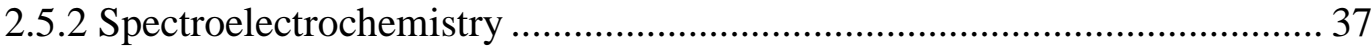

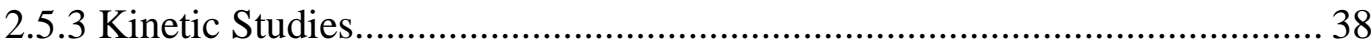

2.5.4 Gel Permeation Chromatography (GPC).................................................. 39

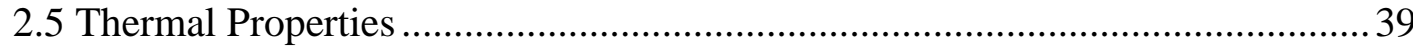

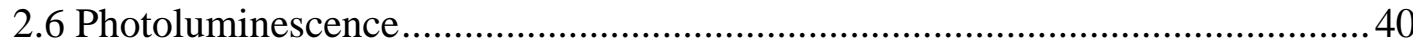

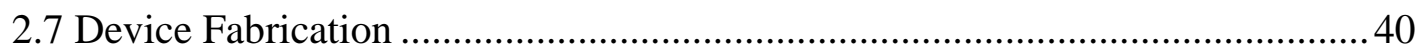

2.8 Characterization of the Solar Cells ................................................................ 41

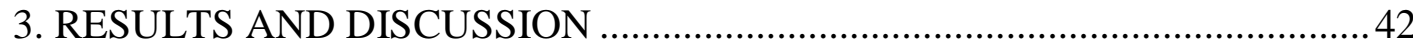

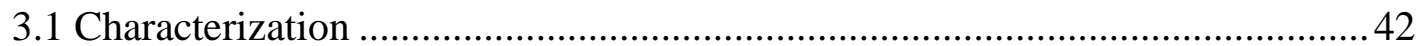

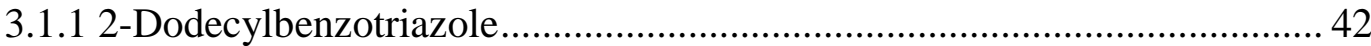


3.1.3 2-Dodecyl-4,7-di(thiophen-2-yl)-2H-benzo[d][1,2,3]triazole (TBT) 45

3.1.4 2-Dodecyl-4,7-bis(4-hexylthiophen-2-yl)-2Hbenzo[d][1,2,3]triazole (HTBT) 47

3.1.5 4,7-Bis(5-bromothien-2-yl)-2-dodecylbenzo[1,2,3]triazole 48

3.1.6 4,7-Bis(5-bromo-4-hexylthien-2-yl)-2-dodecylbenzo[1,2,3]triazole 50

3.1.7 Poly(4-(2-dodecyl-2H-benzo[d][1,2,3]triazol-4 yl) benzo[c] [1,2,5 ] thiadiazole $(\mathrm{P} 1)$. 51

3.1.8 Poly(4-(5-(2-dodecyl-7-(thiophen-2yl)-2H-benzo[d][1,2,3]triazol-4-yl) thiophen-2-yl)benzo[c][1,2,5]thiadiazole (P2) 52

3.1.9 Poly(4-(5-(2-dodecyl-7-(4-hexylthiophen-2-yl)-2H-benzo[d][1,2,3] triazol4-yl)-3-hexylthiophen-2-yl)benzo[c][1,2,5] thiadiazole (P3) 53

3.2 Poly(4-(2-dodecyl-2H-benzo[d][1,2,3]triazol-4 yl) benzo[c] [1,2,5 ] thiadiazole (P1) .54

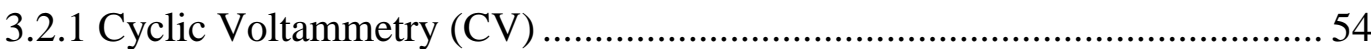

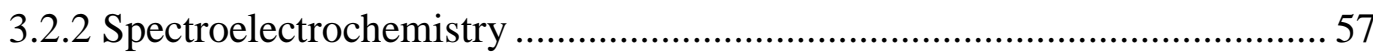

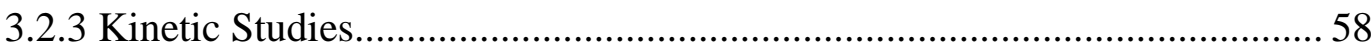

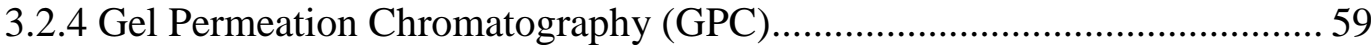

3.3 Poly(4-(5-(2-dodecyl-7-(thiophen-2yl)-2H-benzo[d][1,2,3]triazol-4-

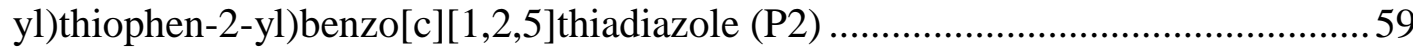

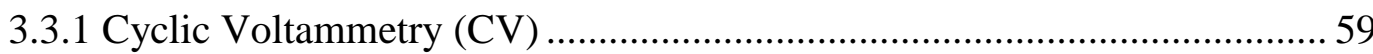

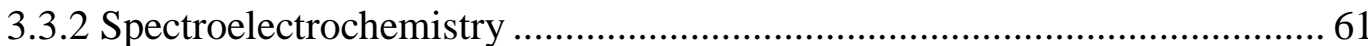


3.3.3 Kinetic Studies. 63

3.3.4 Gel Permeation Chromatography 64

3.4 Poly(4-(5-(2-dodecyl-7-(4-hexylthiophen-2-yl)-2H-benzo[d][1,2,3] triazol-4-

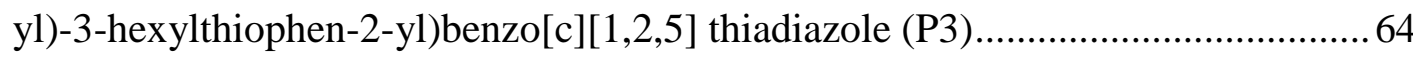

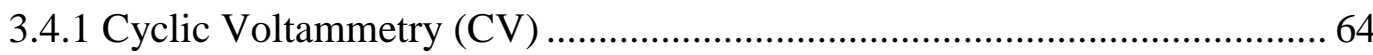

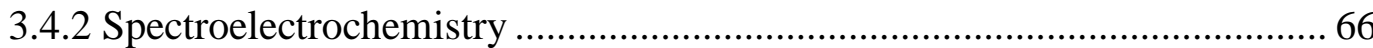

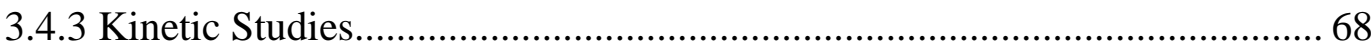

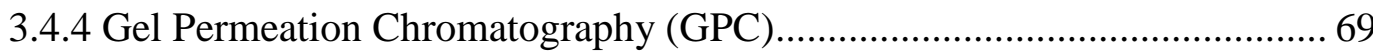

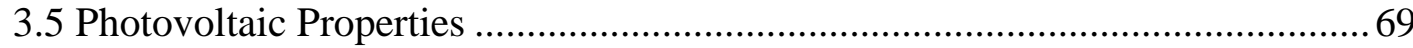

3.5.1 Normalized UV-Vis Absorption of Polymers in Solution and Thin Film... 69

3.5.2 Photoluminescence Spectra of Polymers............................................... 71

3.5.3 BHJ Solar Cell Characterization ............................................................. 72

3.5.3 IPCE Spectrum of the Polymers ............................................................... 74

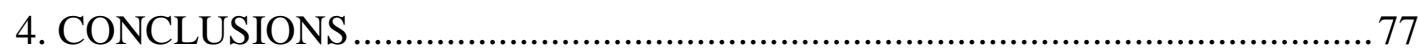

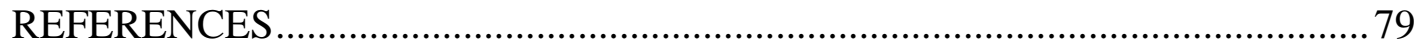

APPENDICES

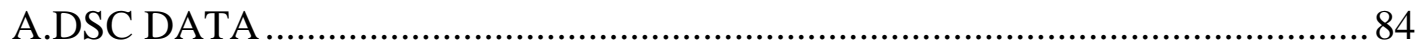

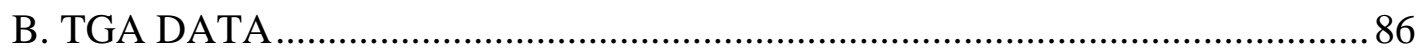




\section{LIST OF TABLES}

\section{TABLES}

Table 1. Cyclic Voltammetry and EVS results of P1 (CV was recorded in $0.1 \mathrm{M}$

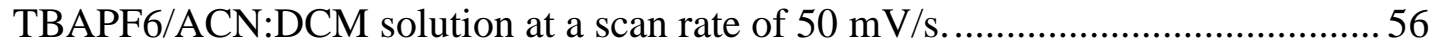

Table 2. Cyclic Voltammetry and EVS results of $\mathrm{P} 2$ (CV was recorded in $0.1 \mathrm{M}$ $\mathrm{TBAPF}_{6} / \mathrm{ACN}$ : DCM solution at a scan rate of $50 \mathrm{mV} / \mathrm{s}$.

Table 3. Cyclic Voltammetry and EVS results of P2 (CV was recorded in $0.1 \mathrm{M}$ $\mathrm{TBAPF}_{6} / \mathrm{ACN}: \mathrm{DCM}$ solution at a scan rate of $50 \mathrm{mV} / \mathrm{s}$.

Table 4. Photovoltaic Performance of the solar cells based on P1:PCBM, P2:PCBM and P3:PCBM 


\section{LIST OF FIGURES}

\section{FIGURES}

Figure 1.1 Chemical structures of some conjugated polymers. (a) polyacetylene, (b) polythiophene, (c) polypyrrole, (d) polyfuran, (e)polyaniline, (f) polycarbazole (g) poly(p-phenylene)

Figure 1.2 Band pictures of an insulator, a semiconductor and a metal.

Figure 1.3 Soliton structures in polyacetylene and corresponding electronic states in

the band gap, a) neutral soliton, b) positive soliton, c) negative soliton. 5

Figure 1.4 Polaron and bipolaron structures in poly(p-phenylenevinylene) with their corresponding electronic states in the band gap.

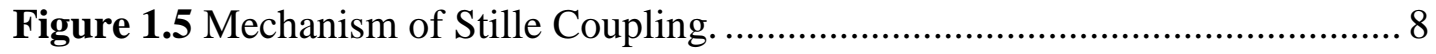

Figure 1.6 Mechanism of Suzuki Coupling. ........................................................... 10

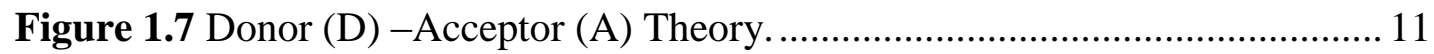

Figure 1.8 Examples of electrochromic polymers synthesized by structural

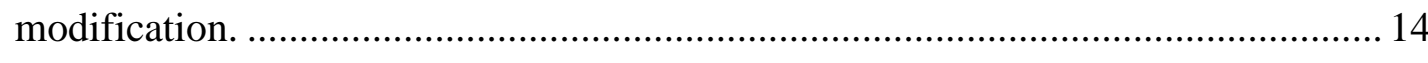

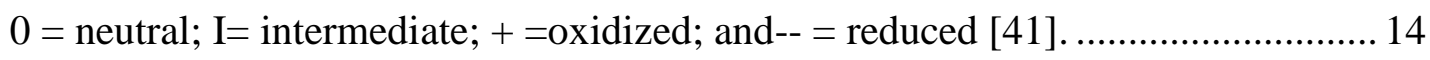

Figure 1.9 Structure of $\mathrm{C}_{60}$, its soluble form [6,6]-phenyl- $\mathrm{C}_{61}$-butyric acid methyl ester $\left(\mathrm{PC}_{61} \mathrm{BM}\right)$ and [6,6]-phenyl- $\mathrm{C}_{71}$-butyric acid methyl ester $\left(\mathrm{PC}_{70} \mathrm{BM}\right)$.

Figure 1.10 Working Principle of BHJ solar cells. Left: kinetic point of view, right: simplified energy diagram. (i) singlet exciton generation. (ii) exciton diffusion to the acceptor interface. (iii) exciton dissociation. (iv) electron-hole pair seperation.(v) charge transport [54].

Figure 1.11 Structure of a Bulk Heterojunction Solar Cell.................................. 20

Figure 1.12 Energy Band Diagram in a BHJ Solar Cell. ..................................... 20 
Figure 1.13 A typical current density -voltage characteristic of a Bulk

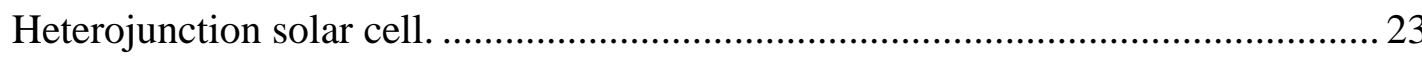

Figure 2.1 Synthetic route for 2-dodecylbenzotriazole..................................... 27

Figure 2.2 Synthetic route for 4,7-dibromo-2-dodecylbenzotriazole...................... 28

Figure 2.3 Synthetic route for stannylation of thiophene and 3-hexyl thiophene.... 28

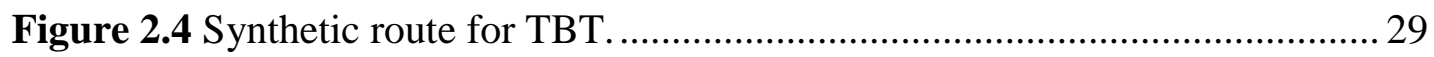

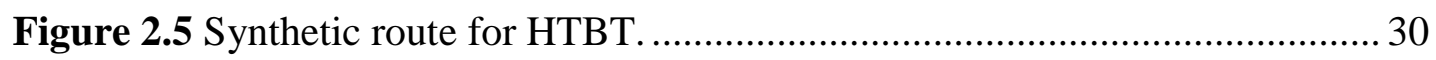

Figure 2.6 Synthetic route for 4,7-bis(5-bromothien-2-yl)-2 dodecylbenzo............ 30

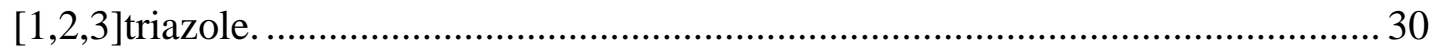

Figure 2.7 Synthetic route for 4,7-bis(5-bromo-4-hexylthien-2-yl)-2-

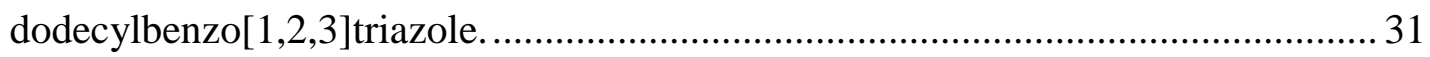

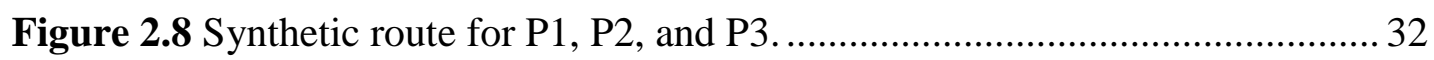

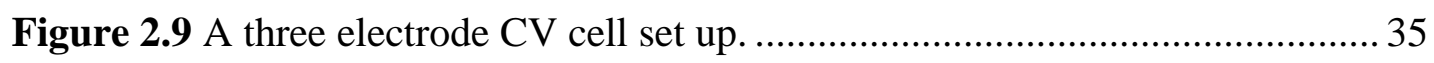

Figure 2.10 A typical cyclic voltammogram of a reversible $\mathrm{O}+$ ne ${ }^{-} \leftrightarrow \mathrm{R}$ redox

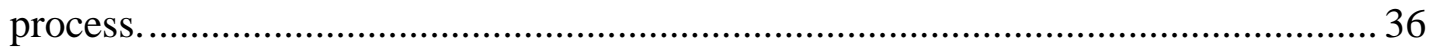

Figure 3.1 a) ${ }^{1} \mathrm{H}-\mathrm{NMR}$ and b) ${ }^{13} \mathrm{C}$ NMR of 2-dodecylbenzotriazole. ...................... 43

Figure 3.2 a) ${ }^{1} \mathrm{H}-\mathrm{NMR}$ and b) ${ }^{13} \mathrm{C}$ NMR of 4,7- Dibromo-2-dodecylbenzotriazole.

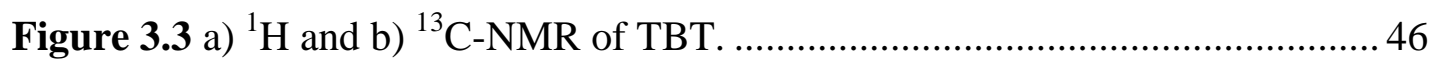

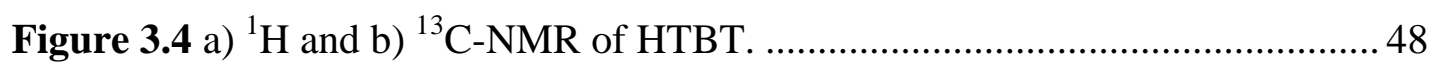

Figure 3.5 a) ${ }^{1} \mathrm{H}$ and b) ${ }^{13} \mathrm{C}-\mathrm{NMR}$ NMR of 4,7-bis(5-bromothien-2-yl)-2-

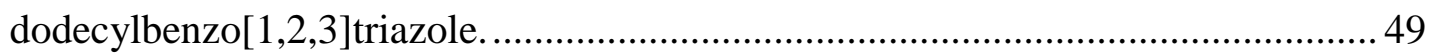

Figure 3.6 a) ${ }^{1} \mathrm{H}$ and b) ${ }^{13} \mathrm{C}-\mathrm{NMR}$ NMR of 4,7-bis(5-bromo-4-hexylthien-2-yl)-2-

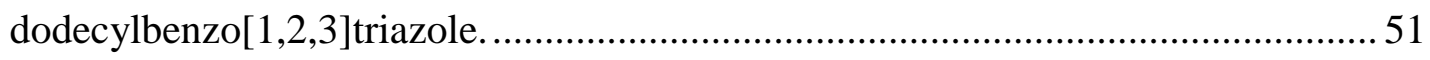

Figure 3.7 ${ }^{1} \mathrm{H}$ NMR of Poly(4-(2-dodecyl-2H-benzo[d][1,2,3]triazol-4 yl) benzo[c]

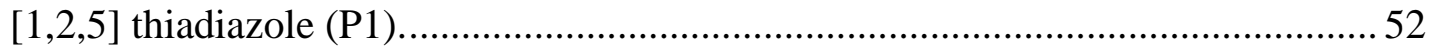


Figure 3.8 ${ }^{1} \mathrm{H}$ NMR of Poly(4-(5-(2-dodecyl-7-(thiophen-2yl)-2H benzo [d] [1,2,3] triazol-4-yl)thiophen-2-yl)benzo[c][1,2,5]thiadiazole (P2).

Figure 3.9 ${ }^{1} \mathrm{H}$ of Poly(4-(5-(2-dodecyl-7-(4-hexylthiophen-2-yl)-2H-benzo[d][1,2,3] triazol-4-yl)-3-hexylthiophen-2-yl)benzo[c][1,2,5] thiadiazole (P3).

Figure 3.10 Cyclic voltammogram of $\mathrm{P} 1$ for both $\mathrm{p}$ and $\mathrm{n}$ type doping in the presence of $0.1 \mathrm{M} \mathrm{TBAPF}_{6} / \mathrm{ACN}: \mathrm{DCM}$ solution at a scan rate of $50 \mathrm{mV} / \mathrm{s}$.

Figure 3.11 p-Doping electronic absorption spectra of P1 between 0.0 and $1.85 \mathrm{~V}$ in 0.1 $\mathrm{M} \mathrm{TBAPF}_{6} / \mathrm{ACN}: \mathrm{DCM}$ (9:1) electrolyte-solvent couple.

Figure 3.12 Optical transmittance changes of $\mathrm{P} 1$ monitored at $460 \mathrm{~nm}$ while switching the potentials between its oxidized and reduced states

Figure 3.13 Cyclic voltammogram of $\mathrm{P} 2$ for both $\mathrm{p}$ and $\mathrm{n}$ type doping in the presence of $0.1 \mathrm{M} \mathrm{TBAPF}_{6} / \mathrm{ACN}: \mathrm{DCM}$ solution at a scan rate of $50 \mathrm{mV} / \mathrm{s}$.

Figure 3.14 p-Doping electronic absorption spectra of $\mathrm{P} 2$ between 0.0 and $1.45 \mathrm{~V}$ in 0.1 M TBAPF 6 / ACN:DCM (9:1) electrolyte-solvent couple.

Figure 3.16 Square wave potential step chronoapsorptometry studies of P2 monitored at its maximum absorption wavelengths between $0.0 \mathrm{~V}$ and $1.4 \mathrm{~V}$.

Figure 3.17 Cyclic voltammogram of $\mathrm{P} 3$ for both $\mathrm{p}$ and $\mathrm{n}$ type doping in the presence of $0.1 \mathrm{M}$ TBAPF6/ACN:DCM solution at a scan rate of $50 \mathrm{mV} / \mathrm{s}$.

Figure 3.18 p-Doping electronic absorption spectra of $\mathrm{P} 3$ between 0.0 and $1.3 \mathrm{~V}$ in 0.1 $\mathrm{M} \mathrm{TBAPF}_{6} / \mathrm{ACN}: \mathrm{DCM}(9: 1)$ electrolyte-solvent couple.

Figure 3.19 Colors of the electrochromic electrodes of P3 at different potentials... 67

Figure 3.20 Square wave potential step chronoapsorptometry studies of P3 monitored at its maximum absorption wavelengths between $0.0 \mathrm{~V}$ and $1.4 \mathrm{~V}$. 68

Figure 3.21 Normalized UV-Vis spectra of the P1, P2, P3 in chloroform............... 70

Figure 3.22 Normalized UV-Vis spectra of the P1, P2, P3 in solid state. ............... 70

Figure 3.23 PL spectra of P1, P2 and P3 in chloroform................................... 71

Figure 3.24 J-V Curve of the solar cells based on P1:PCBM (1-3), P2:PCBM (1:1) and P3:PCBM (1:3). 
Figure 3.25 IPCE spectra of 1:3 P1:PC ${ }_{61} \mathrm{BM}$ based solar cell. .............................. 75

Figure 3.26 IPCE spectra of 1:1 P2:PC ${ }_{61} \mathrm{BM}$ based solar cell. ............................... 75

Figure 3.27 IPCE spectra of 1:3 P3:PC ${ }_{61} \mathrm{BM}$ based solar cell. .............................. 76

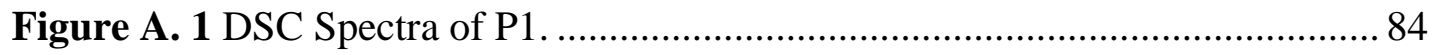

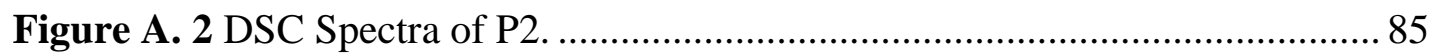

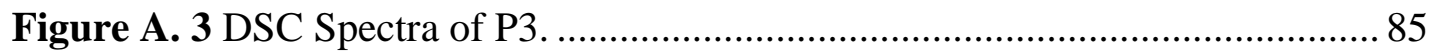

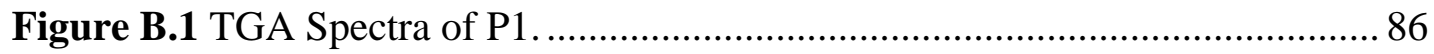

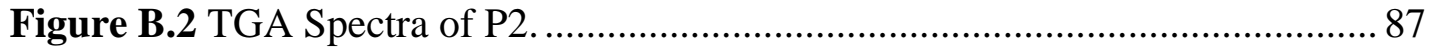

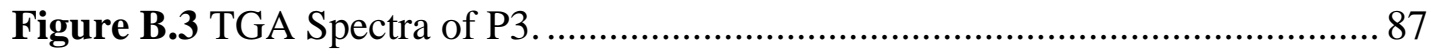




\section{ABBREVATIONS}

\begin{tabular}{ll} 
ACN & Acetonitrile \\
BHJ & Bulk Heterojunction \\
BTz & Benzotriazole \\
BTd & Benzothiadiazole \\
CP & Conjugated Polymer \\
CV & Cyclic Voltammetry \\
DA & Donor Acceptor Donor \\
DCM & Dichloromethane \\
DSC & Differential Scanning Calorimetry \\
LED & Light Emitting Diode \\
IPCE & Incident photon to current efficiency \\
ECDs & Electrochromic Device \\
HOMO & Highest Occupied Molecular Orbital \\
\hline
\end{tabular}

xviii 
NMR Nuclear Magnetic Resonance

OLEDs Organic Light Emitting Diodes

OFETs Organic Field Effect Transistors

PA Polyacetylene

PL Photoluminescence

$\mathbf{P C}_{61} \mathbf{B M} \quad[6,6]$-phenyl- $\mathrm{C}_{61}$-butyric acid methyl ester

P3HT Poly (3-Hexylthiophene)

PEDOT:PSS Poly(3,4-ethylenedioxythiophene)

TBAPF $_{6}$ Tetrabutylammonium hexafluorophosphate

2-Dodecyl-4,7-di(thiophen-2-yl)-2H-benzo[d][1,2,3]triazole

TGA Thermal Gravimetric Analysis

VB Valence Band 


\section{CHAPTER 1}

\section{INTRODUCTION}

\subsection{Conjugated Polymers}

The first conjugated polymer was synthesized by Letheby in 1862 . This conjugated polymer was polyaniline, known as "aniline black" [1], which was produced on an electrode surface via electrolytic oxidation of aniline [2]. Natta and coworkers made the polymerization of polyacetylene (PA) in 1958 [3]. The electrical conducting characteristic of polymers has been used after the discovery that PA can be turned into a conducting polymer upon doping process. Alan Heeger, Hideki Shirakawa and Alan MacDiarmid were awarded with the Chemistry Nobel Prize in 2000 for the idea that plastic can conduct electric current. After this discovery, the conjugated polymers become futuristic new materials that combine the characteristics of metals or semiconductors and plastics. These properties are electrical conductivity, optical activity, flexibility and processability [4-7].

Conjugated polymers have alternating double and single bonds along their chains in which all carbon atoms are singly bonded to neighboring carbon atoms and remaining valence electrons are bound to hydrogen atoms. PA has the simplest structure that includes a conjugated $\pi$ system extending over the polymer chain. (Figure 1.1a) New structures of conjugated polymers (Figure 1.1) have been synthesized over the past two decades [8]. 


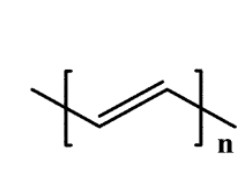

(a)

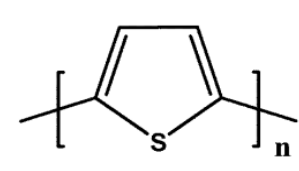

(b)

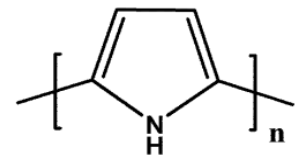

(c)

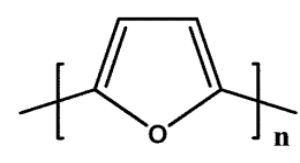

(d)

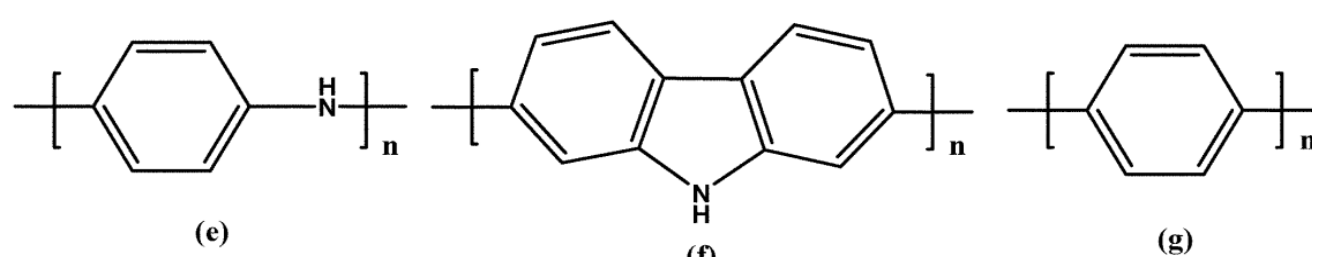

(f)

(g)

Figure 1.1 Chemical structures of some conjugated polymers. (a) polyacetylene, (b) polythiophene, (c) polypyrrole, (d) polyfuran, (e)polyaniline, (f) polycarbazole (g) poly(p-phenylene).

There are numerous synthetic strategies to obtain new $\pi$ conjugated organic structures with high electrical conductivity, optical and environmental stability, processability and flexibility. Most studies related to constructing these types of new materials show that band gap of the materials, as well as the position of the edges of the conduction band and valence band are the most important factors to achieve the required electronic and optical properties [9-11]. 


\subsection{Band Theory}

Band theory explains the electrical behavior of metals, semiconductors and insulators. According to the theory, a metal conducts electricity due to the mobile electrons where the conduction and valence bands overlapped. However, this is not valid for an insulator due to its high band gap which results from the large energy difference between its conduction and valence bands.

A semiconductor has a filled valence band and an empty conduction band separated by a gap where no energy levels are present. After the excitation of electrons by a thermal or a photochemical process, the electrons will transfer to the conduction band from the valence band. This situation explains the electron transfer, thus the conduction of electricity in semiconductors [12].

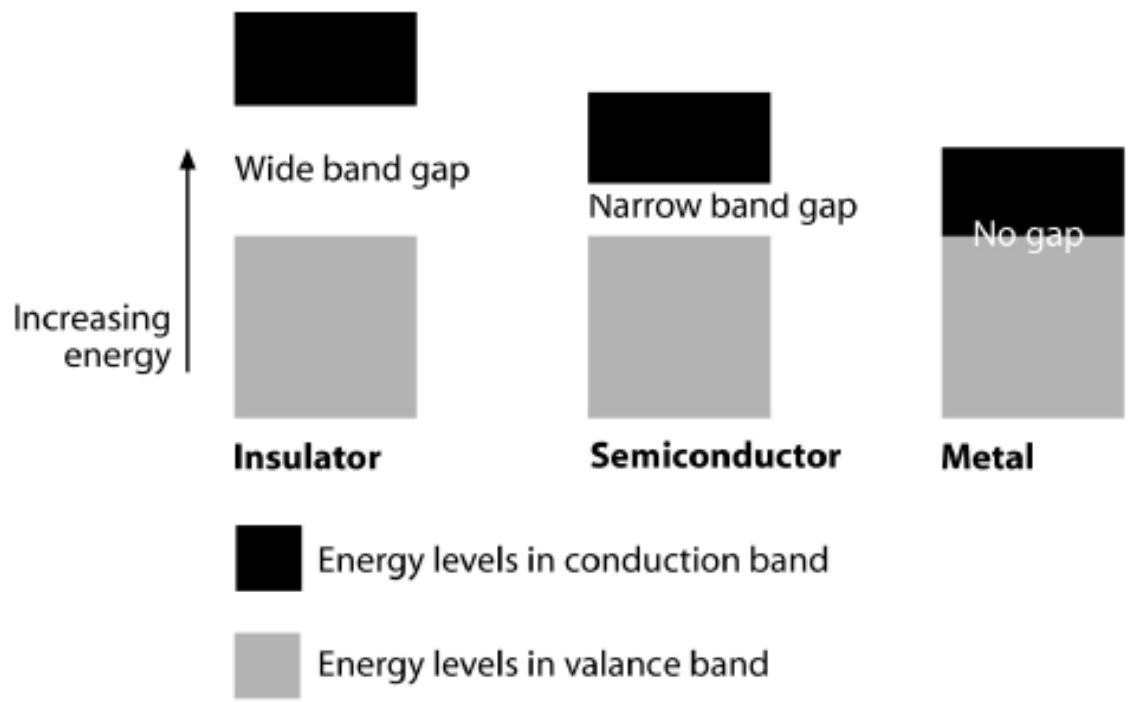

Figure 1.2 Band pictures of an insulator, a semiconductor and a metal. 
Conjugated polymers are similar with semiconductors according to their conductivity. In their neutral states conjugated polymers have an energy gap (Eg) between the valence band (HOMO) and the conduction band (LUMO). After an electrochemical or chemical doping process, the band structure of the polymer will change. These changes are formation of intraband transitions with lower energy and charge carriers, namely, polarons and bipolarons. Therefore, there will be an increase in electrical conductivity and optical property of the polymer [13, 14].

\subsection{Conduction in $\pi$-Conjugated Organic Materials}

Conduction in conjugated polymers is explained not only with band theory, but also by the transport of charge carriers through the polymer chain. These positive ( $p$ type) and negative (n-type) charge carriers are created by oxidation or reduction processes.

\subsubsection{Charge Carriers}

Soliton is a structural defect that has three different types, namely neutral, positive and negative solitons. Positive and negative solitons have no spin, whereas neutral solitons have spin but no charge [15]. 


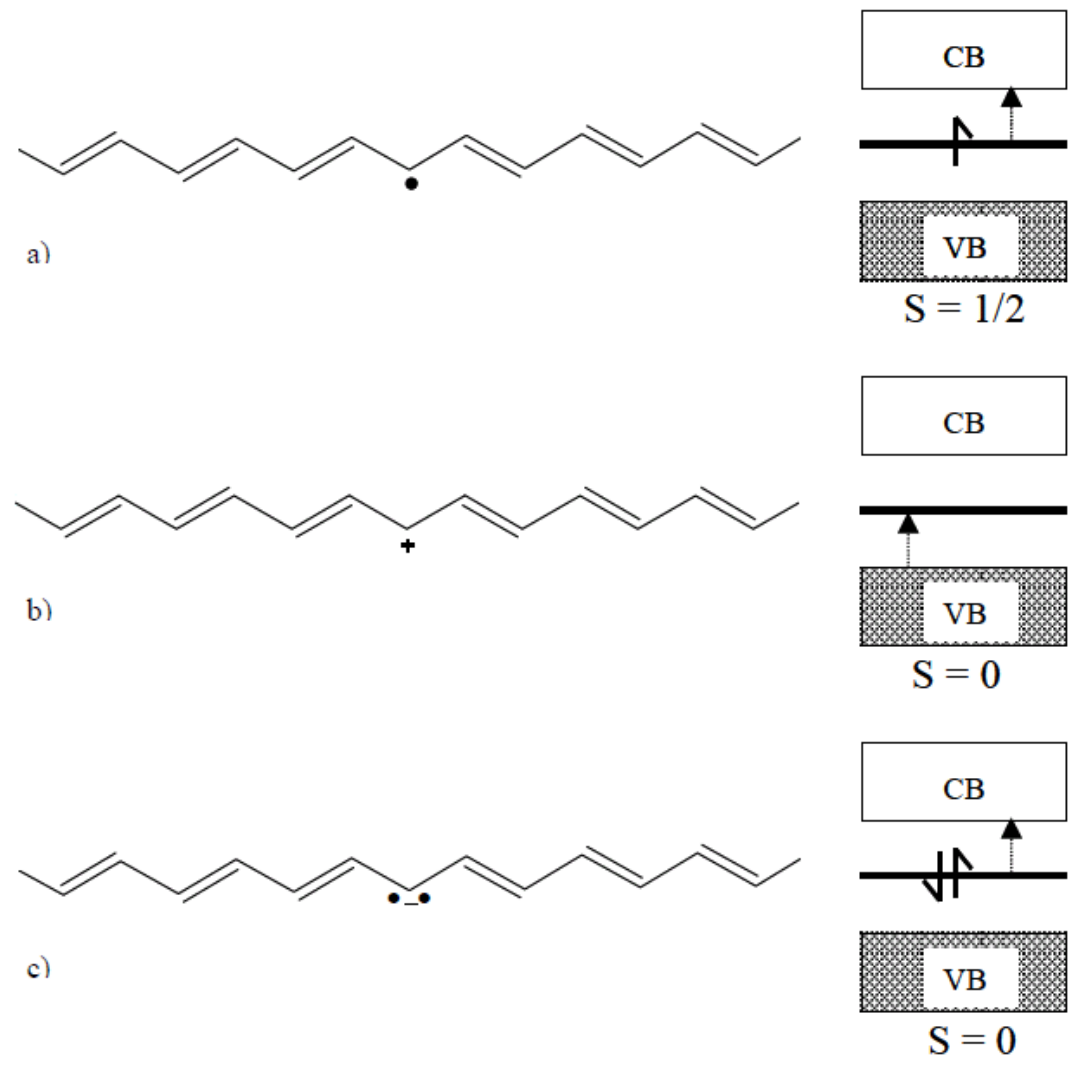

Figure 1.3 Soliton structures in polyacetylene and corresponding electronic states in the band gap, a) neutral soliton, b) positive soliton, c) negative soliton.

Polarons and bipolarons are another kind of structural defects. After $\mathrm{p}$ or $\mathrm{n}$ doping process these charge carriers are formed. Polarons are radical cations or anions with a spin. Bipolarons are spinless dications or dianions formed by further oxidation or reduction of polarons $[16,17]$. 

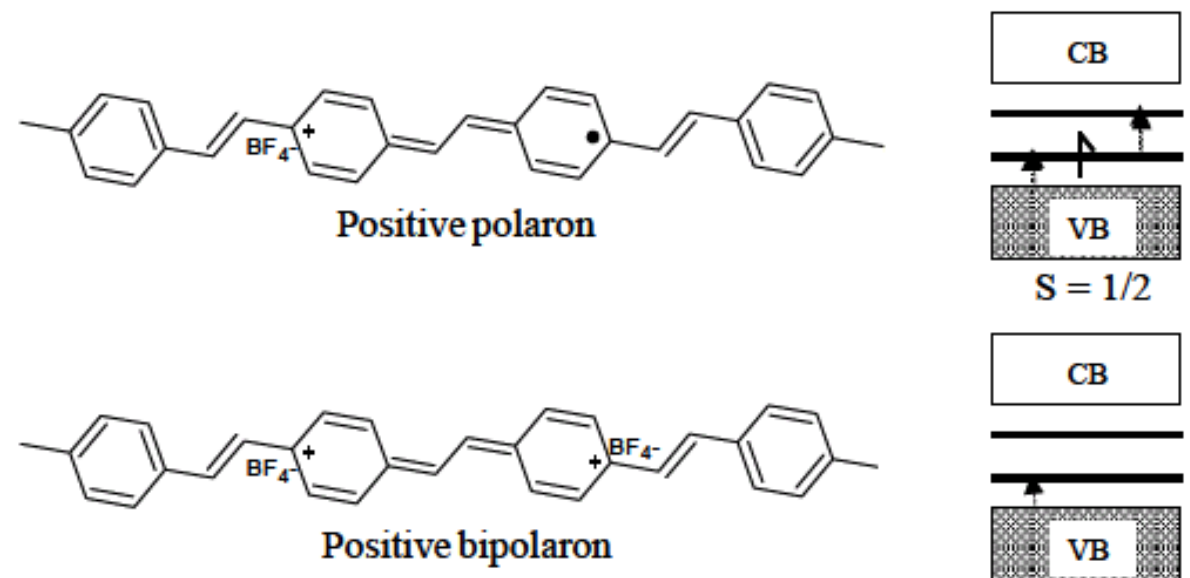

CB
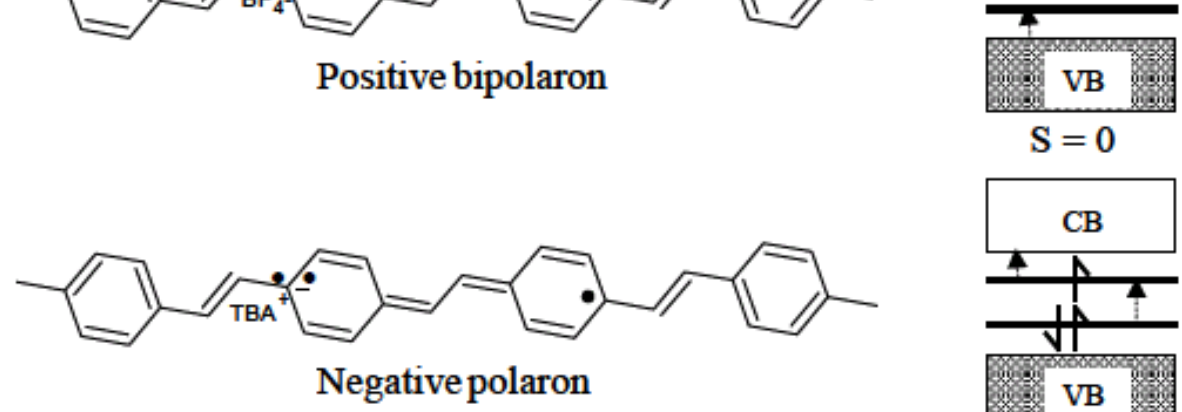

$\mathrm{S}=0$
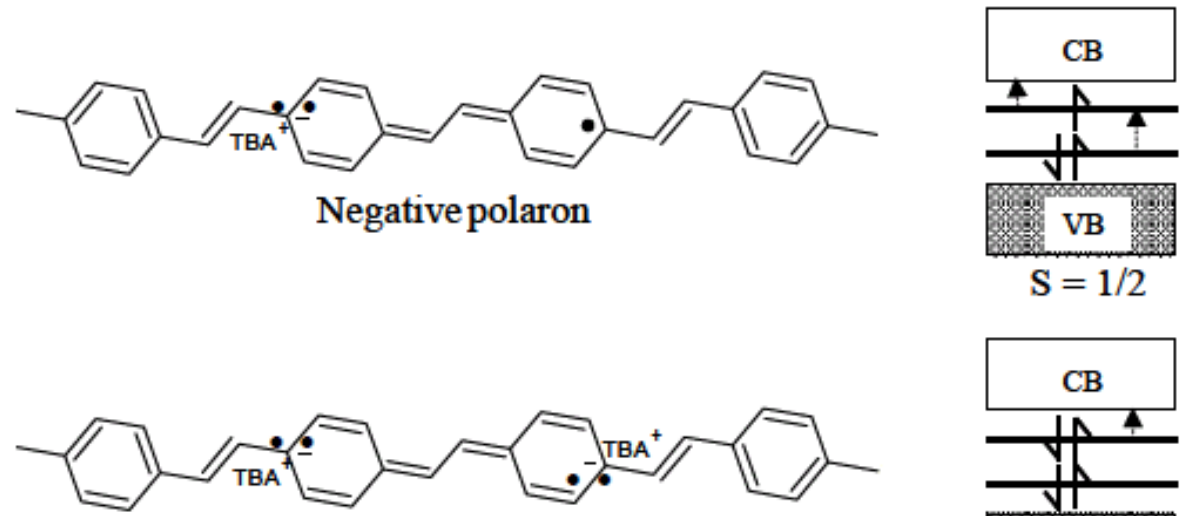

Negative bipolaron

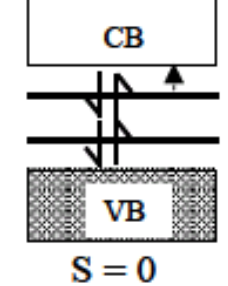

Figure 1.4 Polaron and bipolaron structures in poly(p-phenylenevinylene) with their corresponding electronic states in the band gap.

\subsubsection{Doping Process}

Conductivity of conjugated polymers is achieved by doping which is the reversible injection, ejection of charge to and from the polymer chain. Polymers undergo reversible oxidation and reduction reactions for doping - dedoping processes. [18] 
Doping is done electrochemically by applying appropriate potentials to the polymer in an electrochemical cell. Then the charge on the polymer chain is neutralized with a counter ion from the electrolyte solution. The process is shown by the following examples $[19,20]$;

(a) p type

$(\pi$-polymer $\left.)+\left[\mathrm{Li}^{+}\left(\mathrm{ClO}_{4}^{-}\right)\right]_{\text {solv }} \rightarrow\left[(\pi \text {-polymer })^{\mathrm{x}+(} \mathrm{ClO}_{4}^{-}\right)_{\mathrm{x}}\right]+\mathrm{xLi}^{+}+\mathrm{xe}$

(b) $n$ type

$(\pi$-polymer $\left.)+\mathrm{xe}^{-}+\left[\mathrm{Li}^{+}\left(\mathrm{ClO}_{4}^{-}\right)\right]_{\text {solv }} \rightarrow\left[(\pi \text {-polymer })^{\mathrm{x}-(} \mathrm{Li}^{+}\right)_{\mathrm{x}}\right]+\mathrm{x}\left(\mathrm{ClO}_{4}^{-}\right)$

Chemical doping is done by reducing or oxidizing agents. This process is shown by the following examples;

(a) p type

$(\pi$-polymer $)+\mathrm{A} \rightarrow(\pi \text {-polymer })^{+} \mathrm{A}^{-}$

(b) n type

$(\pi \text {-polymer })^{+} \mathrm{D} \rightarrow(\pi \text {-polymer })^{-} \mathrm{D}^{+}$

\subsection{Polymerization Methods}

To synthesize conjugated polymers, chemical and electrochemical polymerization methods are used. In this work, Stille and Suzuki coupling reactions were used for the polymerization. 


\subsubsection{Stille Coupling}

Stille coupling is the reaction between stannanes and halides via palladium catalyst to form a new C-C sigma bond.

$$
\mathrm{R}^{\prime}-\mathrm{X}+\mathrm{RSnBu}_{3} \stackrel{\mathrm{Pd}-\mathrm{Cat}}{\longrightarrow} \mathrm{R}^{\prime}-\mathrm{R}+\mathrm{XSnBu}_{3}
$$

\section{Mechanism}

The mechanism of Stille coupling includes four stages, namely, oxidative addition, transmetallation, trans/cis isomerization and reductive elimination. Transmetallation is the rate determining step in the cycle. To obtain higher efficiency, the reaction should be performed at an inert atmosphere using dehydrated and degassed solvent since oxygen causes the oxidation of the palladium catalyst [21, 22].

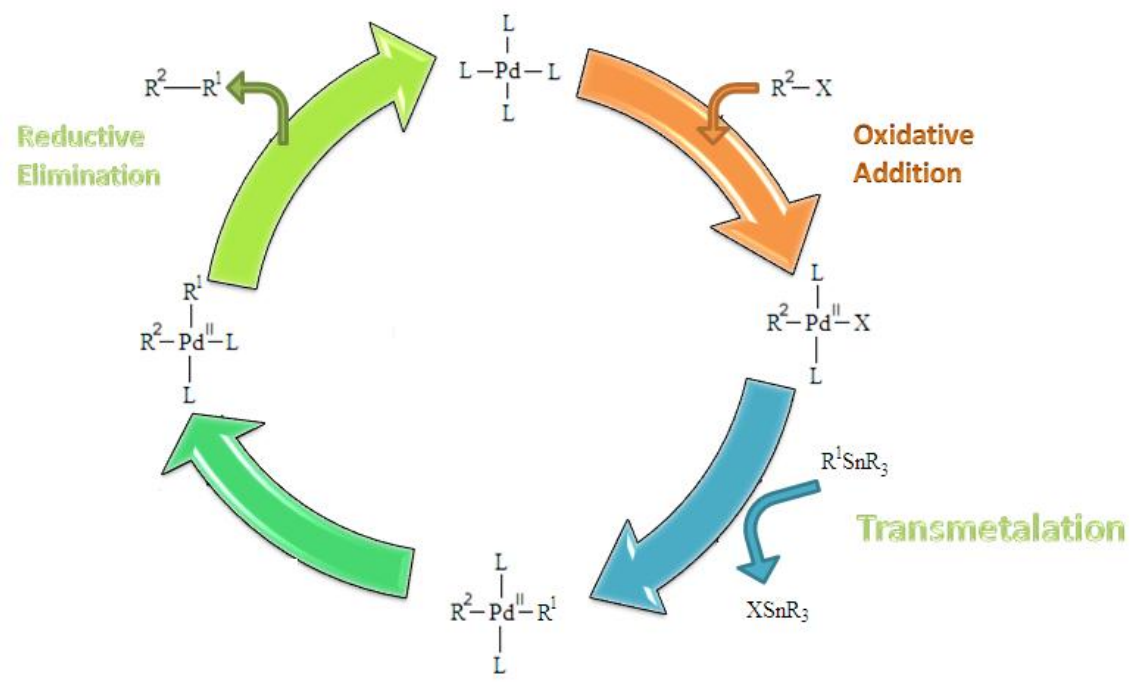

Figure 1.5 Mechanism of Stille Coupling. 


\subsubsection{Suzuki Coupling}

Suzuki coupling is the reaction between an aryl- or vinyl-boronic acid and an arylor vinyl-halide via palladium (0) catalyst.

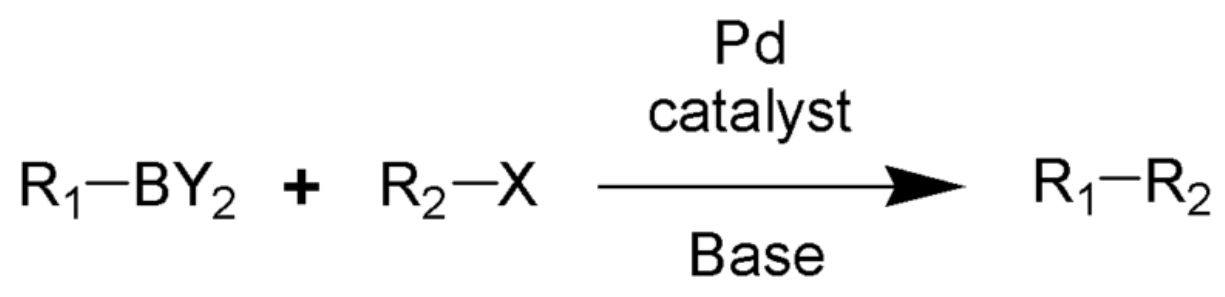

\section{Mechanism}

There are three steps; oxidative addition, transmetallation and reductive elimination in the mechanism of Suzuki coupling. The only difference between Suzuki and Stille reactions is that the boronic acid must be activated with a base. This activation of the boron atom provides the polarization of the organic ligand, and facilitates transmetallation $[23,24]$. 


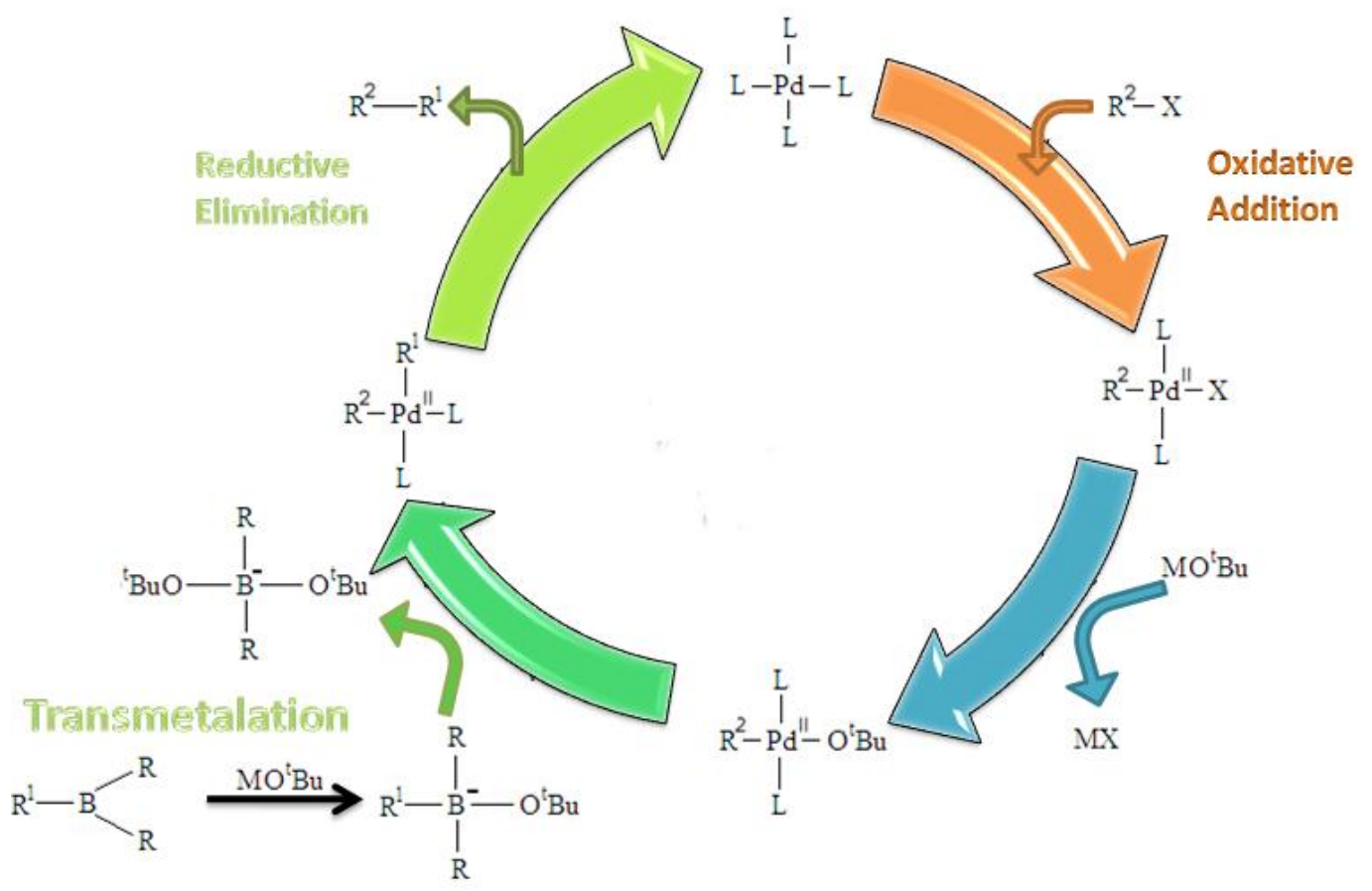

Figure 1.6 Mechanism of Suzuki Coupling.

\subsection{Donor-Acceptor (DA) Theory}

In structural modification of conducting polymers, DA approach is used to tailor the band gap of the polymer. This is achieved by substitution of a donor to an acceptor unit. Different donor and acceptors result in different electron attracting and withdrawing effects; therefore, many studies have been conducted to analyze these effects. According to the theory, newly synthesized polymer has the ionization potential closer to donor and an electron affinity closer to the acceptor due to the hybridization between the highest state of the HOMO level of the donor with the lowest state of the LUMO level of the acceptor (Figure 1.7) [25]. 


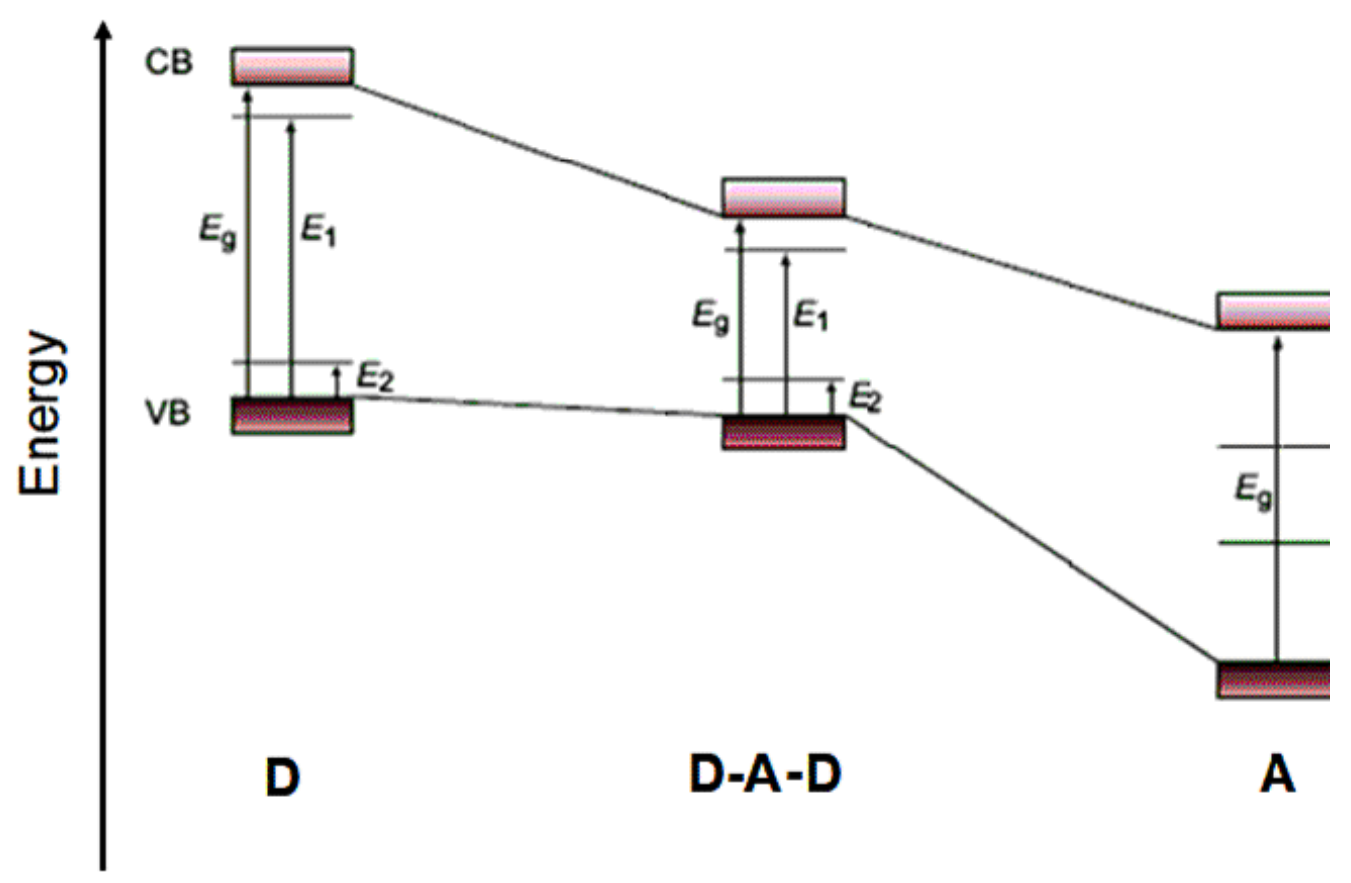

Figure 1.7 Donor (D) -Acceptor (A) Theory.

\subsection{Applications of Conducting Polymers}

Conjugated polymers have received considerable interest as active materials for organic solar cells (OSCs), [26, 27] organic light-emitting diodes (OLEDs), [28] organic field effect transistors (OFETs) [29], electrochromic devices (ECDs) [30], sensors [31] and artificial muscles [32] for the last few decades. Since these polymers have many application areas, they are regarded as multi-purpose materials.

\subsubsection{Electrochromism}

Electrochromism is reversible optical change in a material upon applied potential [33]. An electrochromic material reversibly changes its color after a redox reaction. The color change occurs due to the formation of different electronic absorption 
bands. These newly formed absorption bands may be in near IR region besides the VIS region. This is the reason why cyclic voltammetry and spectroscopic methods are used in the characterization of electrochromic material. By applying external potential to the materials, the $\pi-\pi^{*}$ transitions, band gap, and the generation of new charge carriers in the polymer backbone can be determined. The coloration change in an electrochromic material is generally between a transparent ("bleached") state and a colored state, or between two colored states. However, if the material is multielectrochromic, it shows several colors. The process is called multicolor electrochromism [34, 35].

The important parameters of electrochromic materials are the switching time, electrochromic contrast, coloration efficiency, stability and optical memory. Switching time is the time between the colored and bleached states of an electrochromic material. Electrochromic contrast means the percent transmittance change $(\Delta \% \mathrm{~T})$ between the material's neutral and oxidized states at a specified wavelength where the electrochromic material has the highest optical contrast [36]. Coloration efficiency is defined as absorbance change per unit charge injected per unit area of the electrode. The electrochromic memory is the ability to remember color without applied current and the stability is the ability to retain electrochromic properties over a large number of switching cycles [37, 38].

\subsubsection{Advantages of Conjugated Polymers in Electrochromic Applications}

Metal oxides, organic small molecules (viologens) and conducting polymers are the materials used in electrochromic applications [39]. These electrochromic materials are used as active layers in smart windows, displays, optical shutters, computer data 
storage and mirrors. These large application areas make the conducting polymers very popular in recent years.

Conjugated polymers are preferred over other types of electrochromic materials due to their fast switching times, high contrast ratios, processibility and tunable electronic and optical properties via structural modification. The most important advantage is the ability to modify the structure of the conjugated polymer. This structural modification is done by controlling the band gap. In order to tune the band gap of the polymer, widely used synthetic ways are copolymerization, homopolymerization, modification of main chain and pendant groups [40, 41]. In order to decrease the oxidation potential of polymers, powerful electron-donating units are introduced to the backbone of the polymer. This causes the valence band energy to increase and band gap of the polymer to decrease. If the purpose is to lower the valence band energy, then electron withdrawing groups would be added to the polymer backbone. Additionally, adding alkyl substituents make the polymer processable, and so the polymer would be used for coating larger surfaces with simple techniques such as spin coating or spray coating. 

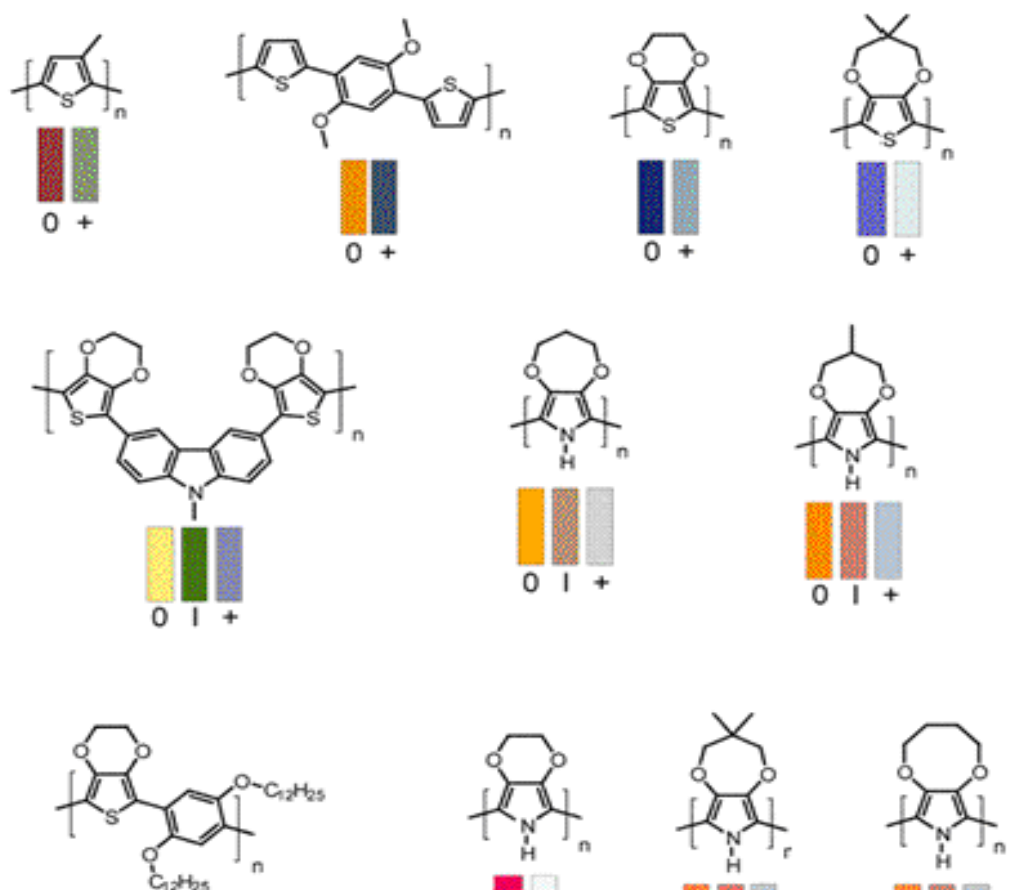

${ }_{01+}$
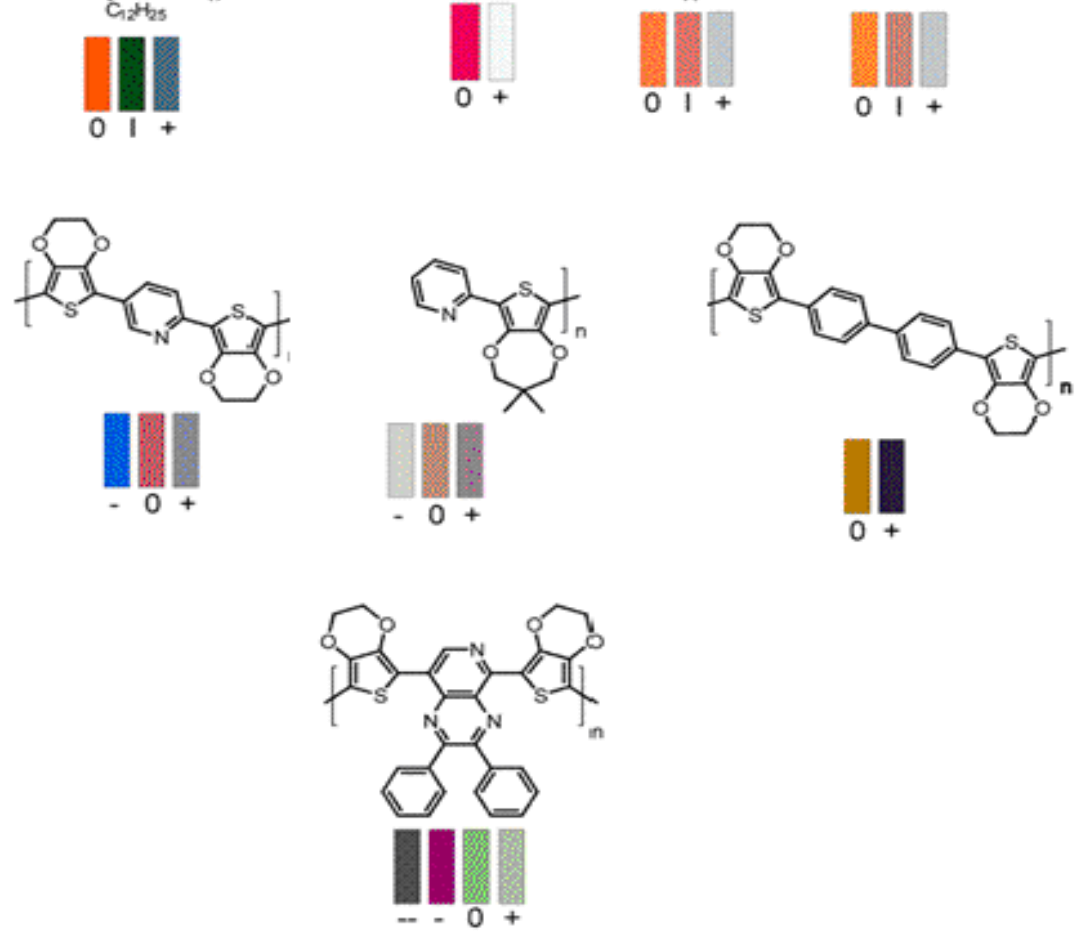

Figure 1.8 Examples of electrochromic polymers synthesized by structural modification.

0 = neutral; $\mathrm{I}=$ intermediate $;+=$ oxidized; and $--=$ reduced [41]. 


\subsubsection{Solar Cells}

Since global warming continues to be a serious problem of today's world, carbon dioxide free source for electricity becomes an important solution to have clean and renewable energy. Solar cell is defined as a device that converts sunlight into electricity. Its modules are used for lightening, telecommunication and household purposes.

The first solar cell based on selenium coating on a thin layer of gold was done by Charles Fritts in 1883 with only 1\% efficiency [42]. Mostly used and efficient silicon solar cell was firstly fabricated in 1954 with $6 \%$ efficiency for energy conversion [43]. Organic solar cell was firstly invented in 1986 with $1 \%$ efficiency [44]. Industrial applications of solar cells require power conversion efficiency around $10 \%$ [45]. This efficiency was a dream for organic solar cells in last years. However, recent studies exhibit around $7-8.3 \%$ power conversion efficiency from organic solar cells [46-48]. These results encourage the organic photovoltaics researchers.

\subsubsection{Advantages of Conjugated Polymers in Solar Cell Applications}

There are two types of solar cells, namely, organic and inorganic. Inorganic solar cells have been preferred industrially due to their high efficiencies and stabilities. However, their highly expensive fabrication causes demand for alternative solutions. Solar cells based on conjugated polymers are useful alternatives to crystalline silicon solar cells. This type will be preferred industrially if an appropriate power efficiency (10\%) and stability (10 years lifetime) could be obtained on a large scale. Many studies include fabrication and optimization of organic solar cells due to their 
processability, flexibility, low cost cell production, low weight, and tunable band gaps $[49,50]$. Processability and flexibility characteristics of a conjugated polymer allow easy polymer processing techniques applicable. These techniques are spin coating, doctor blading, ink-jet printing and roller-casting. Conjugated polymers can be modified for the demand. To illustrate, alkyl substituent introduction on the polymer backbone make the polymer soluble in common organic solvents. This allows wet-processing techniques applicable in solar cell fabrication. These techniques provide easy and cheap production since they are applied at ambient temperature and pressure with a little material loss. Moreover, they provide flexible and large area solar cells.

\subsubsection{Bulk Heterojunction Organic Solar Cells}

Bulk heterojunction (BHJ) organic solar cell consists of donor and acceptor molecules in the same blend as the active layer. This mixture results in the large interfacial area between the donor and acceptor molecules. Therefore, BHJ structure increases probability of the efficient charge dissociation through this large interfacial area.

The active layer composite can be obtained by simple techniques, such as spin coating, doctor blading, ink-jet printing and roller-casting [51]. In the active layer of BHJ structure, conjugated polymer is used as the donor, while soluble derivatives of fullerene are used as the acceptor molecule (Figure 1.9). Fullerenes are preferred as acceptors due to their high electron affinities and high electron mobilities [52]. 
BHJ type organic solar cells provided approximately $1 \%$ power conversion efficiency for poly(phenylene vinylene) (PPV) system in 1995 [53]. This value was reached to 4-5 \% for poly(3-hexylthiphene) (P3HT) system in 2005. Recently, power conversation efficiency of organic solar cells is around $8.3 \%$ for different donor materials[48].
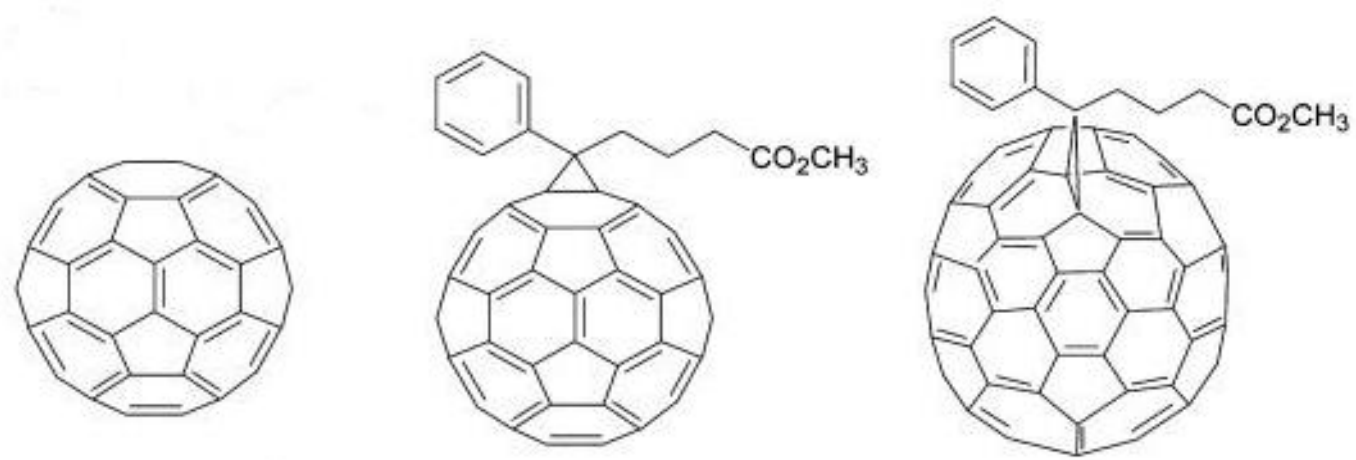

Figure 1.9 Structure of $\mathrm{C}_{60}$, its soluble form [6,6]-phenyl- $\mathrm{C}_{61}$-butyric acid methyl ester $\left(\mathrm{PC}_{61} \mathrm{BM}\right)$ and $[6,6]$-phenyl- $\mathrm{C}_{71}$-butyric acid methyl ester $\left(\mathrm{PC}_{70} \mathrm{BM}\right)$.

\subsubsection{Working Principle of BHJ Organic Solar Cells}

Organic solar cells working principle includes three stages; absorption of light, exciton generation and dissociation, and charge transport to opposite electrons.

1. Absorption of light

Conjugated polymer is the donor material that absorbs light in an organic solar cell (Figure 1.10(i)). Organic semiconductors generally have very high absorption coefficients. Therefore, very low thicknesses between 100 and $300 \mathrm{~nm}$ are enough for a high absorption in organic photovoltaic devices. The absorption spectrum of 
the material used in the photovoltaic cell is an important parameter for current value since the excited electrons will directly converted into current. It should be taken into account that the conjugated polymer's absorption spectrum should match with the solar spectrum. Low band gap organic semiconductors provide such an absorption spectrum, however yields lower open circuit voltage.

\section{Exciton Generation and Dissociation}

After the absorption of light, electron-hole pairs (excitons) are generated (Figure 1.10(i)) on the conjugated polymer. Figure 1.10 (ii) and (iii) show the exciton diffusion and dissociation process at the donor-acceptor interface.

Exciton generation is a short-lived process which has an approximately $10 \mathrm{~nm}$ diffusion length. Thus, BHJ structure provides the required interconnection between donor and acceptor. This interconnection enables continuous paths for both electrons and holes for transportation to the opposite electrodes.

\section{Charge transport to Opposite Electrodes}

The electron and hole are the charges that are separated and transported selectively to the different electrode. The holes are transported by the polymer to ITO (anode) and the electrons to the metal (cathode) (Figure $1.10 \mathrm{iv).} \mathrm{When} \mathrm{charges} \mathrm{are} \mathrm{collected}$ at the electrodes, electricity is produced (Figure $1.10 \mathrm{v}$ ). To obtain efficient charge transport, materials should have high charge carrier mobility $[54,55]$. 

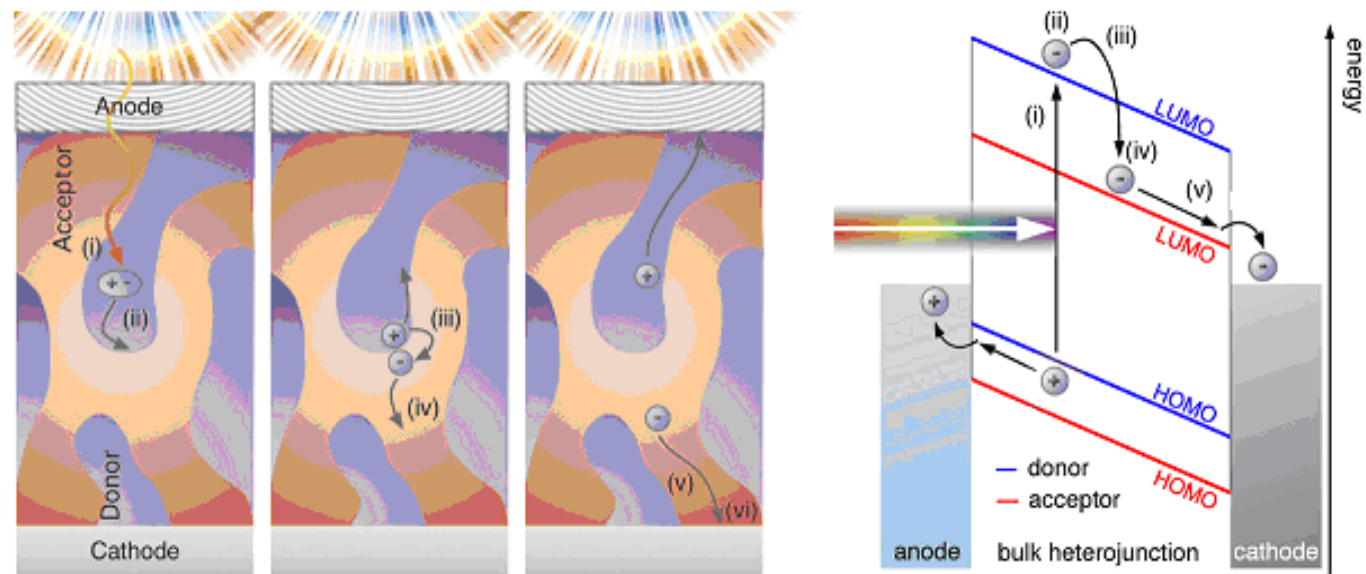

Figure 1.10 Working Principle of BHJ solar cells. Left: kinetic point of view, right: simplified energy diagram. (i) singlet exciton generation. (ii) exciton diffusion to the acceptor interface. (iii) exciton dissociation. (iv) electron-hole pair seperation.(v) charge transport [54].

\subsubsection{Structure of BHJ Organic Solar Cell}

Typical BHJ organic solar cell is shown as ITO/PEDOT:PSS/Polymer:PCBM/ LiF/Al (Figure 1.11). The device contains a glass slide with a thin layer of ITO that is a transparent electrically conducting material. ITO is used due to its high work function and transparency. PEDOT:PSS layer is used as a hole conducting material. This layer smooths the roughness of ITO; therefore, probability of short circuit will be minimized. Additionally, it improves the work function of the anode. Therefore, HOMO level of the donor exhibit a better match with the anode. Mixture of the donor and acceptor is the active layer of the device. Lithium fluoride is the electron transport layer. It improves the contact and lowers the aliminum work function. Aliminum is used as the cathode due to its low work function [56, 57]. The energy band diagram of each part in a solar cell are shown in the figure 1.12. 


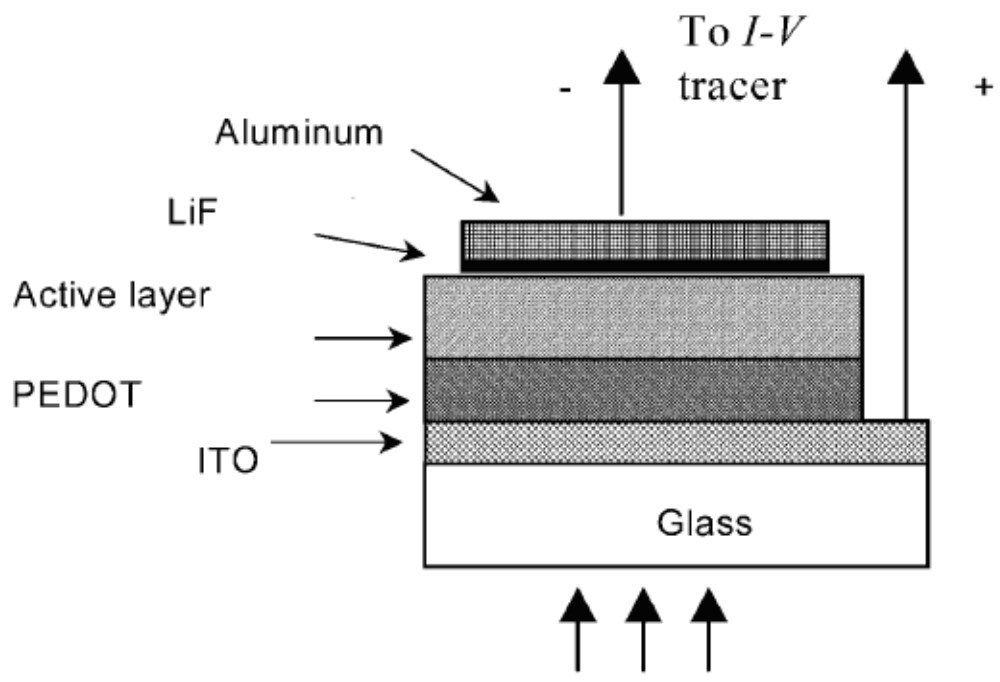

Light

Figure 1.11 Structure of a Bulk Heterojunction Solar Cell.

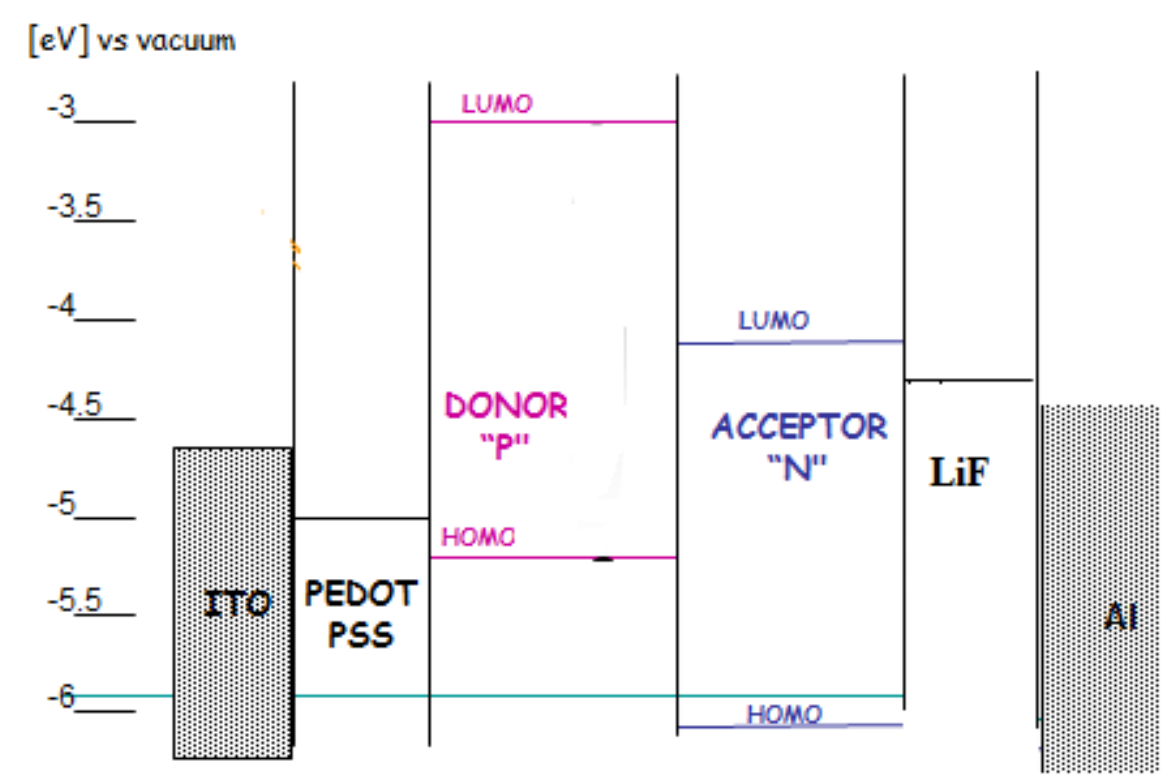

Figure 1.12 Energy Band Diagram in a BHJ Solar Cell. 


\subsubsection{Cell Efficiency}

The efficiency of solar cell is examined by measuring current-voltage $(I-V)$ characteristics under dark and illumination. Figure 1.13 shows a typical current density-voltage characteristic of a solar cell under illumination. From this graph short-circuit current density $J_{S C}$ which is the current density under illumination at zero applied potential can be obtained. Also, open-circuit voltage Voc, which is the maximum voltage that the cell can supply, can be determined from the point where the current-density is zero. The fill factor FF is another important parameter for a photovoltaic cell. This value is determined by dividing the maximum power that can be gathered from the device to open-circuit voltage and short-circuit current. FF value gives information about the quality of the cell as a power source. The ideal fill factor value is unity. Fill factor is calculated from the following equation;

$$
\mathbf{F F}=\mathbf{I}_{\mathrm{mp}} \mathbf{V}_{\mathrm{mp}} / \mathbf{I}_{\mathrm{sc}} \mathbf{V}_{\mathrm{oc}}
$$

The power conversion efficiency $(\eta \%)$ is the ratio of maximum power to the incident radiant power. The equation is:

PCE $\%=\eta \%=(J s c \times \operatorname{Voc} \times \mathrm{FF}) / \mathrm{P}_{\mathrm{L}}$ 
where $\mathrm{P}_{\mathrm{L}}$ is the incident radiant power. The efficiencies should be measured under standard test conditions. The conditions include the temperature of the cell $\left(25^{\circ} \mathrm{C}\right)$, the light intensity $\left(100 \mathrm{~mW} / \mathrm{cm}^{2}\right)$ and the spectral distribution of light (AM 1.5).

Incident photon to current efficiency (IPCE) gives information about the number of photons that contributes to charge generation in a solar cell. It is the ratio of number of collected charge carriers to the number of incident photons. The equation is;

\% IPCE $=$ no of electrons through the external circuit / no of incident photons

$$
=1240 * I_{\text {sc }}\left(\mathrm{mA} / \mathrm{cm}^{2}\right) / P_{\text {in }} * \lambda_{\text {incident }}
$$

where Isc $\left(\mathrm{mA} / \mathrm{cm}^{2}\right)$ is the current density. $\mathrm{P}_{\text {in }}\left(\mathrm{W} / \mathrm{m}^{2}\right)$ is the incident light power, measured with a calibrated silicon diode, and $\lambda(\mathrm{nm})$ is the incident photon wavelength. Ideal IPCE graph has a square shape which means the efficiency is almost constant through the entire spectrum of measured wavelengths [58]. 


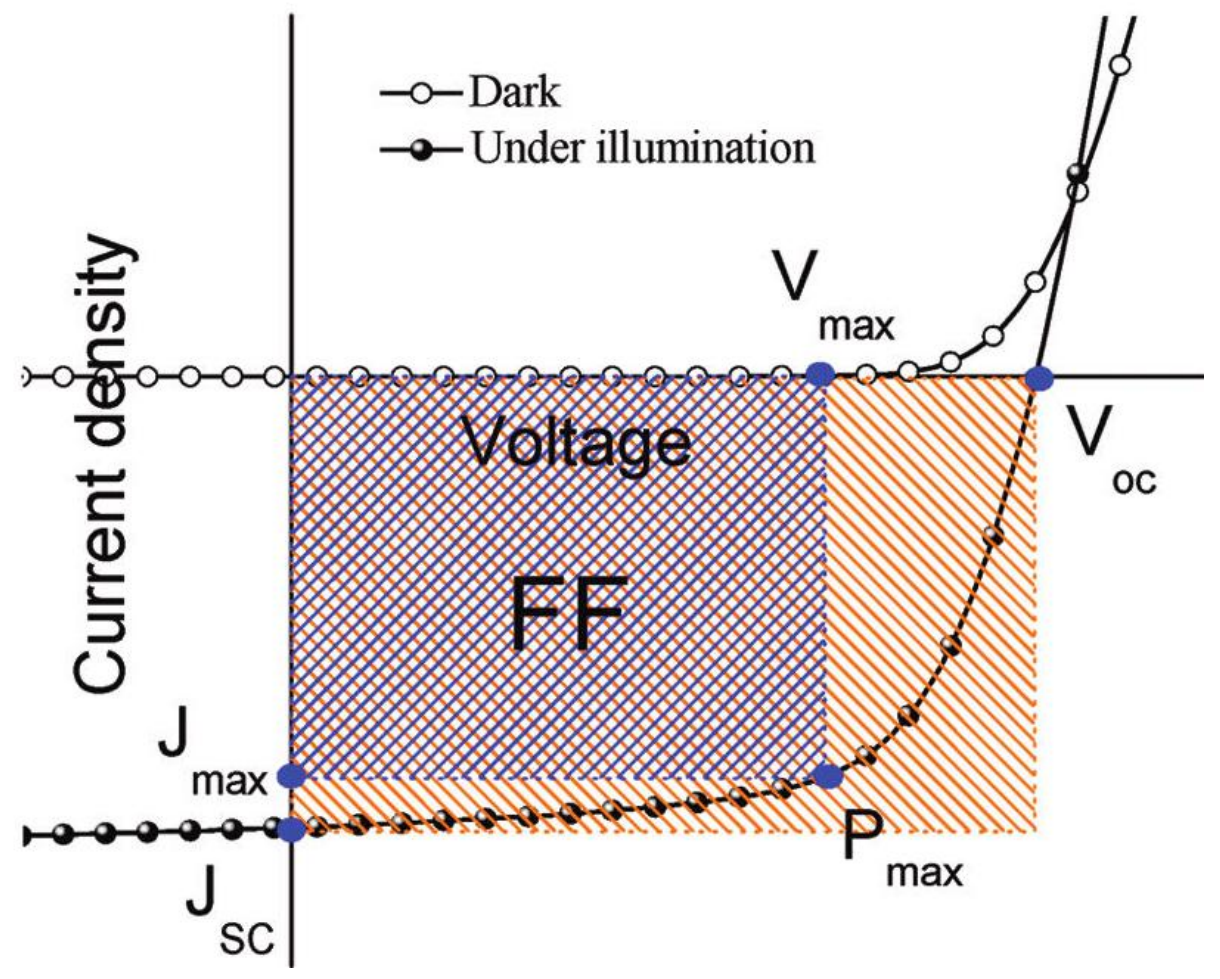

Figure 1.13 A typical current density -voltage characteristic of a Bulk Heterojunction solar cell.

\subsection{Aim of the Work}

In this study 2-dodecyl benzotriazole (BTz) and benzothiadiazole (BTd) containing three alternating copolymers; poly(4-(2-dodecyl-2H-benzo[d][1,2,3]triazol-4-yl) benzo[c][1,2,5] thiadiazole (P1), poly(4-(5-(2-dodecyl-7-(thiophen-2yl)-2Hbenzo[d][1,2,3]triazol-4-yl) thiophen-2-yl)benzo[c] [1,2,5] thiadiazole (P2) and poly(4-(5-(2-dodecyl-7-(4-hexylthiophen-2-yl)-2H-benzo[d] [1,2,3]triazol-4-yl) -3hexylthiophen-2-yl) benzo[c][1,2,5] thiadiazole (P3) were synthesized. They were 
synthesized via chemical polymerization method to use them in solar cell production. Their electrochemical and optoelectronic characteristics were examined. Since the polymers provide appropriate active layers in organic electronics, their solar cell fabrication was conducted and these PV cells were characterized. Benzotriazole and benzothiadiazole are generally preferred acceptor units in tailoring the band gap of CPs according to DA approach. Therefore, the effect of substitution of two different acceptor units in the same polymer chain was the motivation of the work. The effects of these units on band gap, absorption, electrochemical and optical properties of the polymer were examined. 


\section{CHAPTER 2}

\section{EXPERIMENTAL}

\subsection{Materials}

Tetrabutylammonium hexafluorophosphate $\left(\mathrm{TBAPF}_{6}\right)$ (Aldrich), PEDOT: PSS (H.C. Stark) were used as received. Dichloromethane (DCM) (Merck), chloroform (Aldrich), ethanol(Aldrich), $\mathrm{HBr}$ (Merck), acetonitrile (ACN) (Merck), methanol (Merck), tributyl tin chloride (Aldrich), N-butyl lithium (Aldrich), thiophene (Merck), 3-hexyl thiophene (Aldrich) and $\mathrm{MgSO}_{4}$ (Aldrich) were used without further purification. THF (Fisher) was used after distillation. ITO were supplied by Visiontek Systems Ltd., Al and LiF was taken from Kurt J. Lesker and PCBM from Solenne.

\subsection{Equipments}

Electrochemical studies were performed in a three-electrode cell consisting of an ITO as the working electrode, platinum $(\mathrm{Pt})$ as the counter electrode, and $\mathrm{Ag} / \mathrm{AgCl}$ as the reference electrode using a Voltalab 50 potentiostat at room temperature. After each measurement the reference electrode was calibrated with respect to ferrocene. The value of Normal Hydrogen Electrode (NHE) was taken as $-4.75 \mathrm{eV}$. All the data reported in this study were determined using this value. 
${ }^{1} \mathrm{H}$ - NMR and ${ }^{13} \mathrm{C}-\mathrm{NMR}$ spectra of the materials were recorded in $\mathrm{CDCl}_{3}$ on Bruker Spectrospin Avance DPX-400 Spectrometer. Chemical shifts were given in ppm downfield from tetramethylsilane (TMS). Column chromatography of products was performed using Merck Silica Gel 60 (particle size: 0.040-0.063 mm, 230-400 mesh ASTM). Average molecular weights were determined by gel permeation chromatography (GPC) using a Polymer Laboratories GPC 220 in tetrahydrofuran (THF). Thermal analysis of the polymers were done by Perkin Elmer diamond differential scanning calorimetry (DSC) in nitrogen environment, in a $25-250{ }^{\circ} \mathrm{C}$ temperature range with $10{ }^{\circ} \mathrm{C} / \mathrm{min}$ measurements and Perkin Elmer Pyris 1 thermal gravimetric analysis (TGA) in nitrogen environment, in a $25-700{ }^{\circ} \mathrm{C}$ temperature range with $10{ }^{\circ} \mathrm{C} / \mathrm{min}$ measurements.

Spectroelectrochemical studies of the polymers were conducted by Varian Cary $5000 \mathrm{UV}-\mathrm{Vis}$ spectrophotometer. Thin film UV spectra of the polymers were obtained by Agilent 8453 UV -Vis spectrophotometer. Harrick Plasma Cleaner was used to clean ITO. Spin coatings were performed by Speciality Coating Systems G3P-8. All solar cell fabrication and characterizations were carried out using MBraun 200B glove box. Current-voltage (I-V) characteristics of the solar cells were measured Keitley 2400 sourcemeter. An Atlas solar simulator for AM 1.5 G was used as the excitation source with an input power of $100 \mathrm{~mW} / \mathrm{cm}^{2}$ illumination. Incident photon to electron conversion efficiency (IPCE) was measured by an Oriel Quantum Efficiency Measurement Kit. 


\subsection{Synthesis}

\subsubsection{2-Dodecylbenzotriazole}
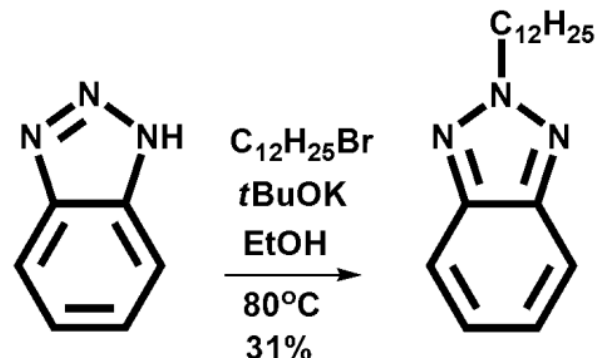

Figure 2.1 Synthetic route for 2-dodecylbenzotriazole.

In the synthesis of 2-dodecylbenzotriazole, 1,2,3-benzotriazole (5.0 g, $42 \mathrm{mmol})$, potassium tert-butoxide (5.0 g, $44 \mathrm{mmol})$, and bromododecane $(12.2 \mathrm{~g}, 49 \mathrm{mmol})$ were dissolved in ethanol $(50 \mathrm{~mL})$. The mixture was refluxed for $12 \mathrm{~h}$. The reaction was monitored by TLC. After removal of the solvent by evaporation the residue was dissolved in $\mathrm{CHCl}_{3}$ and extracted with water. $\mathrm{MgSO}_{4}$ was used to dry the organic extract. Then the solvent was evaporated under reduced pressure. The residue was subjected to column chromatography (3:2 chloroform:hexane; $R \mathrm{f}, 0.29)$ to obtain 2 dodecylbenzotriazole as a colorless oil $(3.7 \mathrm{~g}, 31 \%)$ 


\subsubsection{4,7-Dibromo-2-dodecylbenzotriazole}
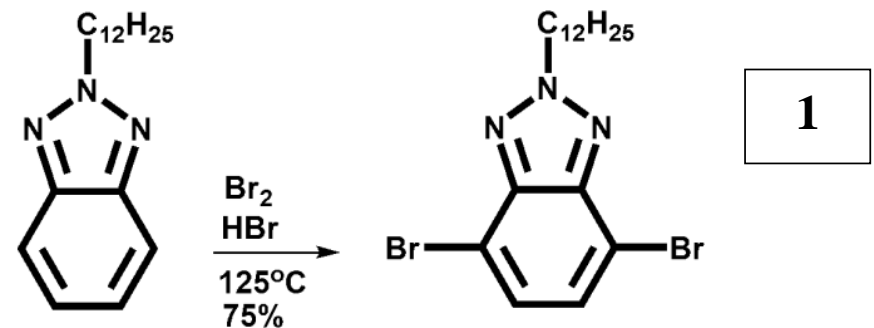

Figure 2.2 Synthetic route for 4,7-dibromo-2-dodecylbenzotriazole.

In the synthesis of 4,7-dibromo-2-dodecylbenzotriazole, 2-dodecylbenzotriazole (3.7 $\mathrm{g}, 13.1 \mathrm{mmol})$ and an aqueous $\mathrm{HBr}$ solution $(5.8 \mathrm{M}, 15 \mathrm{~mL})$ were stirred for $1 \mathrm{~h}$ at $100{ }^{\circ} \mathrm{C}$. After the addition of bromine $(5.9 \mathrm{~g}, 36 \mathrm{mmol})$, the mixture was stirred for $12 \mathrm{~h}$ at $135^{\circ} \mathrm{C}$. The mixture was allowed to cooling process. Then $\mathrm{NaHCO}_{3}$ solution was added and the product was extracted with $\mathrm{CHCl}_{3}$. The organic layer was dried over $\mathrm{MgSO}_{4}$ and the solvent was evaporated under reduced pressure. Using column chromatography $(1: 1 \quad$ chloroform:hexane; $R f, \quad 0.33), \quad 4,7-\quad$ dibromo-2dodecylbenzotriazole was obtained as a light yellow oil (4.3 g, 75\%).

\subsubsection{Tributyl(thiophen-2-yl)stannane and Tributyl(4-hexylthiophen-2} yl)stannane

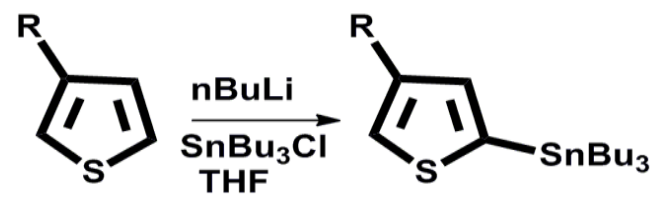

\section{$\mathrm{R}: \mathbf{H}$ or $\mathrm{C}_{6} \mathrm{H}_{13}$}

Figure 2.3 Synthetic route for stannylation of thiophene and 3-hexyl thiophene. 
In the stannylation of thiophene and 3-hexyl thiophene, the same procedure was conducted. Thiophene $(1 \mathrm{~g}, 0.95 \mathrm{~mL})$ or 3-hexyl thiophene $(2 \mathrm{~g}, 2.13 \mathrm{~mL})$ was dissolved in THF $(20 \mathrm{~mL})$, and the solution was cooled to $-78^{\circ} \mathrm{C}$. n-Butyllithium (5.76 $\mathrm{mL}$ of $2.5 \mathrm{M}$ for thiophene or $5.2 \mathrm{~mL}$ of $2.5 \mathrm{M}$ for 3-hexyl thiophene) was added drop-wise. The mixture was stirred at $-78^{\circ} \mathrm{C}$ during $1 \mathrm{~h}$. Then, tributyltin chloride (3.48 mL for thiophene or $3.5 \mathrm{~mL}$ for 3-hexyl thiophene) was added at $78^{\circ} \mathrm{C}$ via a syringe. Then the mixture was stirred at room temperature for $24 \mathrm{~h}$. At the end of the reaction, water was added to the mixture. The phases were separated and organic layer was extracted with $\mathrm{CH}_{2} \mathrm{Cl}_{2}$. All the organic layers were then washed with water. The organic layer was dried over $\mathrm{MgSO}_{4}$. After removal of the solvent, the product was obtained as a brown viscous liquid (70\%).

\subsubsection{2-Dodecyl-4,7-di(thiophen-2-yl)-2H-benzo[d][1,2,3]triazole (TBT)}
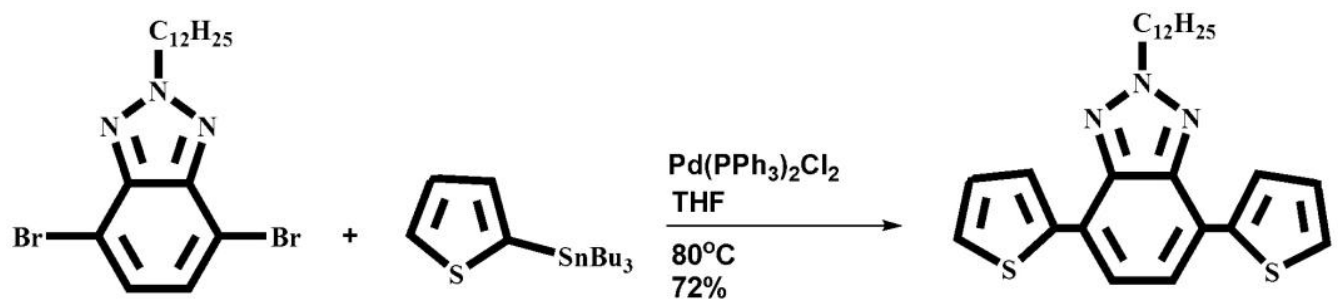

Figure 2.4 Synthetic route for TBT.

TBT was synthesized via Stille coupling. 4,7-Dibromo-2-dodecylbenzotriazole (100 $\mathrm{mg}, 0.224 \mathrm{mmol}$ ), and tributyl(thiophen-2-yl) stannane were dissolved in anhydrous THF (100 ml) and dichlorobis(triphenylphosphine)-palladium(II) (50 mg, 0.045 mmol) was added at room temperature. The mixture was refluxed for 12 hours under argon atmosphere. After the removal of the solvent, the crude product was purified by column chromatography on silica gel to obtain $75 \mathrm{mg}$ (74\%) TBT. 


\subsubsection{2-Dodecyl-4,7-bis(4-hexylthiophen-2-yl)-2Hbenzo[d][1,2,3]triazole}

(HTBT)

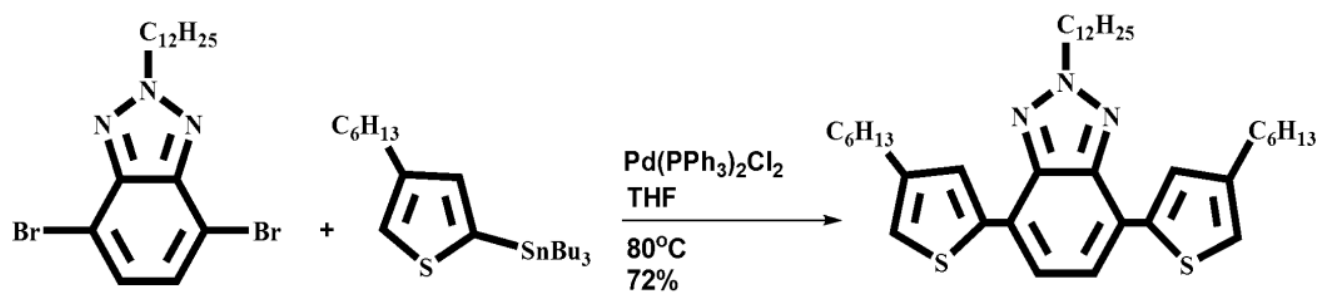

Figure 2.5 Synthetic route for HTBT.

HTBT was synthesized via Stille coupling. 4,7-Dibromo-2-dodecylbenzotriazole (100 mg, $0.224 \mathrm{mmol})$, and tributyl(4-hexylthiophen-2-yl)stannane (511 mg, 1.12 mmol) were dissolved in THF (100 ml) and dichlorobis(triphenylphosphine)palladium(II) (50 mg, $0.045 \mathrm{mmol}$ ) was added at room temperature. The mixture was refluxed for 12 hours under argon atmosphere. After solvent removed, the crude product was purified by column chromatography on silica gel to obtain $95 \mathrm{mg}$ (72 $\%)$ HTBT.

\subsubsection{4,7-Bis(5-bromothien-2-yl)-2-dodecylbenzo[1,2,3]triazole}

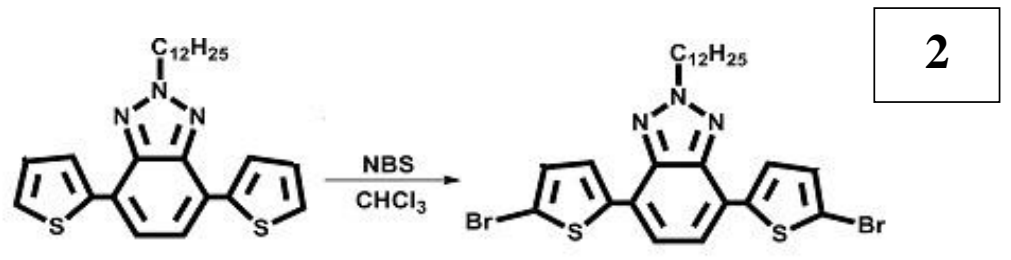

Figure 2.6 Synthetic route for 4,7-bis(5-bromothien-2-yl)-2 dodecylbenzo

$[1,2,3]$ triazole. 
$200 \mathrm{mg}$ of 4,7-bis (thien-2-yl) 2-dodecyl-benzo[1,2,3]triazole (0.44 mmol) and 190 $\mathrm{mg}$ of $\mathrm{N}$-bromosuccinimide $(1.07 \mathrm{mmol})$ were stirred in $100 \mathrm{ml}$ of $\mathrm{CHCl}_{3}$ at room temperature by preventing the mixture from light exposure. After $12 \mathrm{~h}$ solvent was removed under reduced pressure and crude product was filtered over silica by $\mathrm{CHCl}_{3}$ to obtain $250 \mathrm{mg}(93 \%)$ as yellow solid.

\subsubsection{4,7-Bis(5-bromo-4-hexylthien-2-yl)-2-dodecylbenzo[1,2,3]triazole}

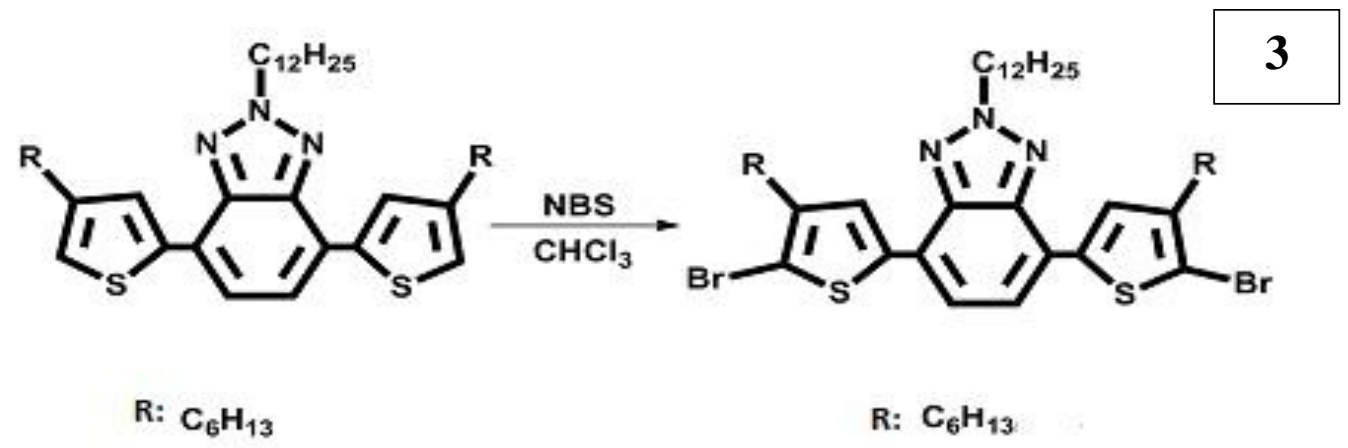

Figure 2.7 Synthetic route for 4,7-bis(5-bromo-4-hexylthien-2-yl)-2dodecylbenzo[1,2,3]triazole.

$200 \mathrm{mg}$ of 4,7-bis (3-hexylthien-5-yl) 2-dodecyl-benzo[1,2,3]triazole $(0.32 \mathrm{mmol})$ and $138 \mathrm{mg}$ of $\mathrm{N}$-bromosuccinimide $(0.77 \mathrm{mmol})$ were stirred in $100 \mathrm{ml}$ of $\mathrm{CHCl}_{3}$ at room temperature by preventing the mixture from light exposure. After $12 \mathrm{~h}$ solvent was removed under reduced pressure and crude product was filtered over silica by $\mathrm{CHCl}_{3}$ to obtain used to obtain $235 \mathrm{mg}(94 \%$ ) as yellow solid. 


\subsection{Synthesis of the Polymers}

Polymers were synthesized by poly condensation Suzuki cross coupling reactions.

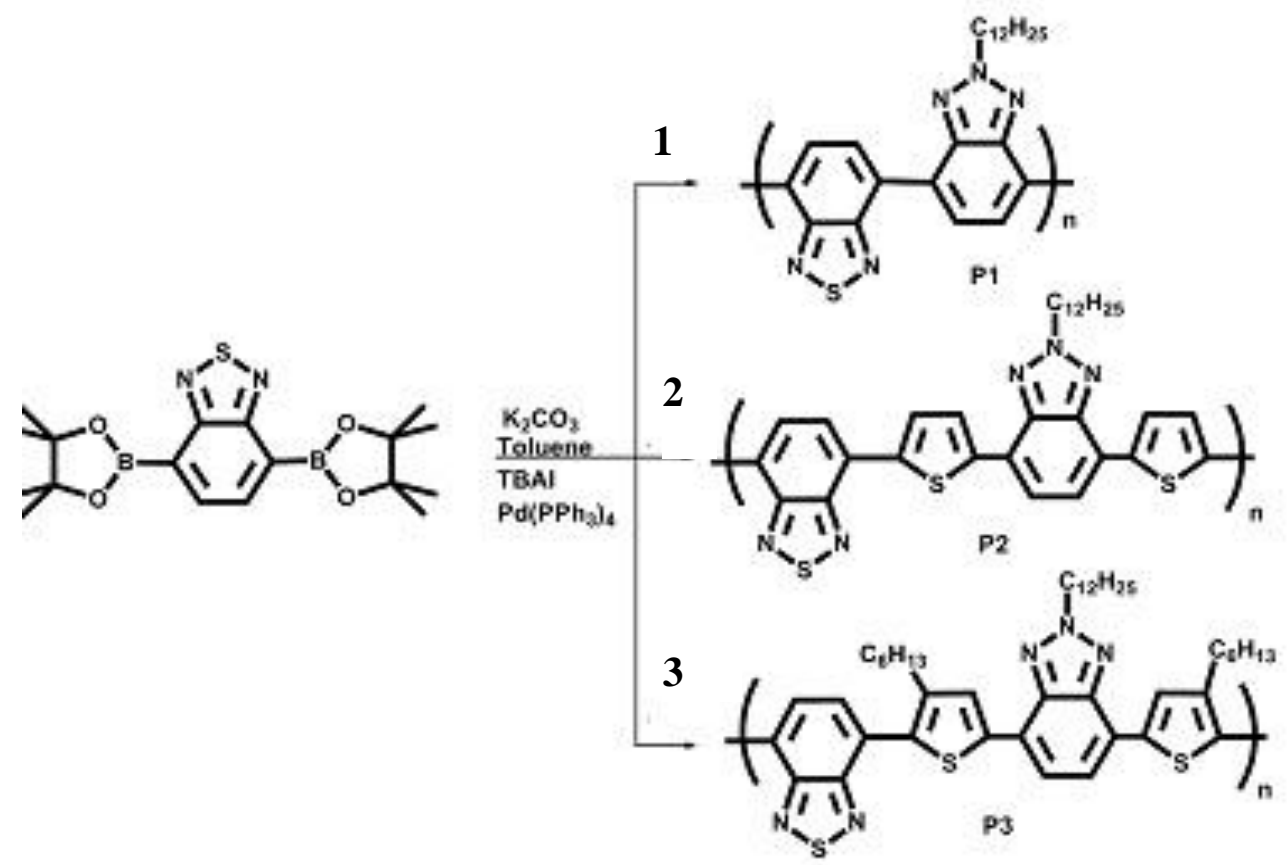

Figure 2.8 Synthetic route for P1, P2, and P3.

\subsubsection{Poly(4-(2-dodecyl-2H-benzo[d][1,2,3]triazol-4 yl) benzo[c] $[1,2,5]$} thiadiazole (P1)

4,7-Dibromo-2-dodecylbenzotriazole (1 mol equivalent) was added into a degassed mixture of potassium carbonate $\left(\mathrm{K}_{2} \mathrm{CO}_{3}, 2 \mathrm{M}\right.$ in $\left.\mathrm{H}_{2} \mathrm{O}\right)$, toluene (3:2 toluene :water). The mixture was refluxed for $1 \mathrm{~h}$ under argon. Then, benzo[c]-1,2,3-thiadiazol-4,7diyl-4,7-diboronic acid dipinacol ester (1 mol equivalent), $\mathrm{Pd}\left(\mathrm{PPh}_{3}\right)_{4}(5 \mathrm{~mol} \%)$ and 
tetrabutylammonium iodide $\left(\mathrm{N}(\mathrm{Bu})_{4} \mathrm{I}, 1 \mathrm{~mol} \%\right)$ were added into the system. The mixture was refluxed for $24 \mathrm{~h}$ under argon flow. Solvent was removed and crude mixture was extracted with $\mathrm{CHCl}_{3}: \mathrm{H}_{2} \mathrm{O}$. Combined organic layers were dried over anhydrous $\mathrm{MgSO}_{4}$ and evaporated under reduced pressure. The product was purified with methanol and acetone consecutively to obtain corresponding polymer.

\subsubsection{Poly(4-(5-(2-dodecyl-7-(thiophen-2yl)-2H-benzo[d][1,2,3]triazol-4- yl)thiophen-2-yl)benzo[c] $[1,2,5]$ thiadiazole (P2)}

4,7-Bis(5-bromothien-2-yl)-2 dodecylbenzo[1,2,3]triazole (1 mol equivalent) was added into a degassed mixture of potassium carbonate $\left(\mathrm{K}_{2} \mathrm{CO}_{3}, 2 \mathrm{M}\right.$ in $\left.\mathrm{H}_{2} \mathrm{O}\right)$, toluene (3:2 toluene :water). The mixture was refluxed for $1 \mathrm{~h}$ under argon. Then, benzo[c]1,2,3-thiadiazol-4,7-diyl-4,7-diboronic acid dipinacol ester (1mol equivalent), $\mathrm{Pd}\left(\mathrm{PPh}_{3}\right)_{4}(5 \mathrm{~mol} \%)$ and tetrabutylammonium iodide $\left(\mathrm{N}(\mathrm{Bu})_{4} \mathrm{I}, 1 \mathrm{~mol} \%\right)$ were added into the system. The mixture was refluxed for $24 \mathrm{~h}$ under argon flow. Solvent was removed and crude mixture was extracted with $\mathrm{CHCl}_{3}: \mathrm{H}_{2} \mathrm{O}$. Combined organic layers were dried over anhydrous $\mathrm{MgSO}_{4}$ and evaporated under reduced pressure. The product was purified with methanol and acetone consecutively to obtain corresponding polymer.

\subsubsection{Poly(4-(5-(2-dodecyl-7-(4-hexylthiophen-2-yl)-2H-benzo[d][1,2,3] triazol- 4-yl)-3-hexylthiophen-2-yl)benzo[c][1,2,5] thiadiazole (P3)}

4,7-Bis(5-bromo-4-hexylthien-2-yl)-2-dodecylbenzo[1,2,3]triazole $\quad(1 \mathrm{~mol}$ equivalent) was added into a degassed mixture of potassium carbonate $\left(\mathrm{K}_{2} \mathrm{CO}_{3}, 2 \mathrm{M}\right.$ in $\mathrm{H}_{2} \mathrm{O}$ ), toluene (3:2 toluene :water). The mixture was refluxed for $1 \mathrm{~h}$ under argon. Then, benzo[c]-1,2,3-thiadiazol-4,7-diyl-4,7-diboronic acid dipinacol ester (1mol 
equivalent), $\mathrm{Pd}\left(\mathrm{PPh}_{3}\right)_{4}(5 \mathrm{~mol} \%)$ and tetrabutylammonium iodide $\left(\mathrm{N}(\mathrm{Bu})_{4} \mathrm{I}, 1 \mathrm{~mol}\right.$ $\%)$ were added into the system. The mixture was refluxed for $24 \mathrm{~h}$ under argon flow. Solvent was removed and crude mixture was extracted with $\mathrm{CHCl}_{3}: \mathrm{H}_{2} \mathrm{O}$. Combined organic layers were dried over anhydrous $\mathrm{MgSO}_{4}$ and evaporated under reduced pressure. The product was purified with methanol and acetone consecutively to obtain corresponding polymer.

\subsection{Characterization of the Polymers}

\subsubsection{Cyclic Voltammetry (CV)}

Cyclic voltammetry is commonly used for qualitative analysis of electrochemical processes, determination of location of reduction and oxidation potentials of active materials and stability characteristics of the polymers.

The CV cell includes an ITO working electrode, a platinum counter electrode and an $\mathrm{Ag} / \mathrm{Ag}+$ reference electrode (Fig. 2.9). 


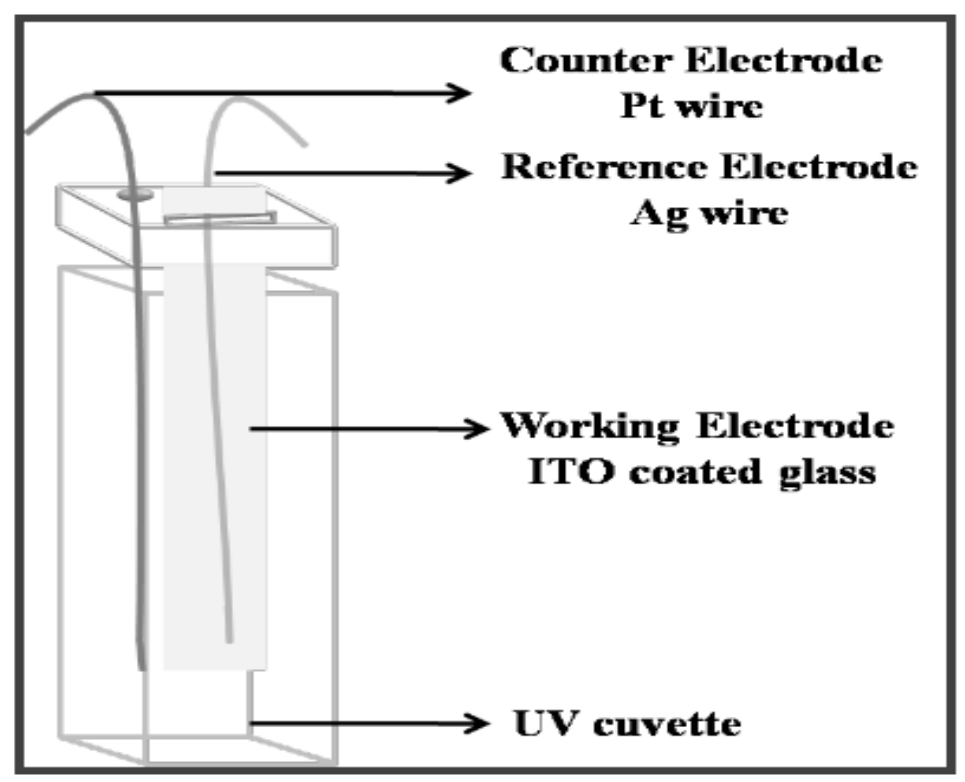

Figure 2.9 A three electrode CV cell set up.

The three electrode CV cell was connected to a potentiostat that applied the desired potential between a working electrode and a reference electrode. Solvent used for $\mathrm{CV}$ should be electrochemically inert and non-nucleophilic in order to avoid decomposition of the solvent at the applied potential. Solvent with high dielectric constant enables the movement of doping ions into or out of the conducting polymer during charge and discharge. Acetonitrile, benzonitrile, tetrahydrofuran, propylene carbonate, and methylene chloride were common solvents used in electrochemical studies. Mostly preferred solvent is acetonitrile due to its inertness. These characteristics provide less solvent retention within the conducting polymer matrix.

Cyclic Voltammetry refers to the cycling the potential of working electrode at a constant rate and measuring the resulting current at the electrode. Hence, a plot of 
current density with respect to the potential is obtained as a cyclic voltammogram (Figure 2.10).

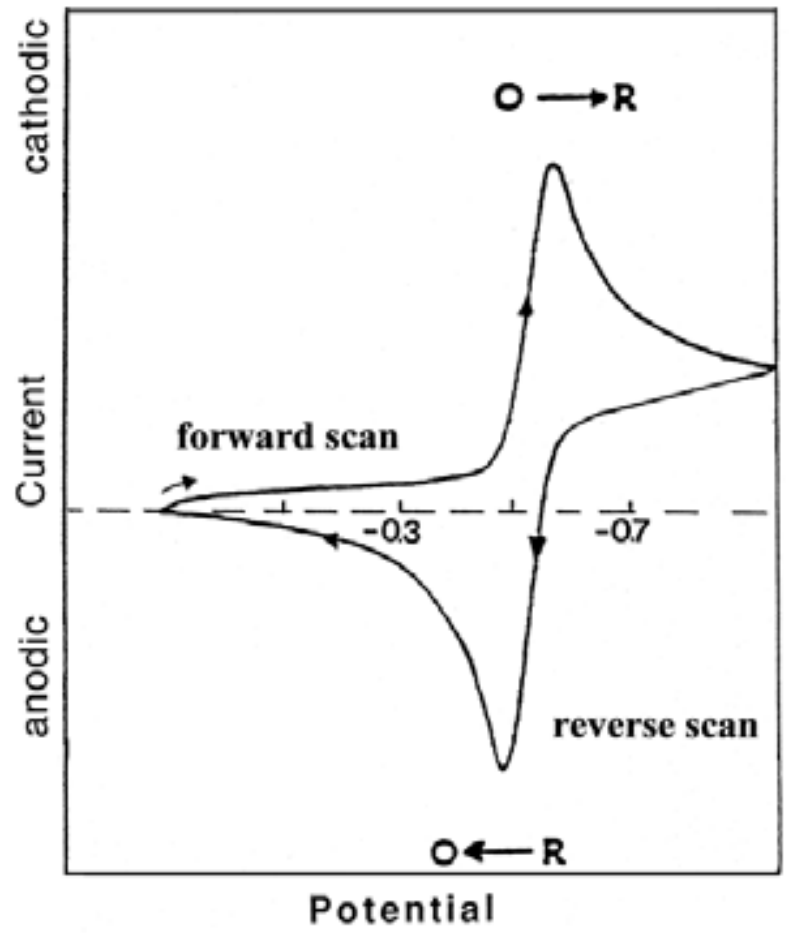

Figure 2.10 A typical cyclic voltammogram of a reversible $\mathrm{O}+\mathrm{ne}^{-} \leftrightarrow \mathrm{R}$ redox process.

The peak current for a reversible couple is given by Randles \& Sevcik equation:

$$
\mathrm{i}_{\mathrm{p}}=\left(2.69 \times 10^{5}\right) \mathrm{n}^{3 / 2} \mathrm{~A} \mathrm{D}^{1 / 2} \mathrm{C} v^{1 / 2}
$$

where $\mathrm{n}$ is the number of electrons, $\mathrm{A}$ is the electrode area $\left(\mathrm{cm}^{2}\right), \mathrm{C}$ is the concentration $\left(\mathrm{mol} / \mathrm{cm}^{3}\right), \mathrm{D}$ is the diffusion coefficient $\left(\mathrm{cm}^{2} / \mathrm{s}\right)$, and $v$ is the scan rate $(\mathrm{V} / \mathrm{s})$. It can be seen from this equation that the current is directly proportional to concentration and increases with the square root of the scan rate. The assumptions 
done for these processes are reactants and products are soluble in solution and the surface processes (adsorption of reactants and products) can be neglected.

Electrochemistry of a polymer is also examined with $\mathrm{CV}$ experiments. This is done in a monomer free environment. The polymer redox process is quasi-reversible. Since the polymer is immobilized at the electrode surface, the redox process is not diffusion controlled. Therefore, instead of Randles \& Sevcik equation the peak current is given by ;

$$
\mathrm{i}_{\mathrm{p}}=\mathrm{n}^{2} \mathrm{~F}^{2} \Gamma v / 4 \mathrm{RT}
$$

according to the theory of immobilized redox centers. In this equation, $\Gamma$ is the total amount of active species present at the electrode surface and the current peak depends linearly on scan rate. Thus investigation of peak current intensity with respect to scan rate will indicate the nature of electrochemical process whether is diffusion controlled or the polymer is adhered to the electrode surface [96, 97].

\subsubsection{Spectroelectrochemistry}

Spectroelectrochemistry is an important method that combines electrochemical and spectroscopic techniques. This method provides information about the material's band gap, intraband states (polaron and bipolaron bands) and color/s of the polymer. This information is obtained in-situ measurements of redox reactions at electrode surfaces. 
Spectroelectrochemistry experiments include a three electrode cell inside a normal cuvette for conducting polymers, a UV-Vis spectroscopy and a spectrophotometer operating in single beam mode. Initially an accurate baseline was obtained using two cuvettes containing bare ITO/glass electrodes immersed in an electrolyte placed in both reference and sample compartments. Secondly, the polymer coated ITO is placed in the sample cell. The spectrum of the polymer was obtained by oxidizing the polymer by increasing the potential stepwise. Absorption change of the polymer with respect to applied potential can be seen from the spectrum. These absorption changes of the conjugated polymer are important in electrochromic applications such as smart windows, mirrors, etc.

In the neutral state the polymer exhibits one transition from the valence band to the conduction band ( $\pi$ to $\pi *$ ). The energy difference between these two levels is the band gap (Eg), and it is measured using the onset of the $\pi-\pi^{*}$ absorption in the neutral state of the polymer. Upon applied voltage, reduction in the intensity of the $\pi-\pi^{*}$ transitions along with evolution of new absorption bands were observed. These transitions are attributed to polaron and bipolaron charge carriers.

\subsubsection{Kinetic Studies}

Kinetic studies were done in order to determine the percent transmittance changes with respect to time and the switching time at polymer's $\lambda_{\max }$ by stepping the potential repeatedly between the neutral and oxidized states. In this study, a square wave potential step method coupled with optical spectroscopy known as chronoabsorptometry was used. 
In order to study switching properties of polymers, P1, P2 and P3 were spray coated on ITO coated glass slides from chloroform $(5 \mathrm{mg} / \mathrm{mL})$ solutions in $0.1 \mathrm{M} \mathrm{TBAPF}_{6}$ in $\mathrm{ACN}$ and DCM mixture (9:1) at a scan rate of $50 \mathrm{mV} / \mathrm{s}$. Then, square-wave potential was applied to polymer coated ITO slides between fully reduced states of polymers to fully oxidized states with a residence time of 5 seconds.

\subsubsection{Gel Permeation Chromatography (GPC)}

Polymer Laboratories Gel Permeation Chromatography (GPC) 220 calibrated with universal standard polystyrene was used to calculate average molecular weights. The average molecular weights ( $\mathrm{Mn} \& \mathrm{Mw}$ ) were determined using $5 \mathrm{mg}$ of polymers dissolved in THF.

\subsection{Thermal Properties}

Perkin Elmer differential scanning calorimetry (DSC) was used to determine transition temperatures $(\mathrm{Tg}, \mathrm{Tm}, \mathrm{Tc})$ of the polymers. The experiments were done in nitrogen environment and within a $25-250{ }^{\circ} \mathrm{C}$ temperature range. The data were taken with $10{ }^{\circ} \mathrm{C} /$ minute measurements.

Perkin Elmer Pyris 1 thermal gravimetric analysis (TGA) was used to determine the decomposition temperature of the polymers. (5\% weight decomposition). The experiments were done in nitrogen environment, a $25-700{ }^{\circ} \mathrm{C}$ temperature range and with $10{ }^{\circ} \mathrm{C} /$ minute measurements. 


\subsection{Photoluminescence}

Photoluminescence spectrum of each polymer was obtained to observe the emission characteristics of the polymers. Polymers were dissolved in chloroform $(5 \mathrm{mg} / \mathrm{mL})$. Light excited the sample and the emitted radiation was given as a photoluminescence spectrum.

\subsection{Device Fabrication}

The BHJ type organic solar cells (Figure 1.11) were fabricated with a configuration of ITO/PEDOT:PSS/Polymer:PCBM/LiF/Al. ITO were taken commercially. Firstly ITO substrates were etched. Half of the ITO surface was masked with a tape and the nonmasked area was etched with $\mathrm{HCl}$ and zinc. With this procedure half of the ITO was removed, hence back electrode connection was efficiently satisfied. To neutralize the acidic area ITO side was put in a $10 \% \mathrm{NaHCO}_{3}$ solution. After etching procedure, the tape was removed and the slide was washed with water. ITO substrates were cleaned with toluene, water and detergent, acetone and isopropanol for 15 minutes in each solvent in an ultrasonic bath. Solvent was removed on a 50 ${ }^{\circ} \mathrm{C}$ hot plate for 10 minutes before the ITO is put into Plasma Cleaner.

Secondly PEDOT:PSS was filtered through a $0.45 \mu \mathrm{m}$ filter (PVDF membrane) to eliminate the undesirable particles. The layer was spin coated onto ITO to eliminate the roughness of the ITO layer and to act as a hole collection layer. The spin coating of PEDOT:PSS layer onto the ITO surface was performed at $5000 \mathrm{rpm}$ to obtain a thin layer. Annealing was performed on a $150{ }^{\circ} \mathrm{C}$ hot plate for 10 minutes. Then, the mixture of polymer and PCBM in a solvent (chloroform) was filtered through a 0.2 $\mu \mathrm{m}$ microfilter (PTFE membrane). This active layer was spin coated on the 
PEDOT:PSS layer at $1500 \mathrm{rpm}$ and $2500 \mathrm{rpm}$. Then, annealing was conducted on a $150^{\circ} \mathrm{C}$ hot plate for 10 minutes.

Thirdly, evaporation of the back electrode was done after the pressure reached the desired value $\left(1 \times 10^{-6} \mathrm{mbar}\right)$ or lower. $\mathrm{LiF}$ was evaporated as the electron transferring layer. Then, aluminum was evaporated as the cathode due to its low work function.

\subsection{Characterization of the Solar Cells}

Current-voltage (I-V) characteristics of devices under dark and illumination (Atlas solar simulator with AM $1.5 \mathrm{G}$ solar light, $100 \mathrm{~mW} / \mathrm{cm}^{2}$ illumination) were measured by Keitley 2400 Sourcemeter in an MBraun 200B glove box. ITO was connected to the positive electrode, $\mathrm{Al}$ to the negative. The curves were recorded by continuously sweeping from $-0.5 \mathrm{~V}$ to $+1.0 \mathrm{~V}$ and recording data points in $10 \mathrm{mV}$ steps. IPCE of devices were measured by Oriel Quantum Efficiency Measurement Kit. 


\section{CHAPTER 3}

\section{RESULTS AND DISCUSSION}

\subsection{Characterization}

${ }^{1} \mathrm{H}-\mathrm{NMR}$ and ${ }^{13} \mathrm{C}-\mathrm{NMR}$ spectra of the materials synthesized were obtained in $\mathrm{CDCl}_{3}$. Tetramethylsilane (TMS) was used as the internal standard to calculate the chemical shifts $(\delta)$. In order to characterize the conjugated polymers only ${ }^{1} \mathrm{H}-\mathrm{NMR}$ spectra were run.

\subsubsection{2-Dodecylbenzotriazole}

$\left.{ }^{1} \mathrm{H}\left(400 \mathrm{MHz}, \mathrm{CDCl}_{3}, \delta\right): 7.76(\mathrm{~m}, 2 \mathrm{H}), 7.26(\mathrm{~m}, 2 \mathrm{H}), 4.62(\mathrm{t}, \mathrm{J}) 7.1 \mathrm{~Hz} 2 \mathrm{H}\right), 2.12$ $(\mathrm{m}, 2 \mathrm{H}), 1.25-1.15(\mathrm{~m}, 18 \mathrm{H}), 0.78(\mathrm{t}, \mathrm{J}) 6.0 \mathrm{~Hz}, 3 \mathrm{H}) .{ }^{13} \mathrm{C} \mathrm{NMR}\left(100 \mathrm{MHz}, \mathrm{CDCl}_{3}\right.$,

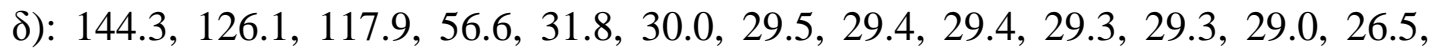
22.6, 14.0 . 


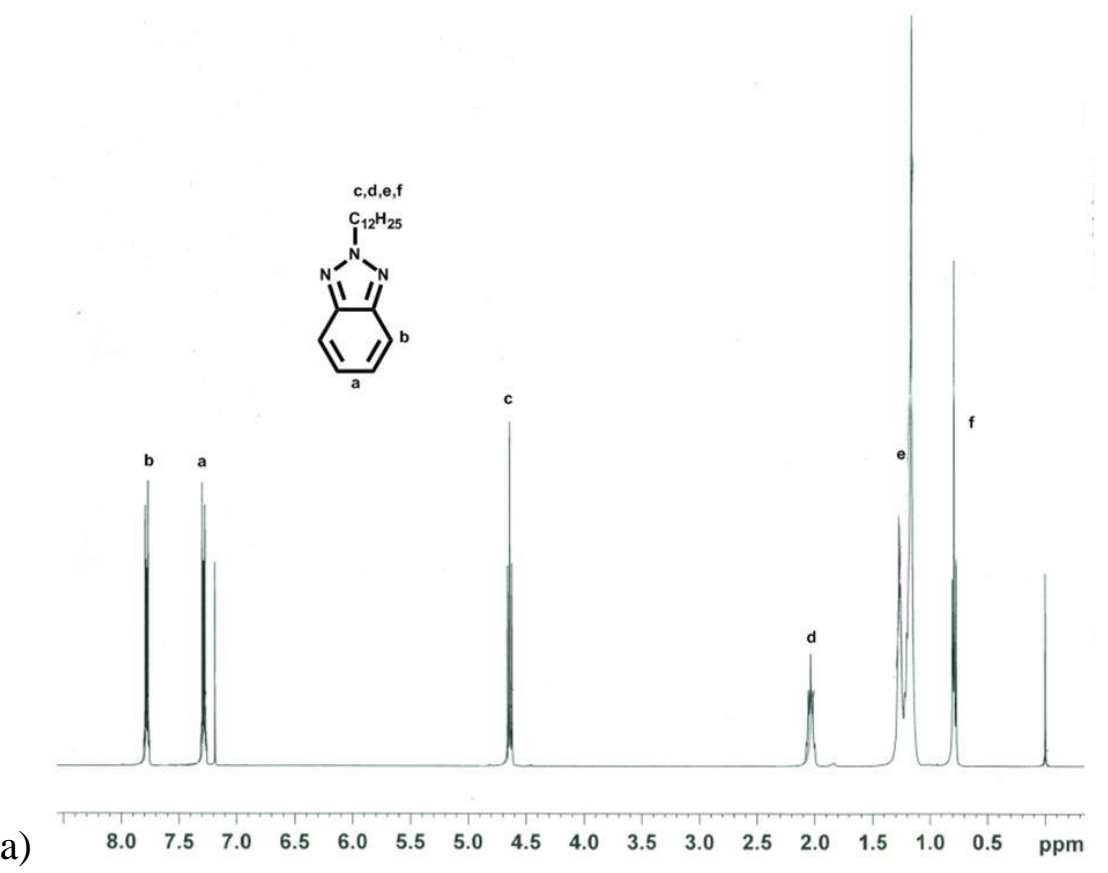

a)

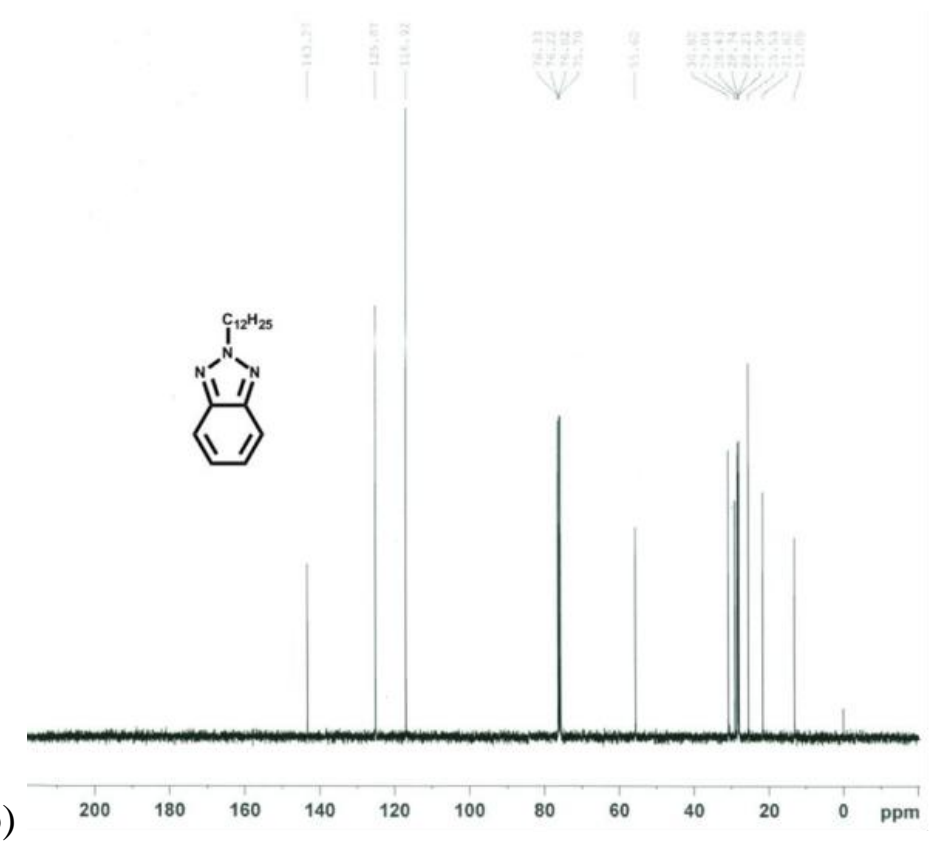

Figure 3.1 a) ${ }^{1} \mathrm{H}-\mathrm{NMR}$ and b) ${ }^{13} \mathrm{C}$ NMR of 2-dodecylbenzotriazole. 


\subsubsection{4,7-Dibromo-2-dodecylbenzotriazole}

${ }^{1} \mathrm{H}(400 \mathrm{MHz}, \mathrm{CDCl} 3, \delta): 7.36$ (s, 2H), 4.60 (t, J ) 7.0 Hz, 2H), 2.10 (m, 2H), 1.38$1.12(\mathrm{~m}, 18 \mathrm{H}), 0.80(\mathrm{t}, \mathrm{J}) 6.9 \mathrm{~Hz}, 3 \mathrm{H}) .{ }^{13} \mathrm{CNMR}\left(100 \mathrm{MHz}, \mathrm{CDCl}_{3}, \delta\right): 143.7,129.4$, 109.9, 57.4, 31.8, 30.1, 29.5, 29.5, 29.4, 29.4, 29.3, 28.9, 26.4, 22.6, 14.0.

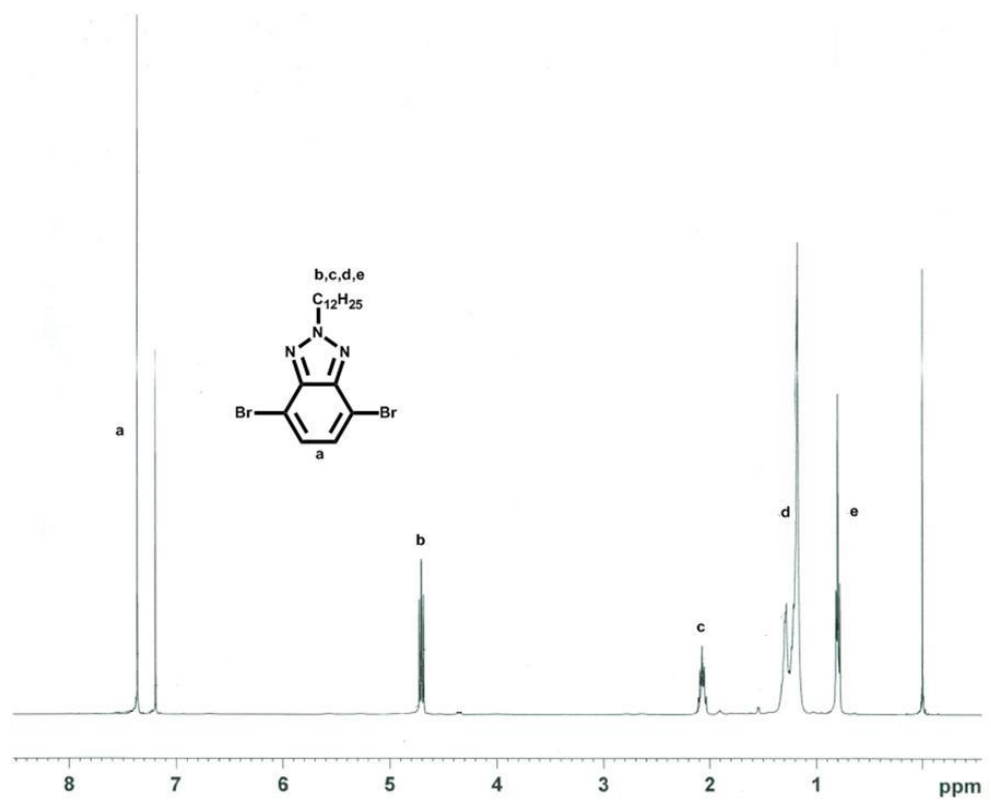

Figure 3.2 a) ${ }^{1} \mathrm{H}-\mathrm{NMR}$ and b) ${ }^{13} \mathrm{C}$ NMR of 4,7- Dibromo-2-dodecylbenzotriazole. 


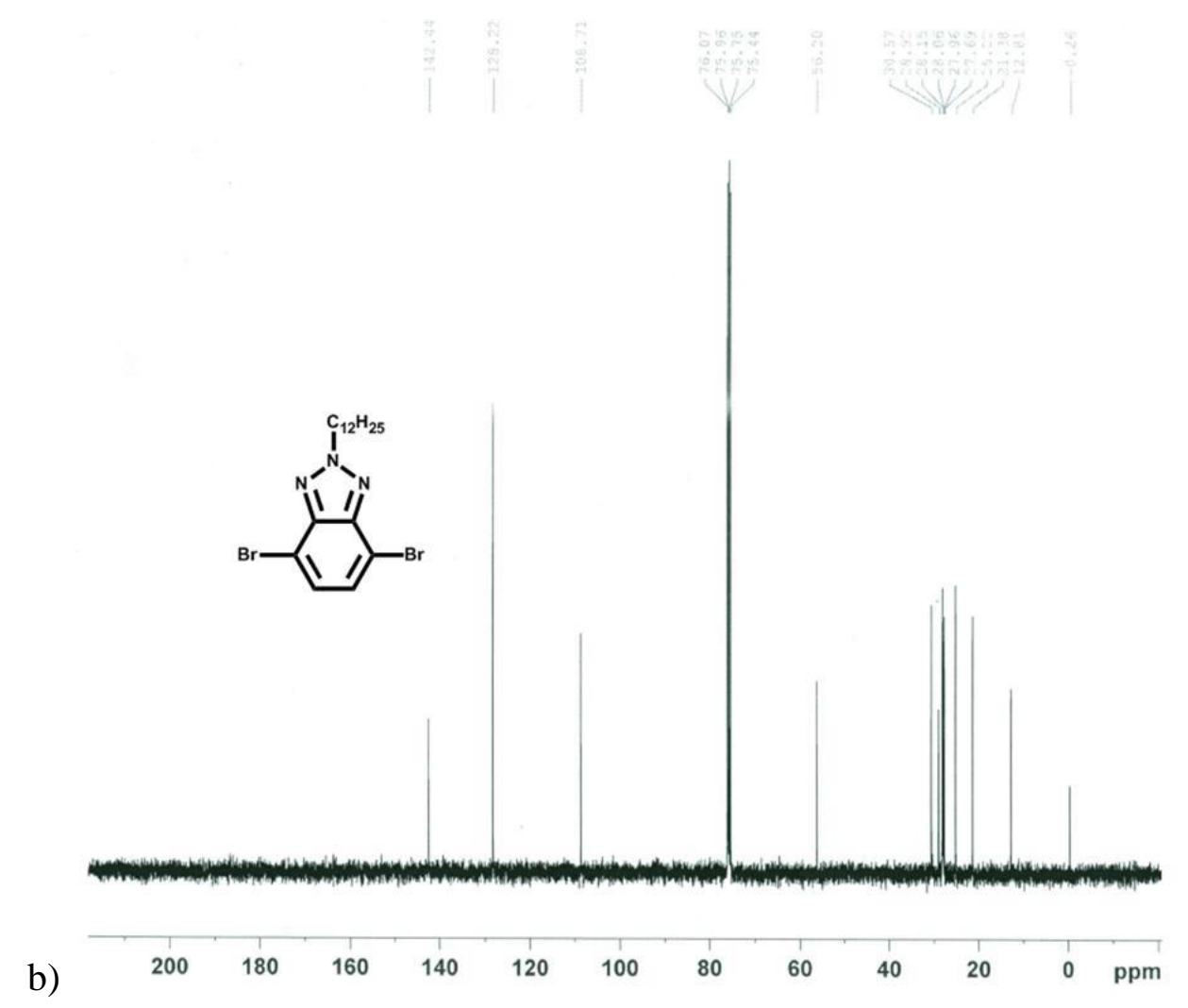

Figure 3.2 a) ${ }^{1} \mathrm{H}-\mathrm{NMR}$ and b) ${ }^{13} \mathrm{C}$ NMR of 4,7- Dibromo-2-dodecylbenzotriazole (continued).

\subsubsection{2-Dodecyl-4,7-di(thiophen-2-yl)-2H-benzo[d][1,2,3]triazole (TBT)}

${ }^{1} \mathrm{H}$ NMR $\left(400 \mathrm{MHz}, \mathrm{CDCl}_{3}, \delta\right): 8.01(\mathrm{~d}, \mathrm{~J}=5.6 \mathrm{~Hz}, 2 \mathrm{H}), 7.52(\mathrm{~s}, 2 \mathrm{H}), 7.28(\mathrm{~d}, \mathrm{~J}=6.0$ $\mathrm{Hz}, 2 \mathrm{H}), 7.09$ (t, JA=8.8 Hz, JB = 4.8, 2H), $4.60(\mathrm{t}, \mathrm{J}=7.0 \mathrm{~Hz}, 2 \mathrm{H}), 2.10(\mathrm{~m}, 2 \mathrm{H})$, 1.38-1.15 (m,18H), 0.80 (t, J=6.9 Hz, 3H); ${ }^{13} \mathrm{C}$ NMR (100 MHz, DMSO-d6, $\left.\delta\right)$ : $142.4,140.2$, 128.4, 127.3, 125.8, 123.9, 123.0, 57.1, 32.2, 30.3, 29.9, 29.8, 29.7, 29.6, 29.5, 29.3, 26.9, 22.9, 14.4. MS (m/z): $451[\mathrm{M}+]$ 

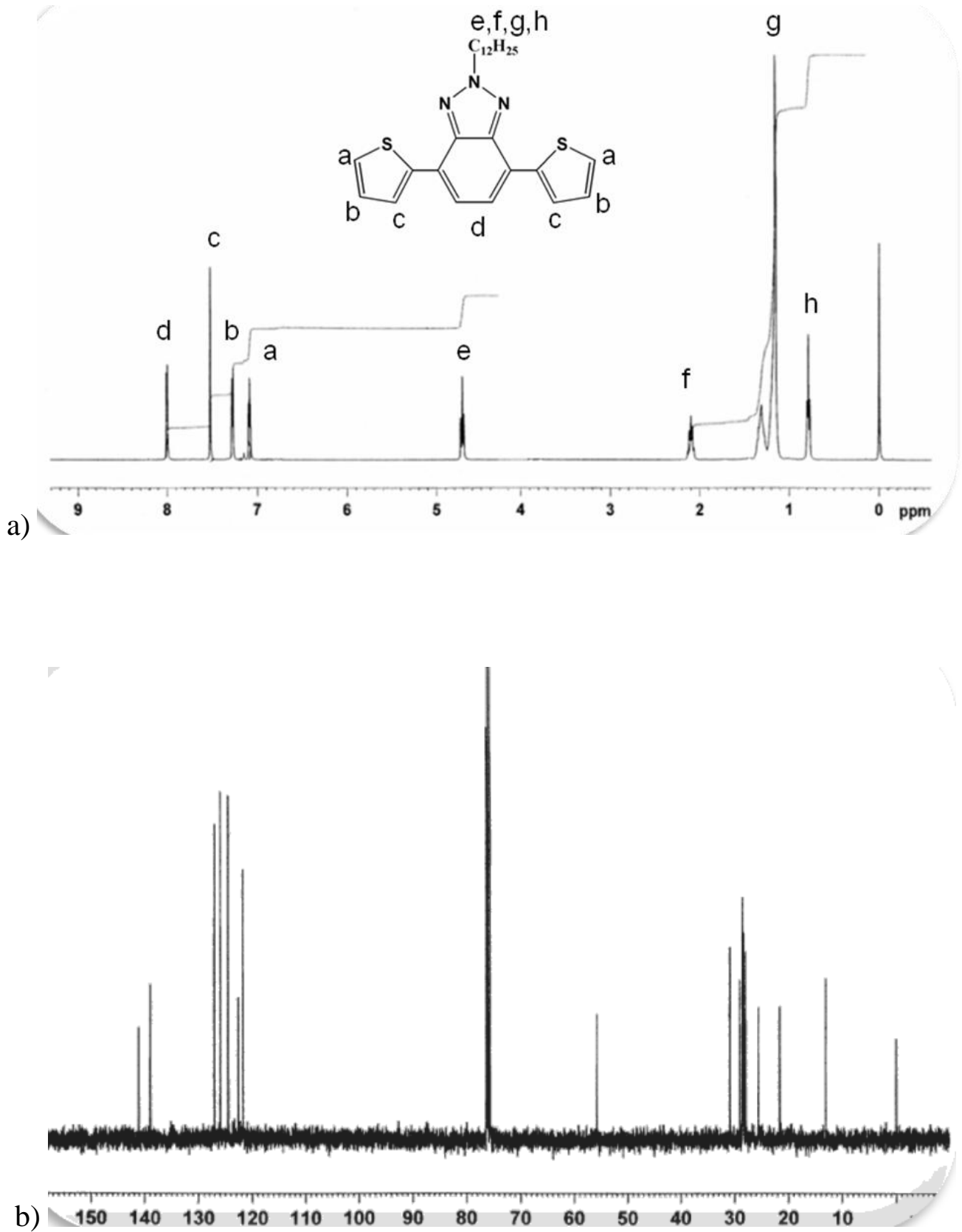

Figure 3.3 a) ${ }^{1} \mathrm{H}$ and b) ${ }^{13} \mathrm{C}$-NMR of TBT. 


\subsubsection{2-Dodecyl-4,7-bis(4-hexylthiophen-2-yl)-2Hbenzo[d][1,2,3]triazole}

(HTBT)

${ }^{1} \mathrm{H}$ NMR (400MHz, $\left.\mathrm{CDCl}_{3}\right): 7.9$ (s, 2H), 7.5 (s, 2H), 6.9 (s,2H), 4.8 (t, J=7.0 Hz, 2H), $2.1(\mathrm{~m}, 2 \mathrm{H}), 1.4-1.1(\mathrm{~m}, 18 \mathrm{H}), 0.9(\mathrm{t}, \mathrm{J}=6.9 \mathrm{~Hz}, 3 \mathrm{H}) ;{ }^{13} \mathrm{C}$ NMR $(100 \mathrm{MHz}$, CDCl3, ): 143.1, 140.1, 138.3, 127.1, 122.4, 121.3, 119.0, 55.5, 30.6, 30.5, 29.5, 29.2, 28.8, 28.4, 28.2, 27.8, 25.49, 21.4, 12.8 MS (m/z): 619 [M+]

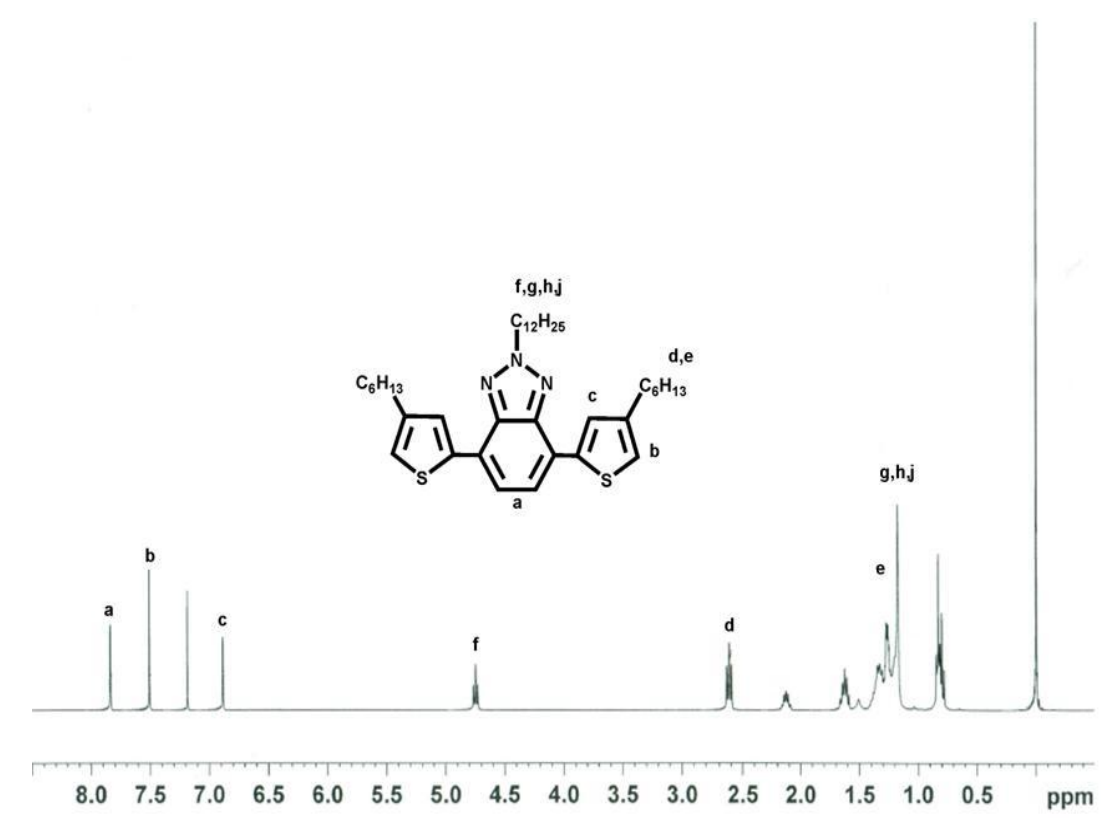

Figure 3.4 a) ${ }^{1} \mathrm{H}$ and b) ${ }^{13} \mathrm{C}-\mathrm{NMR}$ of HTBT. 


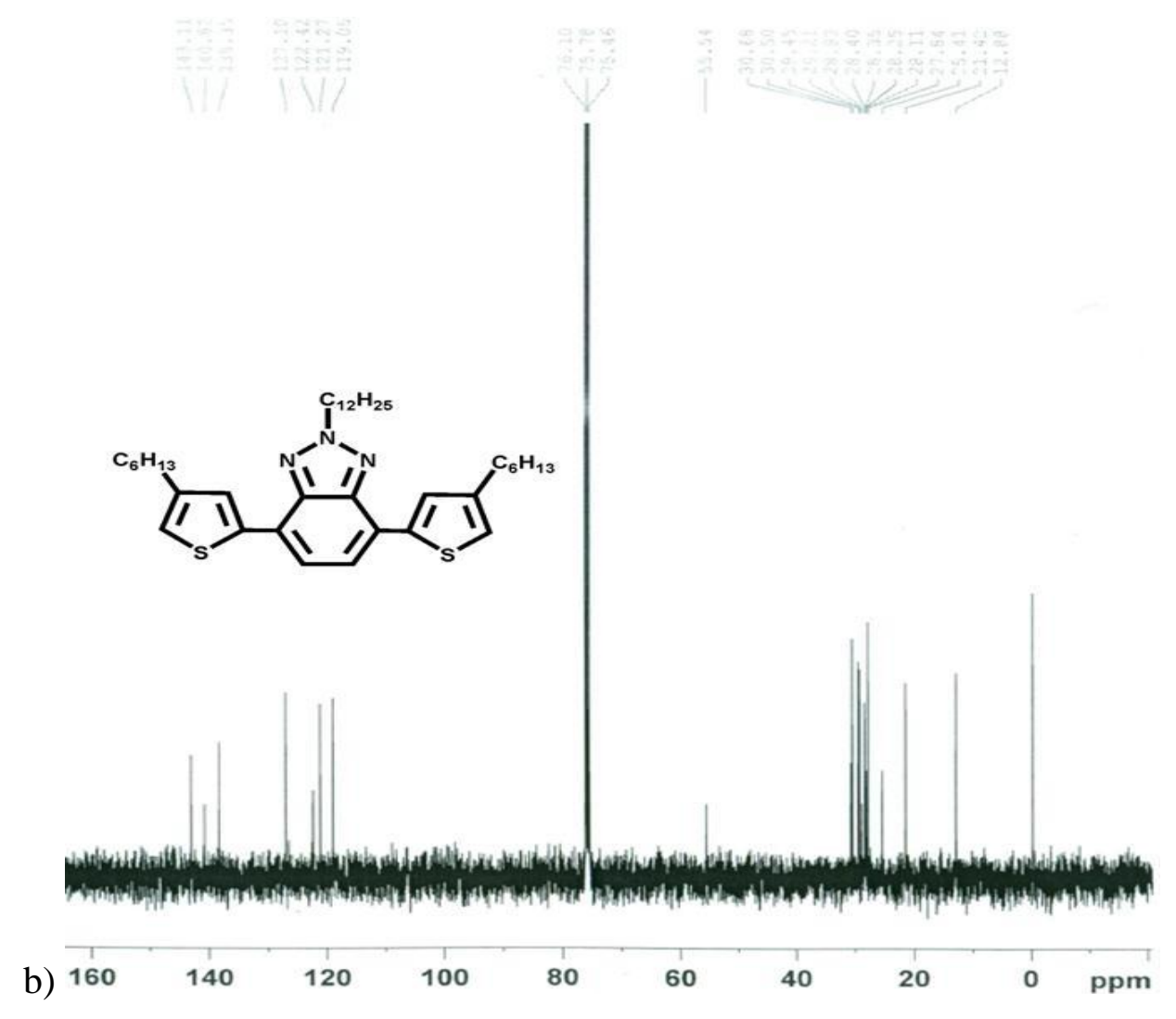

Figure 3.4 a) ${ }^{1} \mathrm{H}$ and b) ${ }^{13} \mathrm{C}-\mathrm{NMR}$ of HTBT (continued).

\subsubsection{4,7-Bis(5-bromothien-2-yl)-2-dodecylbenzo[1,2,3]triazole}

${ }^{1} \mathrm{H}$ NMR (400MHz, CDCl3, ס): 7.72 (d, J=5.6 Hz, 2H), 7.44 (s, 2H), 7.04 (d, J=6.0 $\mathrm{Hz}, 2 \mathrm{H}), 4.72(\mathrm{t}, \mathrm{J}=7.0 \mathrm{~Hz}, 2 \mathrm{H}), 2.10$ (m, 2H), 1.32-1.17 (m,18H), 0.80 (t, J=6.9 Hz,

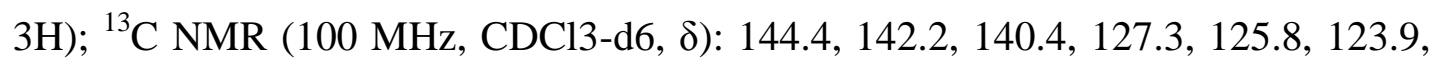
123.0, 57.1, 32.2, 30.3, 29.9, 29.8, 29.7, 29.6, 29.5, 29.3, 26.9, 22.9, 14.4. MS (m/z): 608 [M+] 


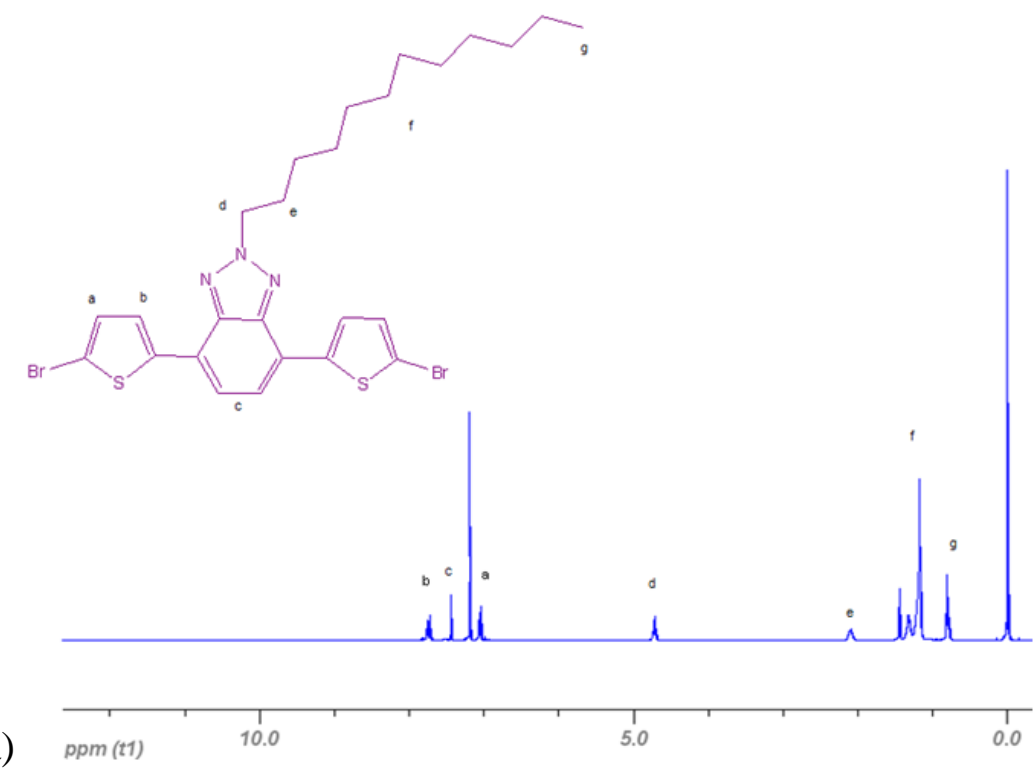

a)

ppm (t1) 10.0

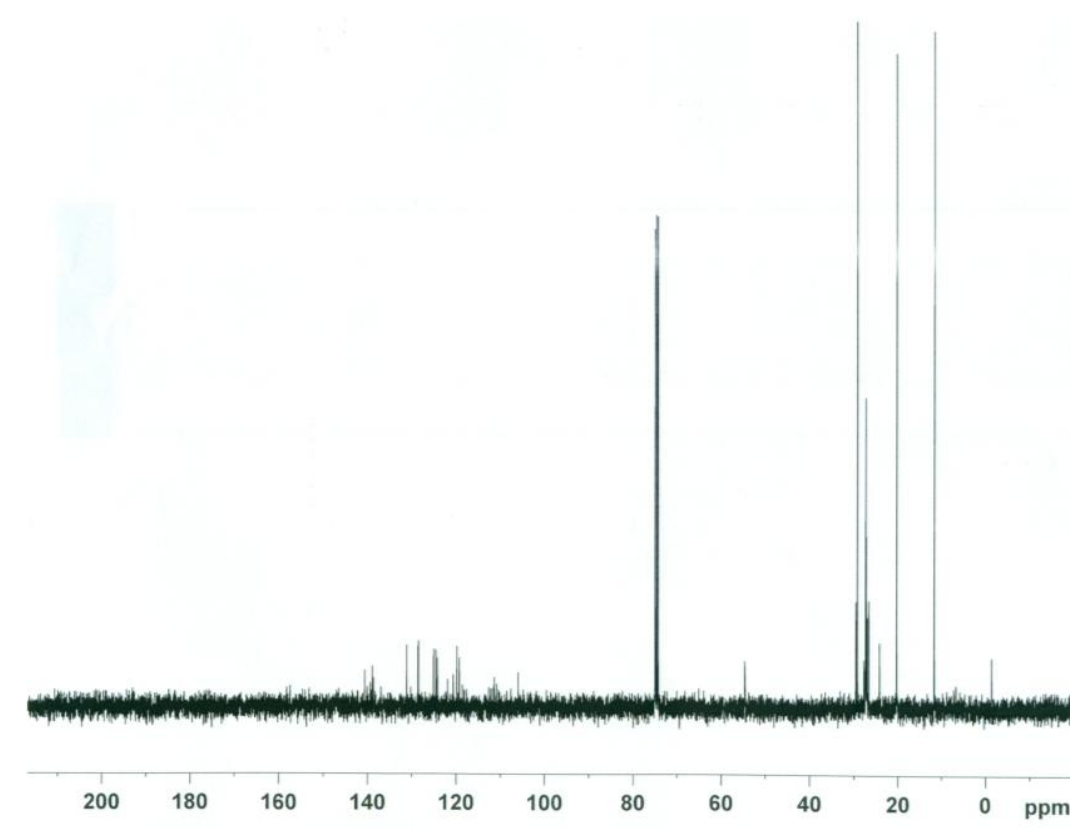

b)

Figure 3.5 a) ${ }^{1} \mathrm{H}$ and b) ${ }^{13} \mathrm{C}-\mathrm{NMR}$ NMR of 4,7-bis(5-bromothien-2-yl)-2dodecylbenzo[1,2,3]triazole. 


\subsubsection{4,7-Bis(5-bromo-4-hexylthien-2-yl)-2-dodecylbenzo[1,2,3]triazole}

${ }^{1} \mathrm{H}$ NMR (400MHz, $\left.\mathrm{CDCl}_{3}, \delta\right): 7.69$ (s, 2H), 7.41 (s, 2H), 4.77 (t, J=8.0 Hz, 2H), 2.61(t, J=8.0 Hz, 4H) $2.16(\mathrm{~m}, 2 \mathrm{H}), 1.65(\mathrm{~m}, 4 \mathrm{H}), 1.41-1.24(\mathrm{~m}, 26 \mathrm{H}), 0.91-0.85(\mathrm{~m}$, 9H); ${ }^{13} \mathrm{C}$ NMR (100 MHz, $\left.\mathrm{CDCl}_{3}, \delta\right): 143.1,141.7,139.2,127.5,123.0,122.0$, $110.1,56.8,32.0,31.7,30.0,29.8,29.7,29.7$ 29.6, 29.5, 29.4, 29.1, 29.0, 26.7, 22.7 14.1. MS $(\mathrm{m} / \mathrm{z}): 778[\mathrm{M}+]$

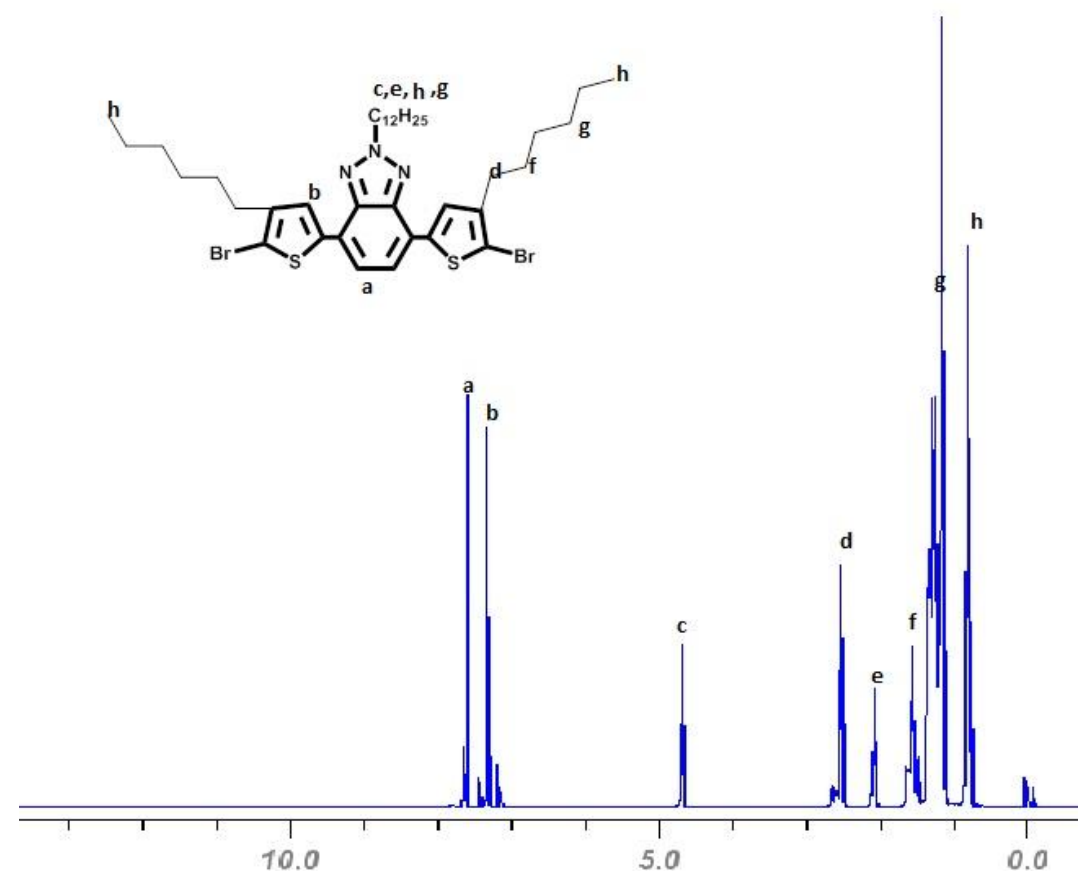

Figure 3.6 a) ${ }^{1} \mathrm{H}$ and b) ${ }^{13} \mathrm{C}-\mathrm{NMR}$ NMR of4,7-bis(5-bromo-4-hexylthien-2-yl)-2dodecylbenzo[1,2,3]triazole. 


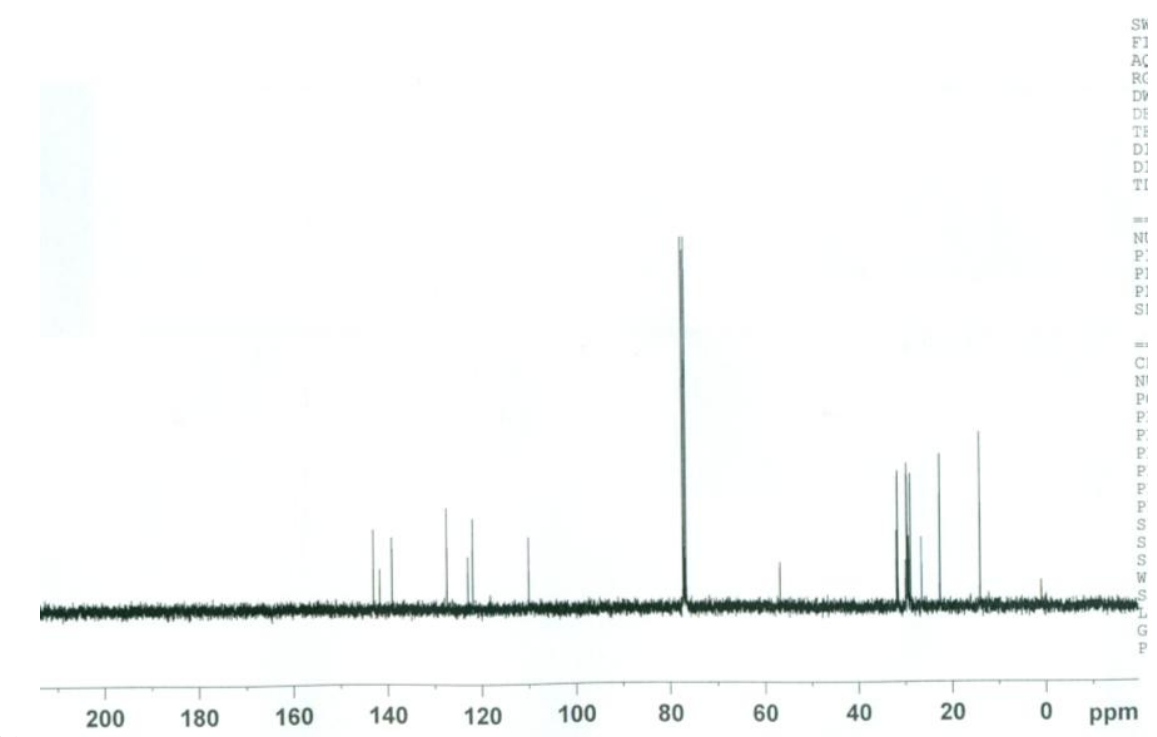

b)

Figure 3.6 a) ${ }^{1} \mathrm{H}$ and b) ${ }^{13} \mathrm{C}-\mathrm{NMR}$ NMR of4,7-bis(5-bromo-4-hexylthien-2-yl)-2dodecylbenzo[1,2,3]triazole (continued).

\subsubsection{Poly(4-(2-dodecyl-2H-benzo[d][1,2,3]triazol-4 yl) benzo[c] [1,2,5 ]} thiadiazole (P1)

${ }^{1} \mathrm{H}$ NMR (400MHz, $\mathrm{CDCl}_{3}, \delta$ ): 8.4-8.8 (br, BTz and BTd), 4.7 (br, N-CH2), 2.2 (br, $-\mathrm{CH}_{2}(\mathrm{BTz})$ ), 1.6-0.7 (pendant alkyl chains) 


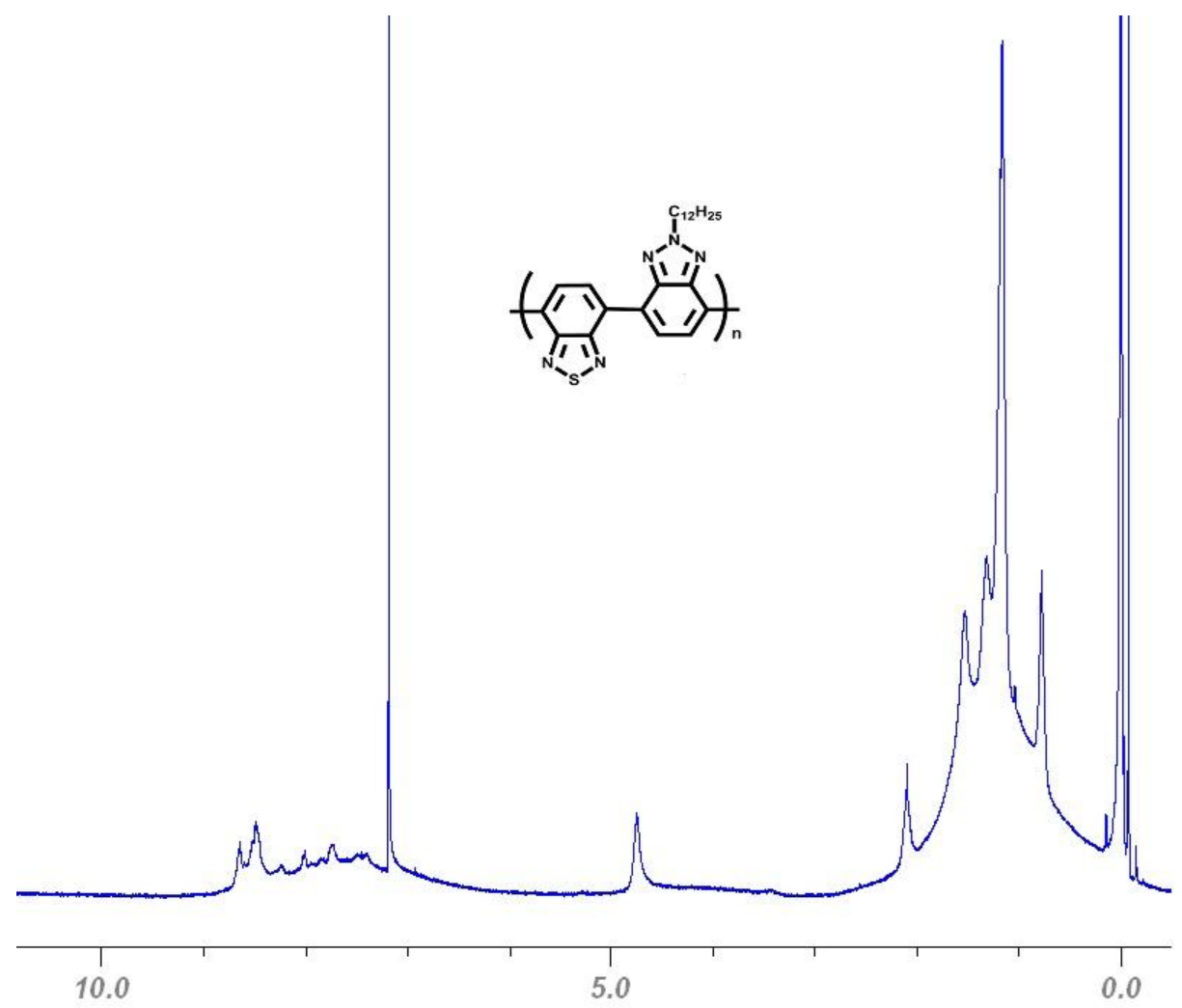

Figure 3.7 ${ }^{1} \mathrm{H}$ NMR of Poly(4-(2-dodecyl-2H-benzo[d][1,2,3]triazol-4 yl) benzo[c] $[1,2,5]$ thiadiazole $(\mathrm{P} 1)$.

3.1.8 Poly(4-(5-(2-dodecyl-7-(thiophen-2yl)-2H-benzo[d][1,2,3]triazol-4-yl) thiophen-2-yl)benzo[c][1,2,5]thiadiazole (P2)

${ }^{1} \mathrm{H}$ NMR (400MHz, $\left.\mathrm{CDCl}_{3}, \delta\right)$ : 7.7-7.4 (br, BTz and BTd), 7.3-7.1 (br, thiophene), $5.2(\mathrm{~N}-\mathrm{CH} 2), 1.9-0.7$ (br, pendant alkyl chains). 


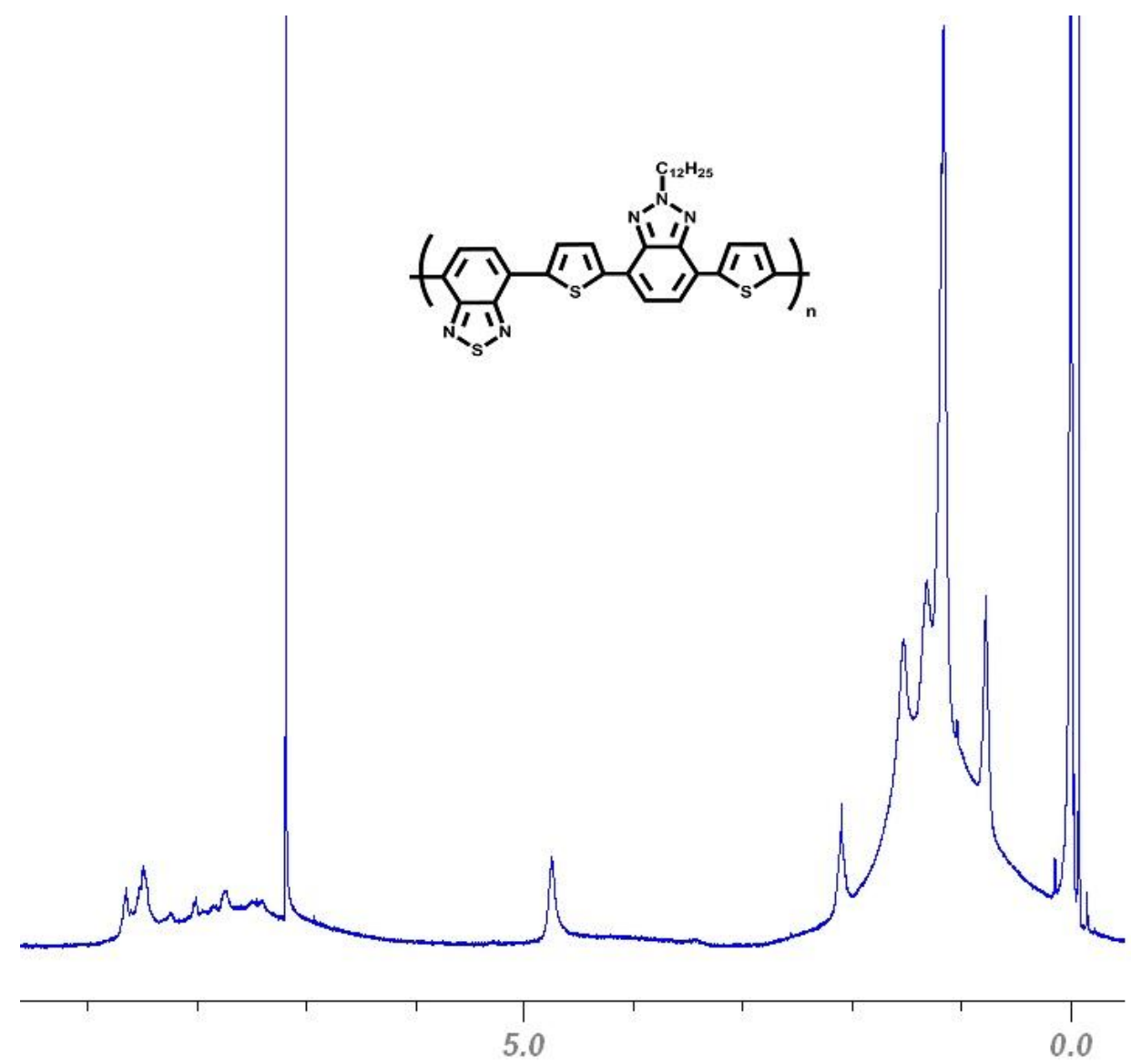

Figure 3.8 ${ }^{1} \mathrm{H}$ NMR of Poly(4-(5-(2-dodecyl-7-(thiophen-2yl)-2H benzo [d][1,2,3] triazol-4-yl)thiophen-2-yl)benzo[c][1,2,5]thiadiazole (P2).

3.1.9 Poly(4-(5-(2-dodecyl-7-(4-hexylthiophen-2-yl)-2H-benzo[d][1,2,3] triazol4-yl)-3-hexylthiophen-2-yl)benzo[c] [1,2,5] thiadiazole (P3)

${ }^{1} \mathrm{H}$ NMR (400MHz, $\mathrm{CDCl}_{3}, \delta$ ): 8.0 (br, BTd), 7.7 (br, BTz), 7.3 (br, thiophene), 4.8 $\left(\mathrm{N}-\mathrm{CH}_{2}\right), 2.8$ (br, $-\mathrm{CH} 2$ (thiophene)) 2.2 (br, $-\mathrm{CH}_{2}(\mathrm{BTz})$ ), 1.9-0.7 (br, pendant alkyl chains). 


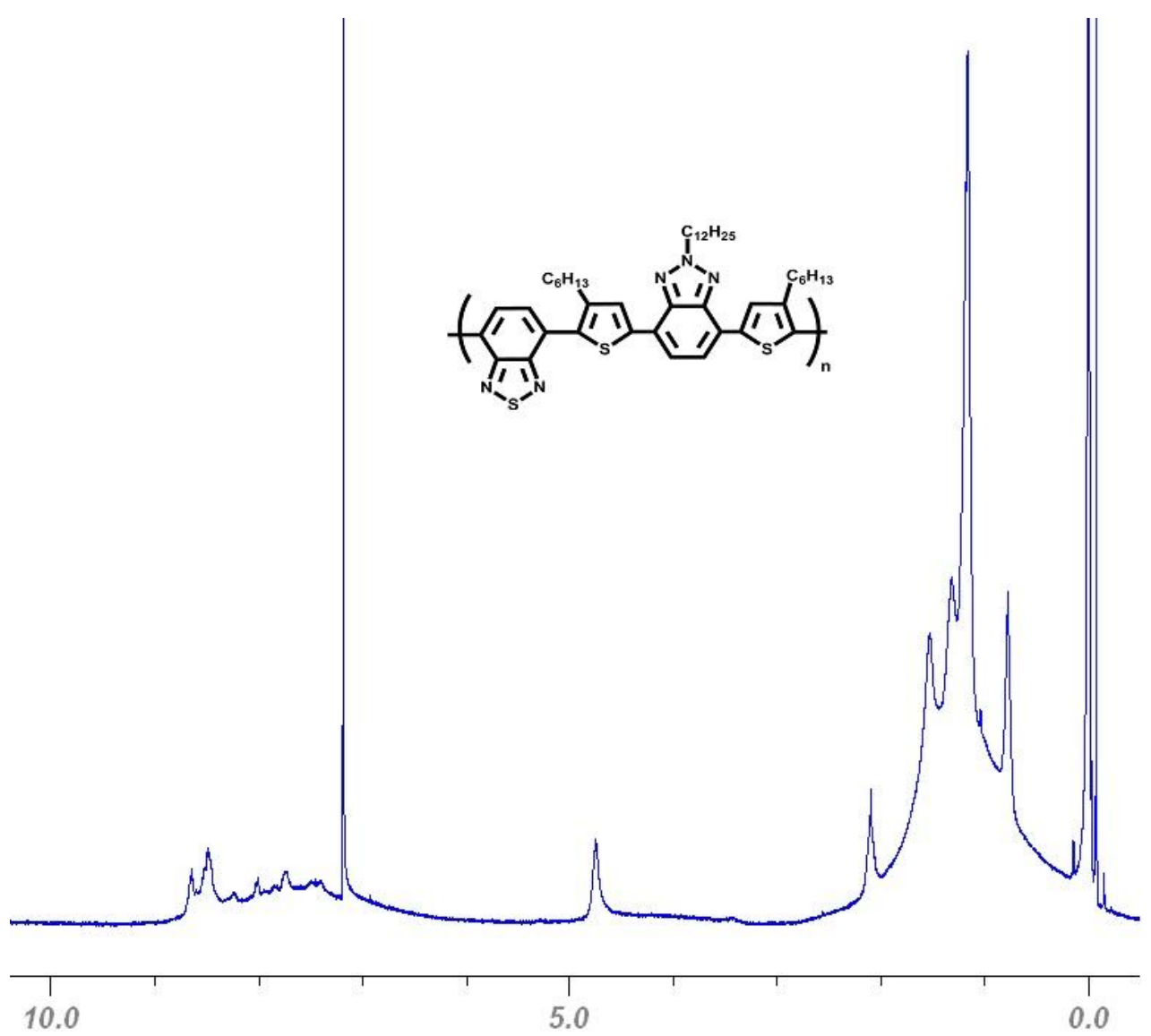

Figure 3.9 ${ }^{1} \mathrm{H}$ of Poly(4-(5-(2-dodecyl-7-(4-hexylthiophen-2-yl)-2H-benzo[d][1,2,3] triazol-4-yl)-3-hexylthiophen-2-yl)benzo[c][1,2,5] thiadiazole (P3).

3.2 Poly(4-(2-dodecyl-2H-benzo[d][1,2,3]triazol-4 yl) benzo[c] $[1,2,5]$ thiadiazole (P1)

\subsubsection{Cyclic Voltammetry (CV)}

In order to investigate the electrochemical properties of $\mathrm{P} 1$, the polymer was spray coated on ITO coated glass slides from chloroform $(5 \mathrm{mg} / \mathrm{mL})$ solution. Then the working electrode was placed in a three electrode cell where Pt wire was the counter 
and $\mathrm{Ag}$ wire was the reference $\left(50 \mathrm{mV}\right.$ vs. $\left.\mathrm{Fc} / \mathrm{Fc}^{+}\right)$electrodes. $0.1 \mathrm{M} \mathrm{TBAPF}_{6}$ in acetonitrile ACN and DCM mixture (9:1) was used as the supporting electrolyte throughout the electrochemical study. Initially polymer film was subjected to a repeated cycling to obtain electrochemically stable and reproducible dopingdedoping at a $50 \mathrm{mV} / \mathrm{s}$ scan rate. The potentials were swept between -2.25 and 1.75 V.

P1 film revealed reversible redox couple at positive potentials pointed at 1.65 and $1.33 \mathrm{~V}$ versus Ag wire pseudo reference electrode. Due to two acceptor units which results in electron poor structure for P1, the highest oxidation potential was observed for this polymer. In fact, this polymer hardly showed electro-activity in the positive working potential range due to the electron poor polymer backbone. Reduction for n-doping of P1 film was observed at $-1.9 \mathrm{~V}$ and the corresponding de-doping peak was at $-1.15 \mathrm{~V}$.

Oxidation and reduction onset values were used to estimate the HOMO-LUMO energy levels of the polymer from the CV due to ambipolar characteristics of the polymer. The onset values were estimated by taking the intersection between the base line and the tangent line drawn to the increasing part of the current. The NHE value was used as $-4.75 \mathrm{eV}$ throughout the study [59]. The energy levels versus vacuum level were calculated according to the following equations:

$$
\begin{aligned}
& E_{\text {HOMO }}=-\left(E_{\text {onset,ox }}+4.75\right)(\mathrm{eV}) \\
& E_{\text {LUMO }}=-\left(E_{\text {onset,red }}+4.75\right)(\mathrm{eV})
\end{aligned}
$$


$E^{e c}=\left(E_{\text {onset,ox }}-E_{\text {onset,red }}\right)(e V)$ whereby $E_{\text {onset,ox }}$ and $E_{\text {onset,red }}$ represent the onset oxidation and reduction potentials, respectively. All these values determined from cyclic voltammogram of P1 were given in Table 1.

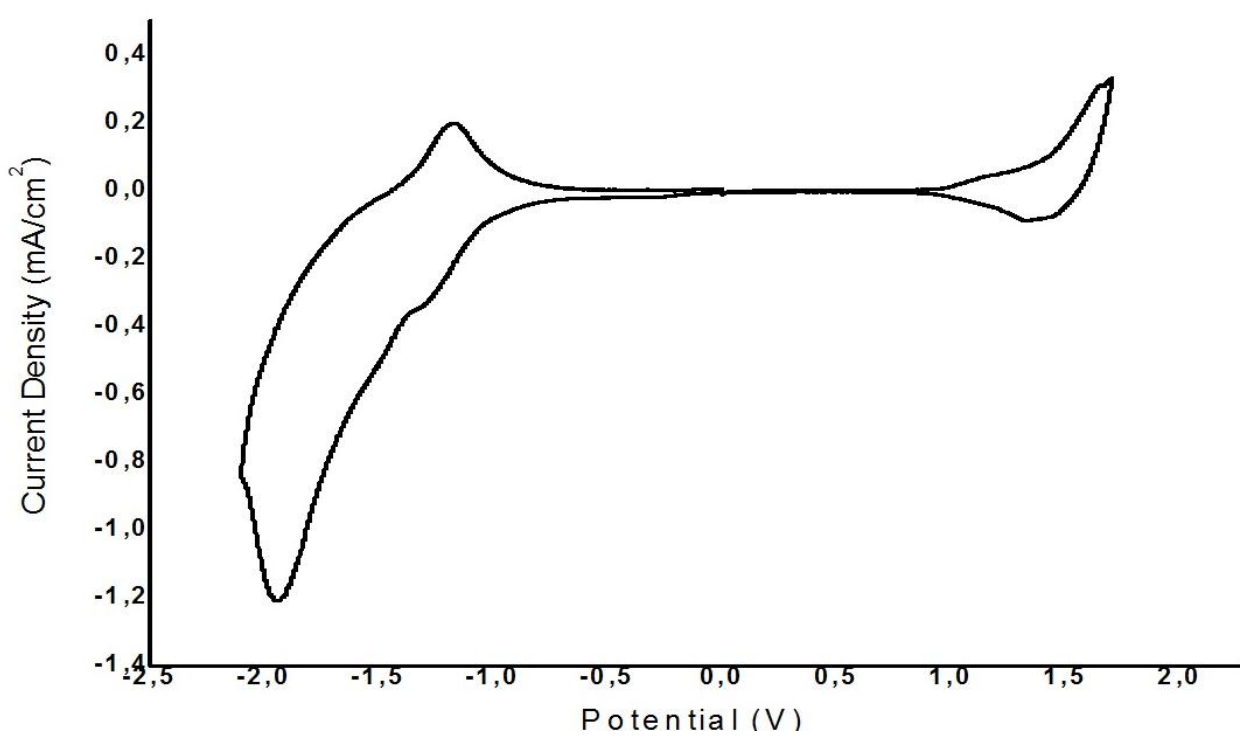

Figure 3.10 Cyclic voltammogram of $\mathrm{P} 1$ for both $\mathrm{p}$ and $\mathrm{n}$ type doping in the presence of $0.1 \mathrm{M} \mathrm{TBAPF}_{6} / \mathrm{ACN}: \mathrm{DCM}$ solution at a scan rate of $50 \mathrm{mV} / \mathrm{s}$.

Table 1. Cyclic Voltammetry and EVS results of P1 (CV was recorded in $0.1 \mathrm{M}$ $\mathrm{TBAPF}_{6} / \mathrm{ACN}: \mathrm{DCM}$ solution at a scan rate of $50 \mathrm{mV} / \mathrm{s}$.

\begin{tabular}{|c|c|c|c|c|c|c|c|c|}
\hline P1 & \multicolumn{2}{|c|}{$\begin{array}{c}\text { Oxidation } \\
\text { Potential (V) }\end{array}$} & \multicolumn{2}{c|}{$\begin{array}{c}\text { Reduction } \\
\text { Potential (V) }\end{array}$} & \multicolumn{2}{|c|}{ Bandgap (eV) } & \multicolumn{2}{|c|}{$\begin{array}{c}\text { Energy Level (eV) } \\
\text { (from CV) }\end{array}$} \\
\hline & $\mathrm{E}_{\text {ox }}$ & $\mathrm{E}_{\text {ox }}{ }^{\text {onset }}$ & $\mathrm{E}_{\text {red1 }}$ & $\mathrm{E}_{\text {red }}{ }^{\text {onset }}$ & $\mathrm{E}_{\mathrm{g}}{ }^{\mathrm{ec}}$ & $\mathrm{E}_{\mathrm{g}}{ }^{\text {op }}$ & HOMO & LUMO \\
\hline & 1.65 & 1.33 & -1.9 & -1.24 & 2.59 & 1.97 & -6.10 & -3.51 \\
\hline
\end{tabular}




\subsubsection{Spectroelectrochemistry}

In order to observe the optoelectronic properties of the polymer, spectral behaviors of P1 should be observed by the electronic absorption spectra under applied potentials. Therefore, neutral polymer film was spray coated from a solution of 5 $\mathrm{mg} / \mathrm{mL}$ in chloroform and the UV-vis-NIR spectra was recorded upon applied potential. Spray coating was carried out until a homogeneous film was achieved. After drying the P1 film, it was subjected to subsequent redox cycling by $\mathrm{CV}$ to obtain electrochemical stability prior to spectroelectrochemical analysis. The absorbance changes were noted as the potential was gradually increased from $0.0 \mathrm{~V}$ to $1.2 \mathrm{~V}$. As also elaborated in electrochemical studies stepwise oxidation of P1 did not yield doped form of the polymer which resulted in a non-electrochromic polymer. It can be seen from the spectrum of P1 film that polaron and bipolaron of the P1 film were not observed.

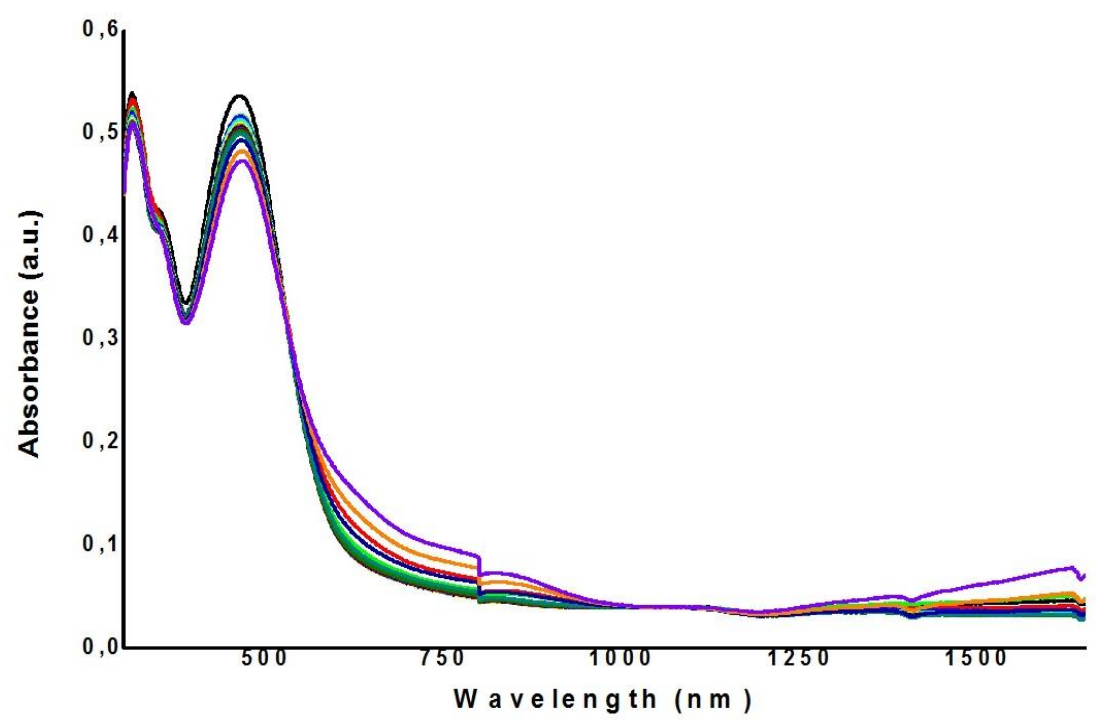

Figure 3.11 p-Doping electronic absorption spectra of $\mathrm{P} 1$ between 0.0 and $1.85 \mathrm{~V}$ in 0.1 M TBAPF 6 ACN:DCM (9:1) electrolyte-solvent couple. 


\subsubsection{Kinetic Studies}

Kinetic studies of the polymer was performed to monitor the percent transmittance changes as a function of time and to determine the switching time of the polymer at its maximum absorption. Optical measurement was carried out in $\mathrm{ACN}_{\mathrm{TBAPF}}$ solution in order to observe the changes between its neutral and fully oxidized states. At its dominant wavelength in the visible region $(460 \mathrm{~nm}), \mathrm{P} 1$ revealed $14 \%$ percent transmittance change. The switching time for P1 at corresponding wavelength was calculated as $4.2 \mathrm{~s}$.

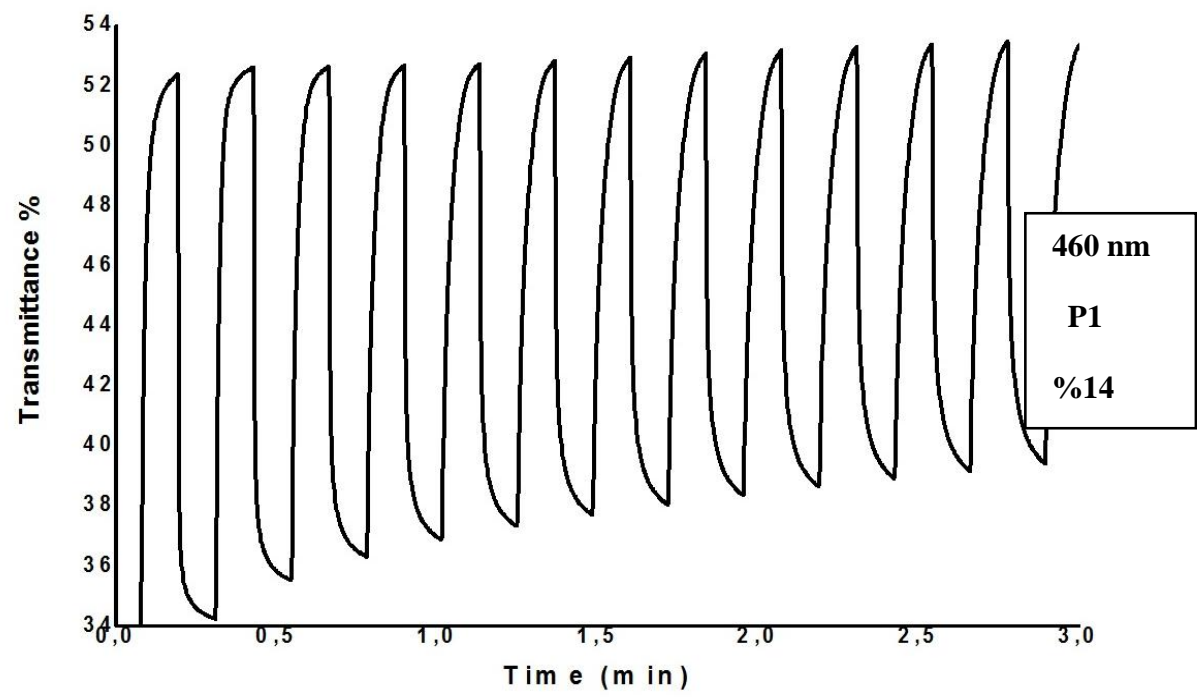

Figure 3.12 Optical transmittance changes of $\mathrm{P} 1$ monitored at $460 \mathrm{~nm}$ while switching the potentials between its oxidized and reduced states. 


\subsubsection{Gel Permeation Chromatography (GPC)}

GPC analysis of P1 showed that the polymer has Mn of 42400, Mw of 257000 and PDI of 6.1 with 97 average number of repeating units.

\subsection{Poly(4-(5-(2-dodecyl-7-(thiophen-2yl)-2H-benzo[d][1,2,3]triazol-4-} yl)thiophen-2-yl)benzo[c] $[1,2,5]$ thiadiazole (P2)

\subsubsection{Cyclic Voltammetry (CV)}

In order to investigate the electrochemical properties of $\mathrm{P} 2$, same conditions and method as was the case for P1 were used. The only difference in P2 was the potential which was swept between -2.0 and $1.1 \mathrm{~V}$. From cyclic voltammogram of the polymer, it can be seen that the polymer is both $\mathrm{p}$ and $\mathrm{n}$ dopable. Additional electron rich thiophene units in $\mathrm{P} 2$ resulted in lower doping/dedoping potentials $(0.92$ and $0.78 \mathrm{~V})$ compared to those of P1 in identical electrolytic media. In the case of electrochemical p-doping/dedoping P2 showed lowest potentials which is in correlation with the trend in BTz bearing copolymers with 9,9'-dioctylfluorene instead of BTd unit [60]. P2 film revealed a reversible reduction couple at -1.53/1.04 V. Moreover, P2 polymer film revealed two reduction peaks at negative potentials $(-1.53 /-1.16)$ due to the separation caused by thiophene units between two different acceptor units. All these electrochemical data and calculated values of HOMO, LUMO energy levels and electrochemical band gap of the polymer from the polymer's cyclic voltammogram were given in Table 2 . 


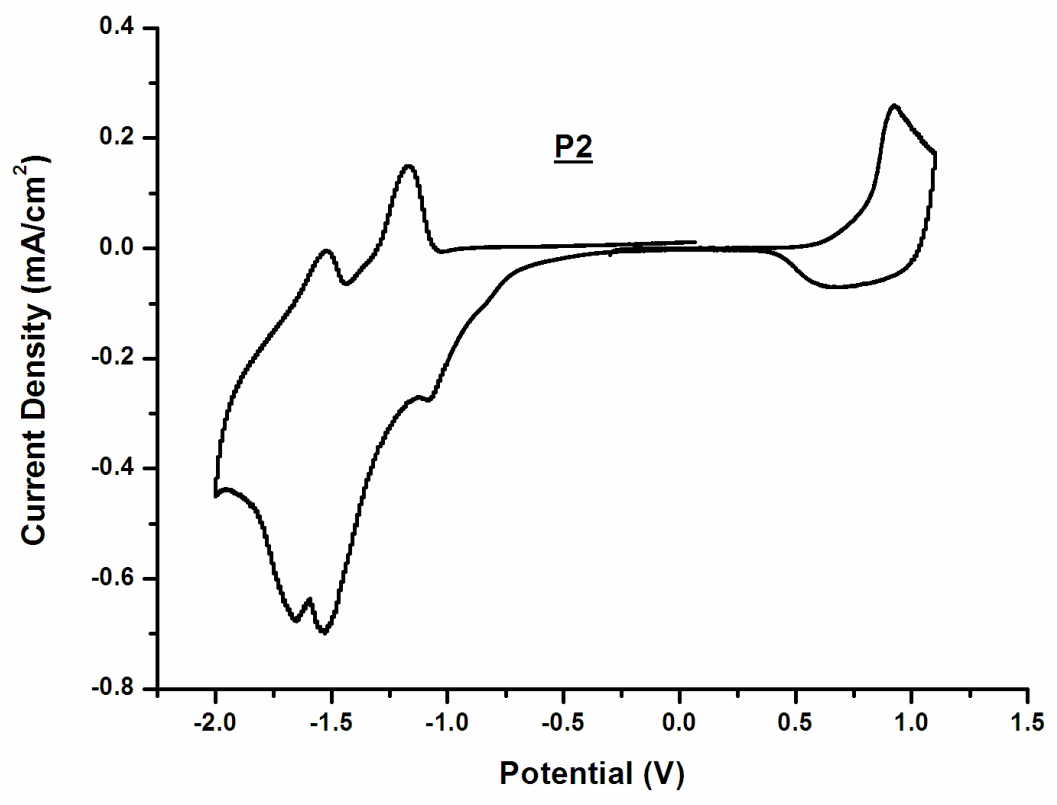

Figure 3.13 Cyclic voltammogram of $\mathrm{P} 2$ for both $\mathrm{p}$ and $\mathrm{n}$ type doping in the presence of $0.1 \mathrm{M} \mathrm{TBAPF}_{6} / \mathrm{ACN}: \mathrm{DCM}$ solution at a scan rate of $50 \mathrm{mV} / \mathrm{s}$.

Table 2. Cyclic Voltammetry and EVS results of P2 (CV was recorded in $0.1 \mathrm{M}$ $\mathrm{TBAPF}_{6} / \mathrm{ACN}$ : DCM solution at a scan rate of $50 \mathrm{mV} / \mathrm{s}$.

\begin{tabular}{|l|l|l|l|l|l|l|l|l|}
\hline P2 & \multicolumn{2}{l|l}{ Oxidation } & \multicolumn{2}{l|}{ Reduction } & \multicolumn{2}{l|}{ Bandgap (eV) } & \multicolumn{2}{l|}{$\begin{array}{l}\text { Energy Level (eV) } \\
\text { (from CV) }\end{array}$} \\
\hline & $\mathrm{E}_{\text {ox }}$ & $\begin{array}{l}\text { Eox } \\
\text { onset }\end{array}$ & $\mathrm{E}_{\text {red1 }} / \mathrm{E}_{\text {red2 }}$ & $\mathrm{E}_{\text {red1 }}{ }^{\text {onset }}$ & $\mathrm{E}_{\mathrm{g}}{ }^{\text {ec }}$ & $\mathrm{E}_{\mathrm{g}}{ }^{\text {op }}$ & HOMO & LUMO \\
\hline & 0.92 & 0.78 & $-1.53 /-1.16$ & -1.04 & 1.98 & 1.62 & -5.67 & -3.69 \\
\hline
\end{tabular}




\subsubsection{Spectroelectrochemistry}

In order to observe the optoelectronic properties of the polymer, same conditions and method used for P1 were used for P2. The absorbance changes were noted as the potential was gradually increased from $0.0 \mathrm{~V}$ to $1.35 \mathrm{~V}$. Thiophene containing P2 showed multicolored electrochromic property in a range of low potentials. P2 has a dominant wavelength in the visible region centered at $600 \mathrm{~nm}$ with an absorption onset at $775 \mathrm{~nm}$ (Figure 3.18). Although it also has absorption peak at $475 \mathrm{~nm}$, dominant transition determined the color for P2 since it has deep blue color in its neutral state. Depletion of these bands at more positive potentials where doping takes place resulted in transmissive for the visible light and polymer film turned out to be almost transparent. As the potential was increased, the absorptions in the visible region started to decrease simultaneously as the new bands were intensified in the NIR region at around $1800 \mathrm{~nm}$. The increase in intensity of absorbance in NIR region indicates the formation of lower energy charge carriers, such as polarons and bipolarons. 


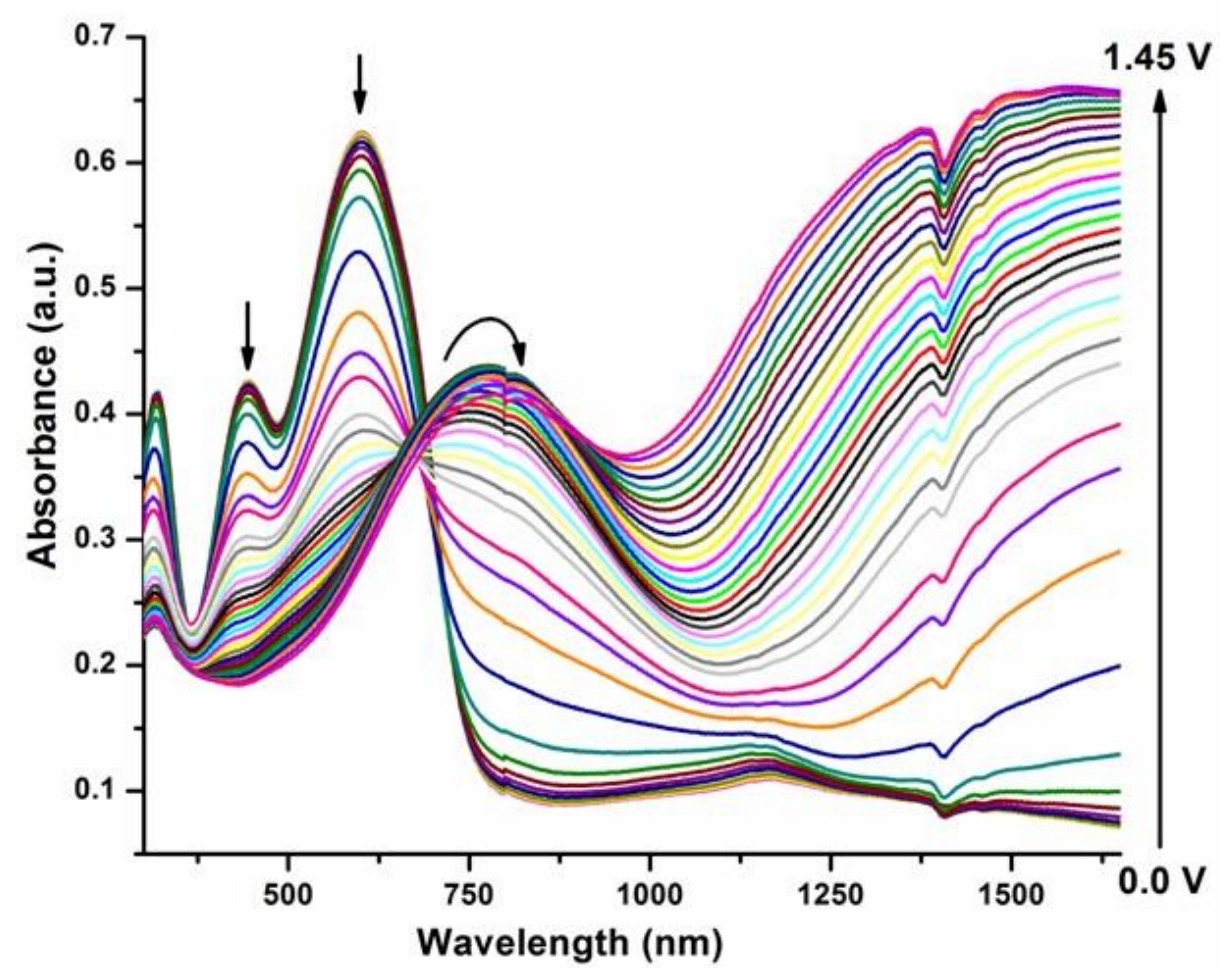

Figure 3.14 p-Doping electronic absorption spectra of $\mathrm{P} 2$ between 0.0 and $1.45 \mathrm{~V}$ in 0.1 M TBAPF 6 ACN:DCM (9:1) electrolyte-solvent couple.

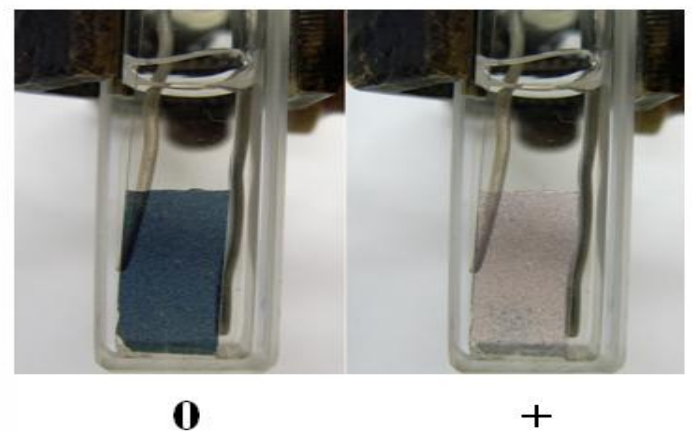

Figure 3.15 Colors of the electrochromic electrodes of P2 at different potentials. 


\subsubsection{Kinetic Studies}

Optical experiments of $\mathrm{P} 2$ were carried out for $\mathrm{P} 2$ in $\mathrm{ACN} / \mathrm{TBAPF}_{6}$ solution in order to observe the changes between its neutral and fully oxidized states. At its dominant wavelength in the visible region $(600 \mathrm{~nm}), \mathrm{P} 2$ revealed $23 \%$ percent transmittance change. The switching time for P2 at corresponding wavelength was calculated as $0.7 \mathrm{~s}$. In NIR region at around $1800 \mathrm{~nm}$, the change in the optical properties was increased to $47 \%$ for P2 with a very short switching time of $0.66 \mathrm{~s}$. Polymer film for P2 exhibits high stability when it was exposed to repetitive and consecutive switching studies.

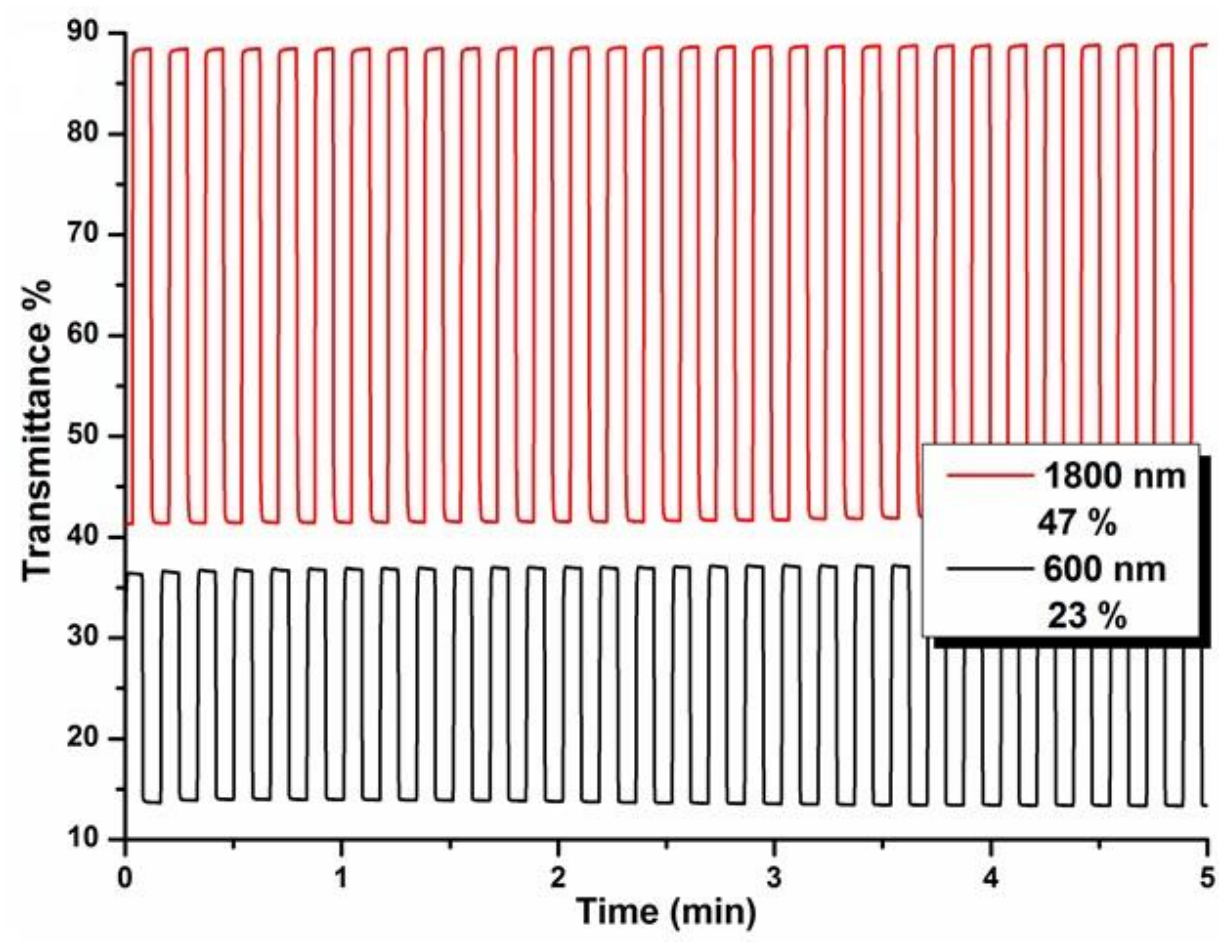

Figure 3.16 Square wave potential step chronoapsorptometry studies of P2 monitored at its maximum absorption wavelengths between $0.0 \mathrm{~V}$ and $1.4 \mathrm{~V}$. 


\subsubsection{Gel Permeation Chromatography}

GPC analysis of P2 showed that the polymer has Mn of 10300, Mw of 53500 and PDI of 5.2 with 18 average number of repeating units.

3.4 Poly(4-(5-(2-dodecyl-7-(4-hexylthiophen-2-yl)-2H-benzo[d][1,2,3] triazol-4yl)-3-hexylthiophen-2-yl)benzo[c][1,2,5] thiadiazole (P3)

\subsubsection{Cyclic Voltammetry (CV)}

In order to investigate the electrochemical properties of $\mathrm{P} 3$, same conditions and method were used. The only difference in P3 was the potentials which were swept between -2.0 and $1.25 \mathrm{~V}$. From the cyclic voltammogram of the polymer, it can be seen that the polymer is both $\mathrm{p}$ and $\mathrm{n}$ dopable. $\mathrm{P} 3$ film revealed reversible redox couple at 1.15 and $0.89 \mathrm{~V}$. P3 films revealed two reduction peaks at negative potentials $(-1.67 /-1.98)$ due to the separation caused by thiophene units between two different acceptor units as in the case of P2 film. P3 showed reversible reduction couples at $-1.67 /-0.99 \mathrm{~V}$. All these electrochemical data and calculated values of HOMO, LUMO energy levels and electrochemical band gap of the polymer from the polymer's cyclic voltammogram were given in Table 3. 


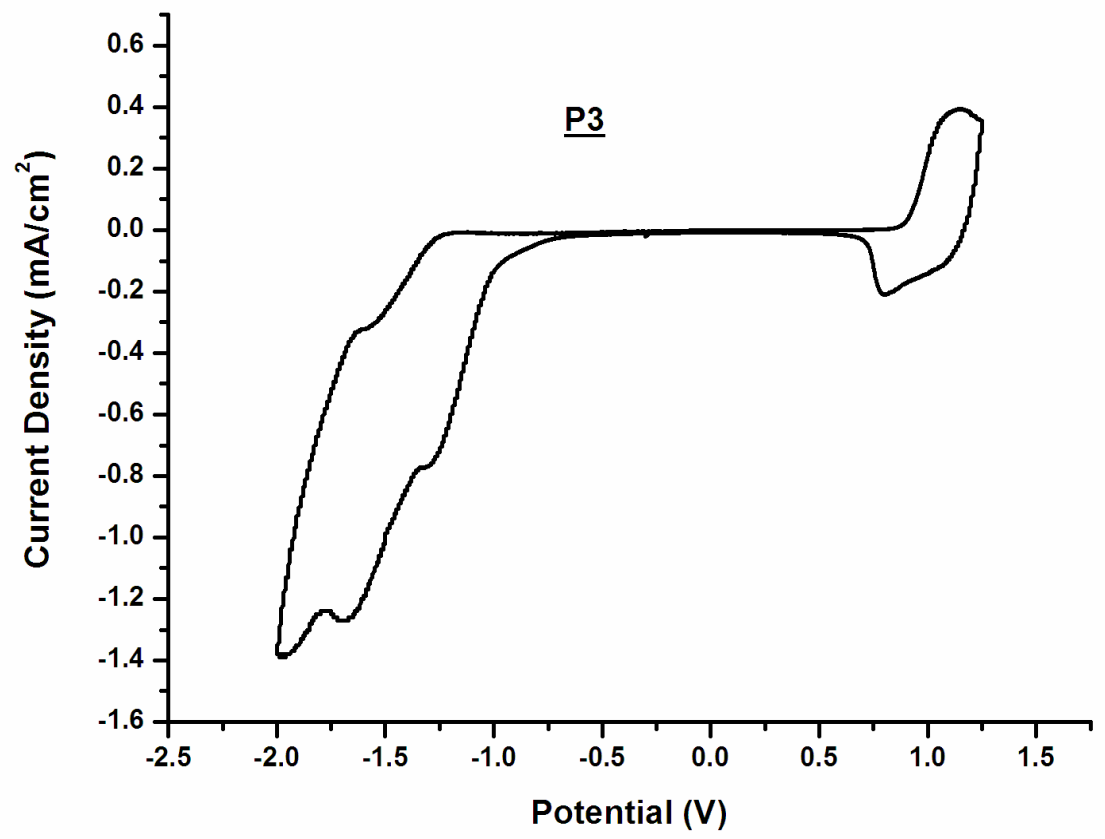

Figure 3.17 Cyclic voltammogram of $\mathrm{P} 3$ for both $\mathrm{p}$ and $\mathrm{n}$ type doping in the presence of $0.1 \mathrm{M}$ TBAPF6/ACN:DCM solution at a scan rate of $50 \mathrm{mV} / \mathrm{s}$.

Table 3. Cyclic Voltammetry and EVS results of $\mathrm{P} 2$ (CV was recorded in $0.1 \mathrm{M}$ $\mathrm{TBAPF}_{6} / \mathrm{ACN}: \mathrm{DCM}$ solution at a scan rate of $50 \mathrm{mV} / \mathrm{s}$.

\begin{tabular}{|c|c|c|c|c|c|c|c|c|}
\hline \multirow[t]{2}{*}{ P3 } & \multicolumn{2}{|c|}{$\begin{array}{l}\text { Oxidation } \\
\text { Potential (V) }\end{array}$} & \multicolumn{2}{|c|}{$\begin{array}{l}\text { Reduction } \\
\text { Potential (V) }\end{array}$} & \multicolumn{2}{|c|}{ Bandgap (eV) } & \multicolumn{2}{|c|}{$\begin{array}{l}\text { Energy Level }(\mathrm{eV}) \\
(\text { from } \mathrm{CV})\end{array}$} \\
\hline & $\mathrm{E}_{\mathrm{ox}}$ & $\mathrm{E}_{\mathrm{ox}}{ }^{\text {onset }}$ & $\mathrm{E}_{\text {red } 1} / \mathrm{E}_{\mathrm{red} 2}$ & $\mathrm{E}_{\text {red1 }}{ }^{\text {onset }}$ & $E_{g}{ }^{e c}$ & $\mathrm{E}_{\mathrm{g}}{ }^{\mathrm{op}}$ & HOMO & LUMO \\
\hline & 1.15 & 0.89 & $-1.67 /-1.98$ & -0.99 & 1.88 & 1.93 & -5.64 & -3.76 \\
\hline
\end{tabular}




\subsubsection{Spectroelectrochemistry}

In order to observe the optoelectronic properties of the polymer, spectral behaviors of P3 should be observed by the electronic absorption spectra under applied potentials. The same conditions and method used for P1 and P2 were also used for P3. The absorbance changes were noted as the potential was gradually increased from $0.0 \mathrm{~V}$ to $1.45 \mathrm{~V}$.

Compared to $\mathrm{P} 2, \mathrm{P} 3$ revealed a relatively blue shifted maximum absorption in the visible region at $434 \mathrm{~nm}$ with an onset at $652 \mathrm{~nm}$ (Figure 3.26). With increasing potentials, the absorptions in the visible region started to decrease simultaneously as the new bands were intensified in the NIR region at around $1200 \mathrm{~nm}$ for P3. The increase in intensity of absorbance in NIR region indicates the formation of lower energy charge carriers, namely, polarons and bipolarons. Polaronic absorption bands tailed into visible region and a green transition colored state became detectable when the polymer film was partially doped. 


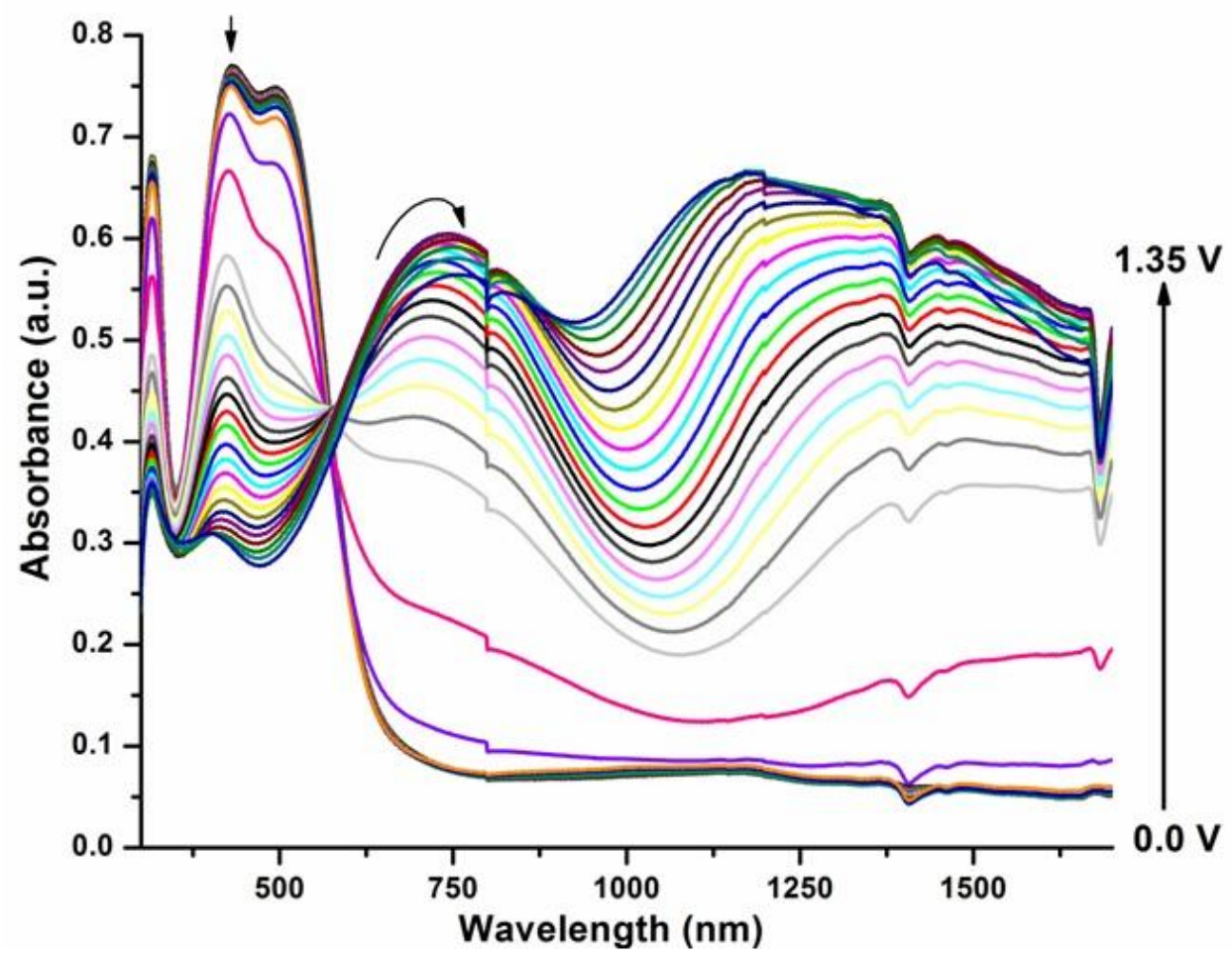

Figure 3.18 p-Doping electronic absorption spectra of $\mathrm{P} 3$ between 0.0 and $1.3 \mathrm{~V}$ in 0.1 M TBAPF 6 / ACN:DCM (9:1) electrolyte-solvent couple.

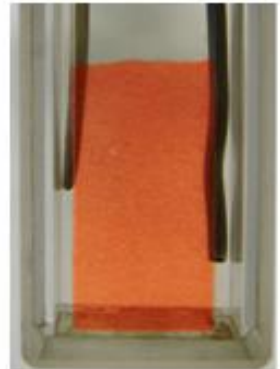

0

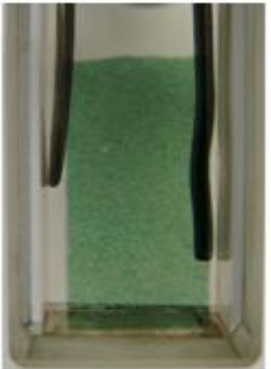

$+$

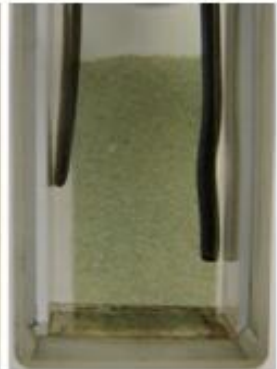

$++$

Figure 3.19 Colors of the electrochromic electrodes of P3 at different potentials. 


\subsubsection{Kinetic Studies}

Kinetic studies of $\mathrm{P} 3$ were performed in $\mathrm{ACN}^{\mathrm{T}} \mathrm{TBAPF}_{6}$ solution in order to observe the changes between its neutral and fully oxidized states. P3 exhibited $21 \%$ optical contrast with a switching time of $1.9 \mathrm{~s}$ in visible region (at $430 \mathrm{~nm}$ ) and $49 \%$ transmittance change $(2.2 \mathrm{~s})$ was recorded between its doped and de-doped states in NIR region (at $1200 \mathrm{~nm}$ ) (Fig. 3.19). Due to the high rigidity in P3 films which stems from the long alkyl chains on thiophene and benzotriazole units, polymer film was switched slower when compared to its homologue P2. Polymer film for P3 exhibit high stability when they exposed to repetitive and consecutive switching studies as in the case of $\mathrm{P} 2$.

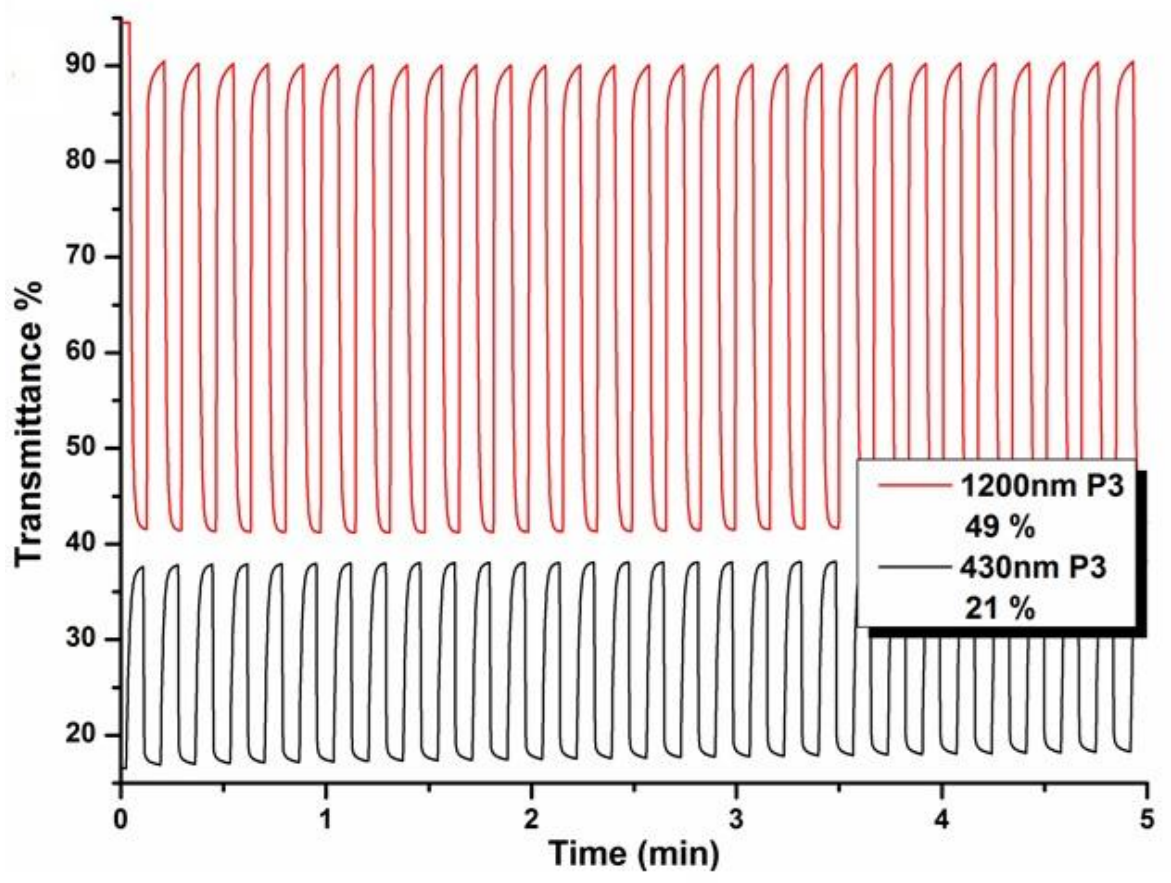

Figure 3.20 Square wave potential step chronoapsorptometry studies of P3 monitored at its maximum absorption wavelengths between $0.0 \mathrm{~V}$ and $1.4 \mathrm{~V}$. 


\subsubsection{Gel Permeation Chromatography (GPC)}

GPC analysis of P3 showed that the polymer has Mn of 11000, Mw of 18000 and PDI of 1.6 with 14 average number of repeating units.

\subsection{Photovoltaic Properties}

\subsubsection{Normalized UV-Vis Absorption of Polymers in Solution and Thin Film}

UV- Vis absorption spectra of the polymers in solution $\left(\mathrm{CHCl}_{3}\right)$ showed that all these polymers had two absorption peaks which were observed in all donor acceptor type polymers. The shorter wavelength absorption peak (between 300-400 nm) was the absorption of the donor unit, while the longer wavelength absorption belonged to the polymer. Maximum absorption wavelengths for the polymers P1, P2 and P3 are $453 \mathrm{~nm}, 568 \mathrm{~nm}$ and $417 \mathrm{~nm}$, respectively.

UV-Vis absorption spectra of the polymers in thin film form showed that red shift was observed at the maximum absorption wavelength for each of the polymers. Maximum absorption wavelengths for the polymer films P1, P2 and P3 are $500 \mathrm{~nm}$, $610 \mathrm{~nm}$ and $425 \mathrm{~nm}$. This is resulted from decreased conformational freedom, solvent polymer interactions and tendency to aggregate in thin film form. 


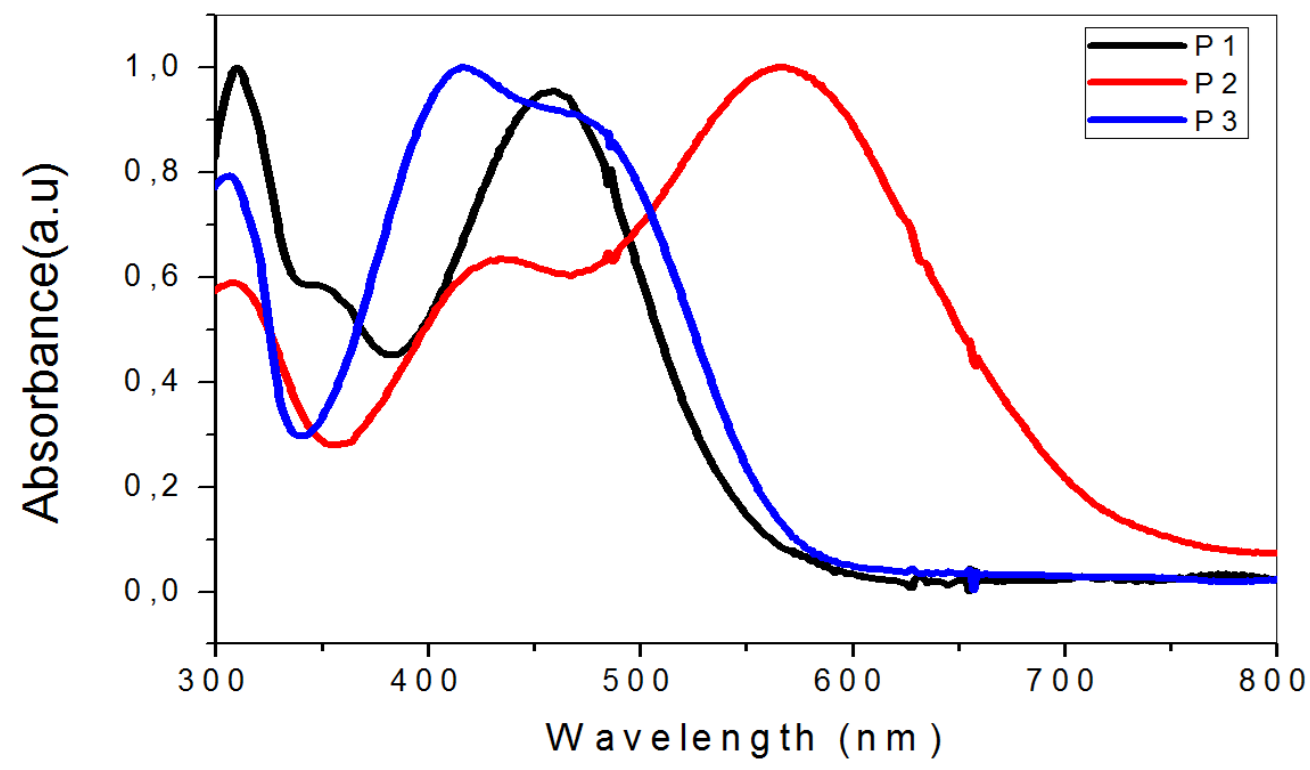

Figure 3.21 Normalized UV-Vis spectra of the P1, P2, P3 in chloroform.

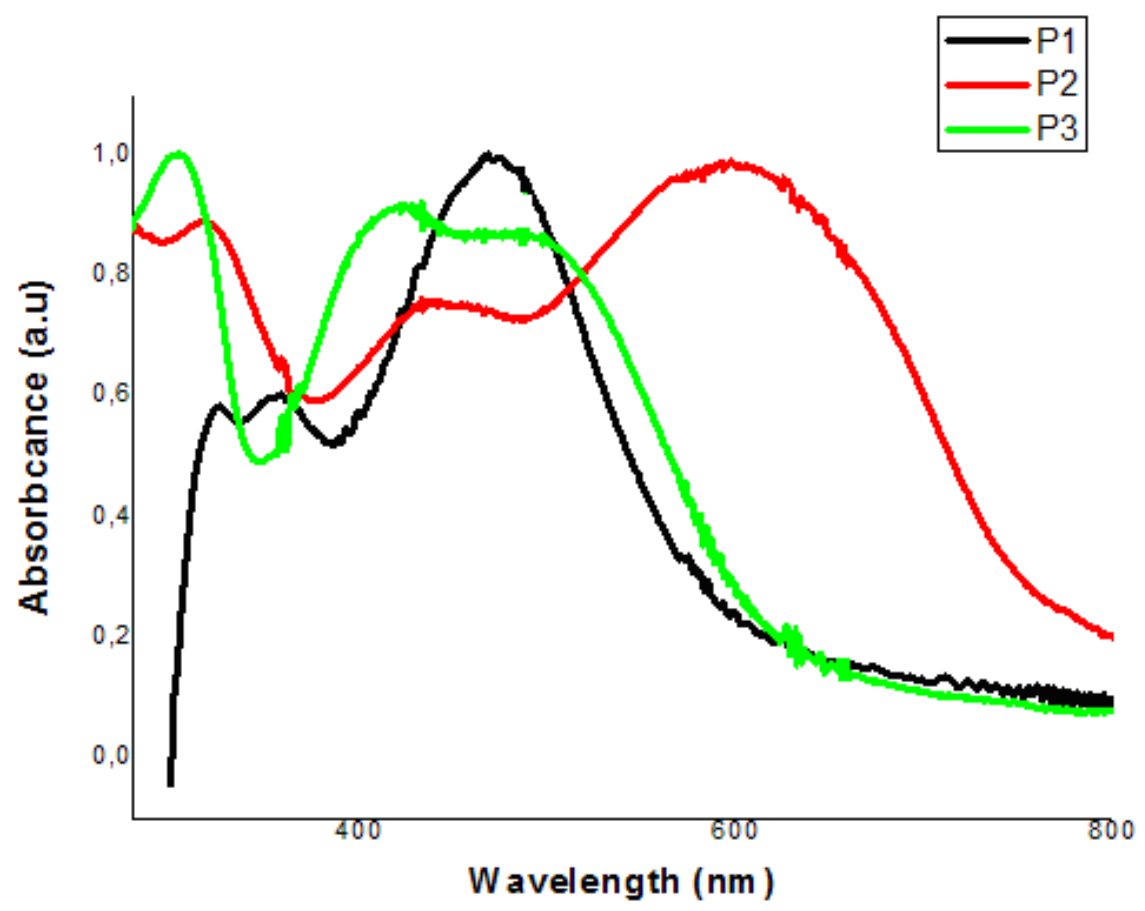

Figure 3.22 Normalized UV-Vis spectra of the P1, P2, P3 in solid state. 


\subsubsection{Photoluminescence Spectra of Polymers}

Photoluminescence spectra of the polymers showed that the polymers P1, P2 and P3 emitted light at 545, 660 and $638 \mathrm{~nm}$. These data revealed that P1 emits green while P2 and P3 emit bluish green light. All of these polymers can be used in OLED applications.

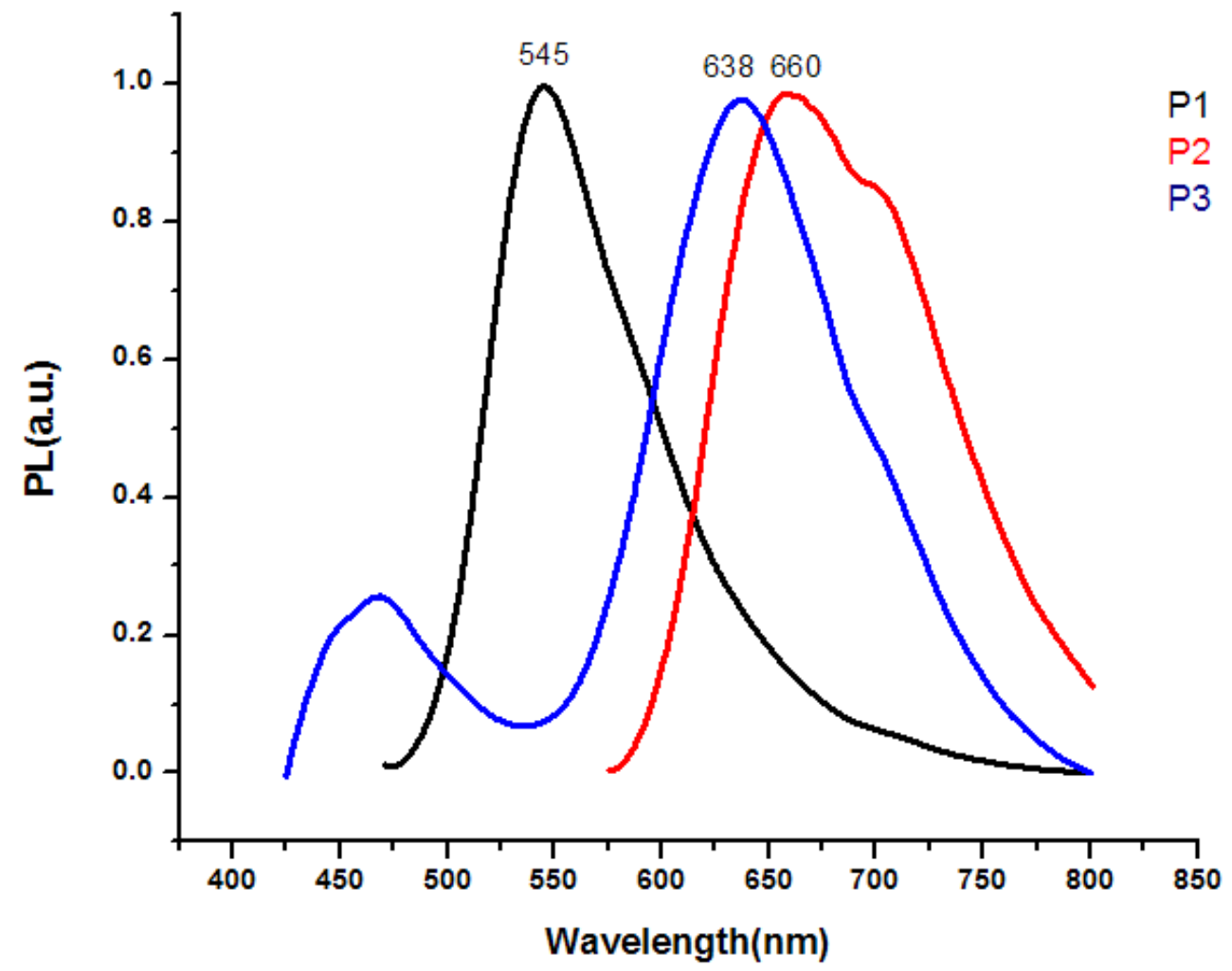

Figure 3.23 PL spectra of P1, P2 and P3 in chloroform. 


\subsubsection{BHJ Solar Cell Characterization}

The BHJ solar cells were fabricated with 1:1, 1:2 and 1:3 weight ratios to optimize the performance of the device. Figure 3.23 shows the J-V curve of the solar cells with the highest PCE. The highest PCE values were observed in 1:3 weight ratio for P1:PCBM and P3:PCBM based solar cells, while 1:1 ratio for P2:PCBM. P1:PCBM based solar cell exhibited its highest PCE of $0.15 \%$ with a $\mathrm{V}_{\mathrm{oc}}$ of $0.48 \mathrm{~V}, \mathrm{~J}_{\mathrm{sc}}$ of 0.92 $\mathrm{mA} / \mathrm{cm}^{2}$ and FF of 0.34. P2:PCBM based solar cell showed its highest PCE of 0.45 $\%$ with a $\mathrm{V}_{\mathrm{oc}}$ of $0.4 \mathrm{~V}, \mathrm{~J}_{\mathrm{sc}}$ of $3.48 \mathrm{~mA} / \mathrm{cm}^{2}$ and $\mathrm{FF}$ of 0.33 . P3:PCBM based solar cell showed its highest PCE of $0.1 \%$ with a $\mathrm{V}_{\mathrm{oc}}$ of $0.37 \mathrm{~V}, \mathrm{~J}_{\mathrm{sc}}$ of $0.96 \mathrm{~mA} / \mathrm{cm}^{2}$ and FF of 0.28. The P1:PCBM based solar cell showed higher $\mathrm{V}_{\text {oc }}$ due to the lower lying HOMO energy level (-6.1) than that of P2 (-5.67) and P3 (-5.64) since the difference between LUMO energy level of the acceptor and HOMO energy level of the donor determines the $\mathrm{V}_{\mathrm{oc}}$ of the device. The P2:PCBM based solar cell exhibited higher Jsc than that of P2 and P3 due to its broader absorption and lower band gap with respect to the others. This result is also consistent with the broader IPCE spectra (Figure 3.34) of the device based on P2:PCBM. 


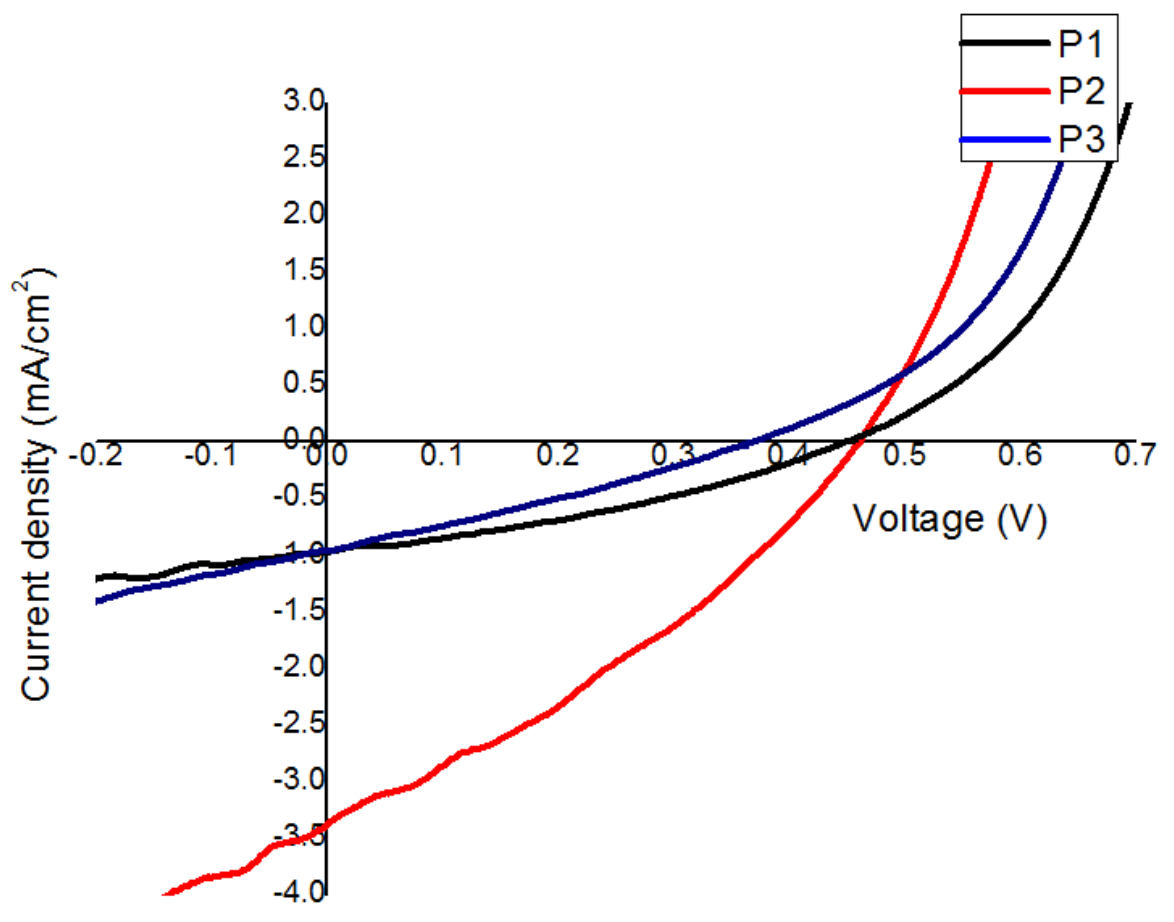

Figure 3.24 J-V Curve of the solar cells based on P1:PCBM (1-3), P2:PCBM (1:1) and P3:PCBM (1:3). 
Table 4. Photovoltaic Performance of the solar cells based on P1:PCBM, $\mathrm{P} 2: \mathrm{PCBM}$ and P3:PCBM

\begin{tabular}{|l|l|l|l|l|l|}
\hline Polymer & $\begin{array}{l}\text { Active layer } \\
\text { weight ratio } \\
\text { (Px:PCBM) }\end{array}$ & $\mathbf{V}_{\text {oc }}(\mathbf{V})$ & $\begin{array}{l}\mathbf{J}_{\text {sc }} \\
(\mathbf{m A} / \mathbf{c m} 2)\end{array}$ & $\mathbf{F F}$ & $\begin{array}{l}\text { PCE } \\
(\mathbf{\%})\end{array}$ \\
\hline \multirow{3}{*}{ P1 } & $1: 1$ & 0.45 & 0.57 & 0.29 & 0.075 \\
\cline { 2 - 6 } & $1: 2$ & 0.51 & 0.85 & 0.32 & 0.14 \\
\cline { 2 - 6 } & $1: 3$ & 0.48 & 0.92 & 0.34 & 0.15 \\
\hline \multirow{3}{*}{$\mathbf{P 2}$} & $1: 1$ & 0.4 & 3.48 & 0.33 & 0.45 \\
\cline { 2 - 6 } & $1: 2$ & 0.53 & 1.12 & 0.39 & 0.23 \\
\cline { 2 - 6 } & $1: 3$ & 0.43 & 1.33 & 0.31 & 0.18 \\
\hline $\mathbf{P 3}$ & $1: 1$ & 0.40 & 0.90 & 0.26 & 0.095 \\
\cline { 2 - 6 } & $1: 2$ & 0.37 & 0.88 & 0.29 & 0.095 \\
\cline { 2 - 6 } & $1: 3$ & 0.37 & 0.96 & 0.28 & 0.1 \\
\hline
\end{tabular}

\subsubsection{IPCE Spectrum of the Polymers}

IPCE curves of the polymers between 300 and $900 \mathrm{~nm}$ are shown in the following figures. They were used to obtain information on the number of photons that contributes to charge generation in the solar cell. P1 has a maximum at $489 \mathrm{~nm}$ with a peak value of $0.23 \%$ when mixed with in a ratio of 1:3. P2 has a maximum at 590 $\mathrm{nm}$ with a peak value of $11.51 \%$ when mixed with in a ratio of $1: 1$. P3 has a maximum at $550 \mathrm{~nm}$ with a peak value of $3.68 \%$ when mixed with in a ratio of 1:3. 


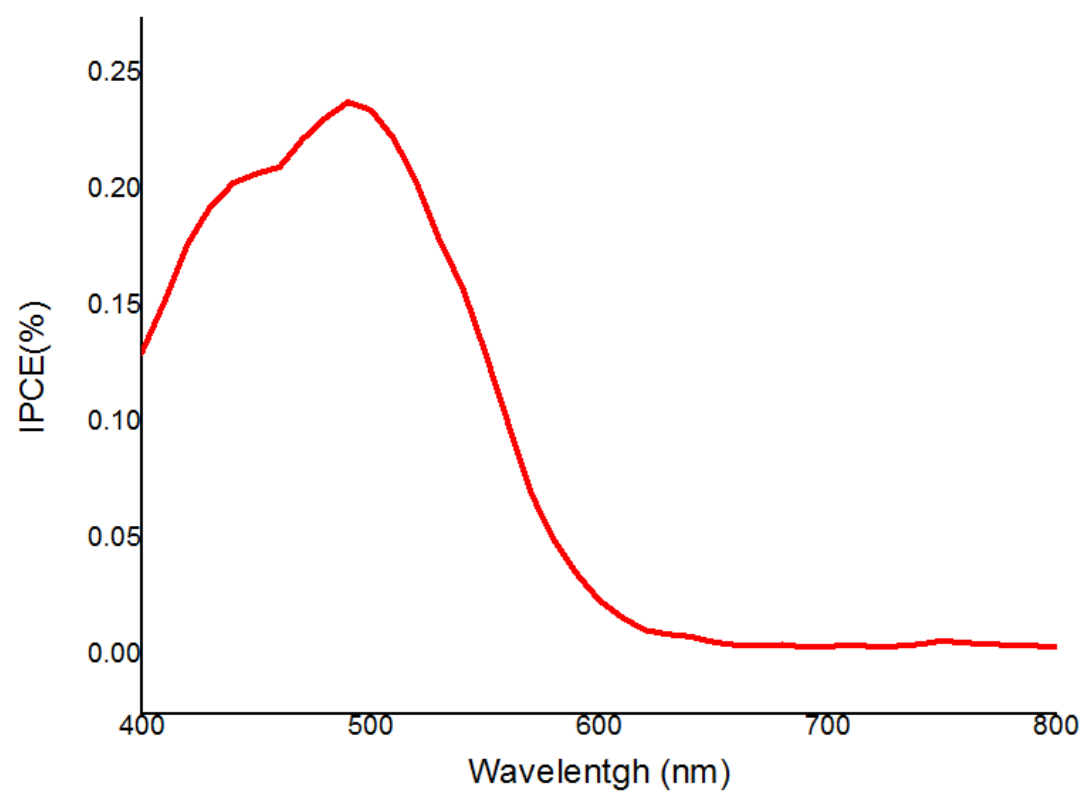

Figure 3.25 IPCE spectra of 1:3 $\mathrm{P} 1: \mathrm{PC}_{61} \mathrm{BM}$ based solar cell.

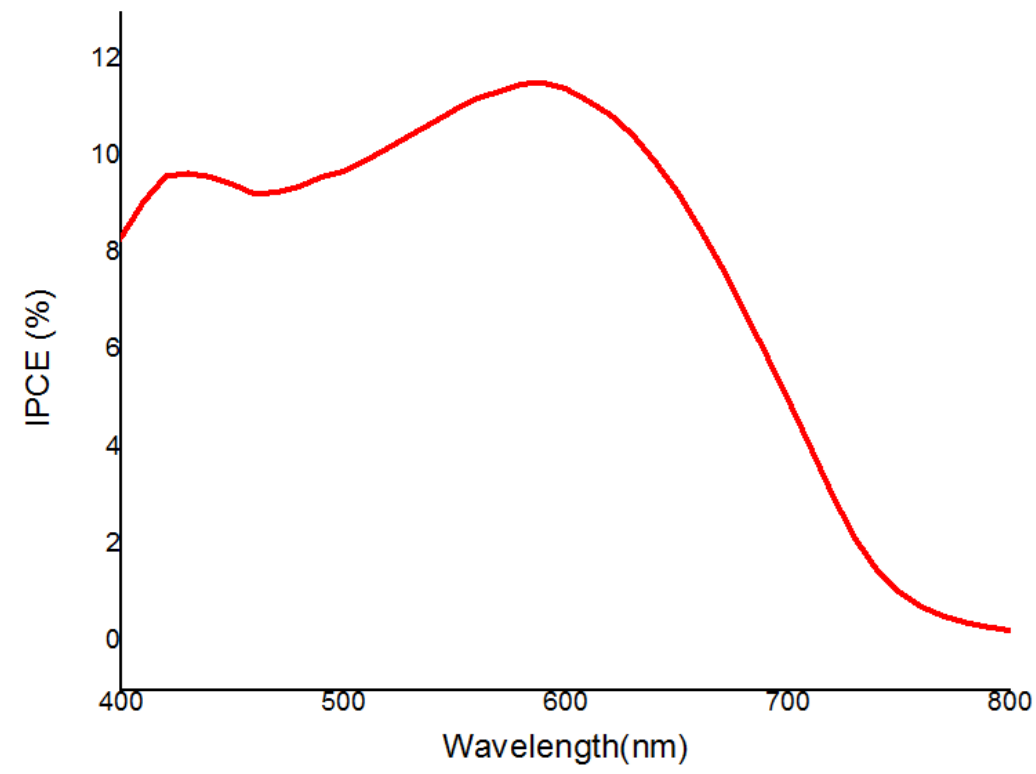

Figure 3.26 IPCE spectra of 1:1 P2:PC ${ }_{61} \mathrm{BM}$ based solar cell. 


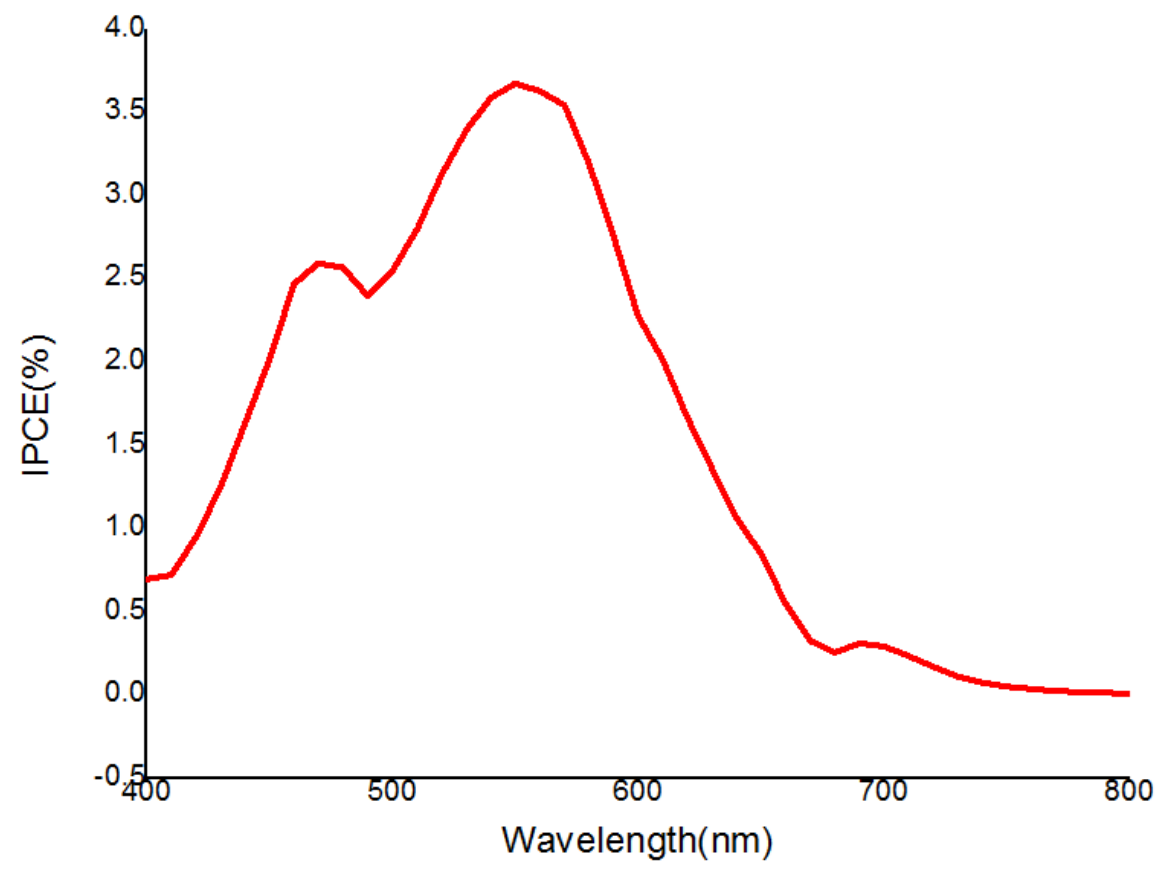

Figure 3.27 IPCE spectra of 1:3 P3:PC $61 \mathrm{BM}$ based solar cell. 


\section{CHAPTER 4}

\section{CONCLUSIONS}

Three D-A type polymers containing two acceptor units, benzotriazole and benzothiadiazole, P1, P2 and P3 were synthesized via Suziki coupling. Characterizations of the polymers were carried out by NMR, GPC, TGA and DSC. To determine the electrochemical and optical properties of these polymers, cyclic voltammetry, spectroelectrochemistry and kinetic studies were performed. Additionally, UV Absorption, PL, J-V and IPCE measurements were carried out in order to analyze photovoltaic properties of these polymers.

Electrochemical and optical studies of the polymers showed that the polymers containing BTz and BTd heterocycles exhibit true spectral and thus color change on demand when thiophene moiety is present on polymer backbone. P1 which has no thiophene units, hardly showed electroactivity. Polaron and bipolaron of the polymer were not observed in the spectroelectrochemistry studies of the polymer. The polymer revealed $14 \%$ percent transmittance change with 4.2 s switching time in the kinetic studies. P2 film showed blue neutral state with highly transparent oxidized state by changing externally applied potential. Additional alkyl chain on thiophene units affected the absorption behavior of the polymer in the neutral state in the case of P3 and polymer revealed orange-red color. Doping process for this polymer resulted in a green colored transition state and highly transparent-light green oxidized state. In combination with their solubility in common organic 
solvents polymers P2 and P3 are potential candidates to be exploited for electrochromic display devices.

Since the polymers have strong absorption, appropriate HOMO and LUMO energy levels, and good film forming and processability characteristics they were used in solar cell fabrication. The BHJ type solar cells based on the P1:PCBM, P2:PCBM, and P3:PCBM active layers were produced. The BHJ solar cell containing P2:PCBM active layer exhibited the highest PCE of $0.45 \%$ due to its broader absorption, lower band gap, broader and higher IPCE of $11.51 \%$ than those of P1 and P3. The determined $\mathrm{V}_{\mathrm{oc}}$ and $\mathrm{J}_{\mathrm{sc}}$ characteristics were appropriate with the expected results. The results obtained from the solar cells with highest PCE (1:3 for P1:PCBM and P3:PCBM, and 1:1 for P2: PCBM) were compared. The higher $\mathrm{V}_{\mathrm{oc}}$ $(0.48 \mathrm{~V})$ value was obtained from the polymer (P1) with lower lying HOMO energy level (-6.1) than that of other polymers. Moreover, higher $\mathbf{J}_{\mathrm{sc}}$ value was obtained from the polymer (P2) with broader absorption and lower band gap than other two polymers (P1 and P3). 


\section{REFERENCES}

[1] H.Letheby, J. Chem. Soc., 1862, 15, 161.

[2] E. Noelting, Scientific and Industrial History of Aniline Black; J.Matheson: New York, 1989.

[3] G. Natta, G. Mazzanti, P. Corradini, Atti Accad. Lincei Cl. Sci. Fis. Mat. Nat. Rend., 1958, 25, 3.

[4] H. Shirakawa, E. J. Louis, A. G. MacDiarmid, C. K. Chiang, A. J. Heeger, J. Chem. Soc. Chem. Comm., 1977, 578.

[5] C. K. Chiang, Jr. C. R. Fincher, Y. W. Park, A. J. Heeger, H. Shirakawa, E. J. Louis, S. C. Gau, A. G. MacDiarmid, Phys. Rev. Lett., 1977, 39, 1098.

[6] H. Shirakawa, Angew. Chem. Int. Ed., 2001, 40, 2574.

[7] A.J. Heeger, Angew. Chem. Int. Ed., 2001, 40, 2591.

[8] J. C. W. Chien, Polyacetylene: Chemistry, Physics and Materials Science, Academic, Orlondo, 1984.

[9] T. A. Skotheim, R. L. Elsenbaumer, J. R. Reynolds, Handbook of Conducting Polymers, New York, 1998. 197.

[10] G. Sonmez, Chem. Commun., 2005, 5251.

[11] T. T. Steckler, K. A. Abboud, M. Craps, A. G. Rinzler, J. R. Reynolds, Chem. Commun., 2007, 4904.

[12] P. Chandrasekhar, Conducting Polymers, Fundamentals and Applications: A Practical Approach, 1999, 10. 
[13] A. A. Argun, P. H. Aubert, B. C. Thompson, I. Schwendeman, C. L. Gaupp, J. Hwang, N. J. Pinto, D. B. Tanner, A. G. Macdiarmid, J. R. Reynolds, Chem. Mater., 2004, 16, 4401.

[14] A. J. Heeger, S. Kivelson, J. R. Schrieffer, W.P. Su, Rev. Mod. Phys., 1988, 60, 3,781 .

[15] W. P. Su, J. R. Schrieffer, A. J. Heeger, Phys. Rew. Lett., 1979, 42, 25, 1698.

[16] J. L. Bradas, G. B. Street, Acc. Chem. Res., 1985, 18, 309.

[17] J. I. Bredas, R. R. Chance, R. Silbey, Phys. Rew. B, 1982, 26, 10, 5843.

[18] A. G. Macdiarmid, Angew. Chem. Int. Ed., 2001, 40, 2581.

[19] D. M. de Leeuw, M. M. J. Simenon, A. R. Brown, R. E. F. Einerhand, Synth. Met., 1997, 87, 53.

[20] C. J. DuBois, F. Larmat, D. J. Irvin, J. R. Reynolds, Synth. Met., 2001, 119, 321.

[21] J. K. Stille, Angew. Chem. Int. Ed. Engl., 1986, 25, 508.

[22] L. Kurti, B. Czako, Strategic Applications of Named Reactions in Organic Synthesis: Elsevier Academic Press 2005.

[23] N. Miyaura, A. Suzuki, Chem. Rev., 1995, 95, 2457.

[24] J. H. Kirchhoff, M. R. Netherton, I. D. Hills, G. C. Fu, J. Am. Chem. Soc., $2002,124,1362$.

[25] E. R. Kötz, H. Neff, K. Müller, J. Electroanal. Chem., 1986, 215, 33.

[26] S. Gunes, H. Neugebauer and N. S. Sariciftci, Chem. Rev., 2007, 107, 1324. 
[27] S. H. Park, A. Roy, S. Beaupre, S. Cho, N. Coates, J. S. M. D. Moses, M. Leclerc, K. Lee and A. J. Heeger, Nat. Photon., 2009, 3, 297.

[28] A. C. Grimsdale, K. L. Chan, R. E. Martin, P. G. Jokisz and A. B. Holmes, Chem. Rev., 2009, 109, 897.

[29] J. Zaumseil and H. Sirringhaus, Chem. Rev., 2007, 107, 1296.

[30] P. M. S. Monk, R. J. Mortimer, D. R. Rosseinsky, Electrochromism and Electrochromic Devices, Cambridge University Press, New York 2007.

[31] L.S. Hwang, J.M. Ko, H.W. Rhee, C.Y. Kim, Synth. Met., 1993, 57, 3671.

[32] R.H. Baughman, Syth. Met., 1996, 78, 3, 339.

[33] P. M. S Monk, R. J. Mortimer, D. R. Rosseinsky, Electrochromism: Fundamentals and Applications; VCH: Weinheim, Germany, 1995.

[34] C. L. Gaupp, J. R. Reynolds, Macromolecules, 2003, 36, 6305.

[35] D. R. Rosseinsky, R .J. Mortimer, Adv. Mater., 2001, 13, 783.

[36] P. R. Somani, S. Radhakrishnan, Mater. Chem. Phys., 2002, 77, 117.

[37] J. Padilla, V. Seshadri, G.A. Sotzing, T.F. Otero, Electrochem. Commun., 2007, 9, 1931.

[38] J. Padilla, V. Seshadri, J. Filloramo, W. K. Mino, S. P. Mishra, B. Radmard, A. Kumar, G. A. Sotzing, T. F. Otero, Synt. Met., 2007, 157, 6-7, 261.

[39] R. J. Mortimer, Chem. Soc. Rev., 1997, 26, 147.

[40] J. Roncali, Chem. Rev., 1997, 97, 173.

[41] A.A. Argun, A. Cirpan, J.R. Reynolds, Adv. Mater. 2003, 15, 1338.

[42] C. E. Fritts. Am. J. Sci., 1883, 26, 465. 
[43] W. Shockley. Electrons and Holes in Semiconductors, D. van Nostrand, Princeton, 1950 .

[44] C.W. Tang, Appl. Phys. Lett., 1986, 48,183.

[45] M. C, Scharber, D. Meuhlbacher, M. Koppe, P. Denk, C. Waldauf, A.J. Heeger, C. J. Brabec, Adv. Mater., 2006, 18, 789.

[46] Cho, S.; Coates, N.; Moon, J. S.; Park, S. H.; Roy, A.; Beaupre,S.; Moses, D.; Leclerc, M.; Lee, K.; Heeger, A. J. Bulk Heterojunction Solar Cells with Internal Quantum Efficiency Approaching 100\%. Nat. Photon. 2009, 3, 297.

[47] Chen, H.-Y.; Hour, J.; Zhang, S.; Liang, Y.; Yang, G.; Yang, Y.; Yu, L.; Li, G. Polymer Solar Cells with Enhanced Open-Circuit Voltage and Efficiency. Nat. Photon. 2009, 3, 649.

[48] Konarka's Power Plastic Achieves World Record 8.3\% Efficiency Certification from National Energy Renewable Laboratory (NREL), http://www.konarka.com/, last accessed on 06/07/2011.

[49] K. M. Coakley, M. D. McGehee, Chem. Mater., 2004, 16, 4533.

[50] A. Facchetti, Chem. Mater., 2011, 23, 733.

[51] Y. Liang, Z. Xu, J. Xia, S-T. Tsai, Y. Wu, G. Li, C. Ray, L.Yu, Adv. Mater., 2010, 22, 135 .

[52] E. Von Hauff, V. Dyakonov, J. Parisi, Sol. Energy Mater. Sol. Cells, 2005, 87, 149.

[53] G. Yu, J. Gao, J. C. Hummelen, F. Wudl, A. J. Heeger, Science, 1995, 270, 1789.

[54] C Deibel, V Dyakonov, Rep. Prog. Phys., 2010, 73, 096401. 
[55] Y-J. Cheng, S-H.Yang, C-S. Hsu, Chem. Rev., 2009, 109, 5868.

[56] M. Jorgensen, E. Bundgaard, R. Bettignies, F.C. Krebs, The Polymer Solar Cell, Polymer Photovoltaics: A Practical Approach, Chapter - SPIE Press Book, 2008.

[57] R. Po, M. Maggini, N. Camaioni, J. Phys. Chem. C, 2010, 114, 695.

[58] G. P Smestad, Solar Cell Equations, Chapter - SPIE Press Book, 2002.

[59] E. R. Kötz, H. Neff, K. Müller, J. Electroanal. Chem., 1986, 215, 33.

[60] E. Kaya, A. Balan, D. Baran, A. Cirpan, L. Toppare, Org. Electron., 2011, 12, 202. 
APPENDIX A

\section{DSC DATA}

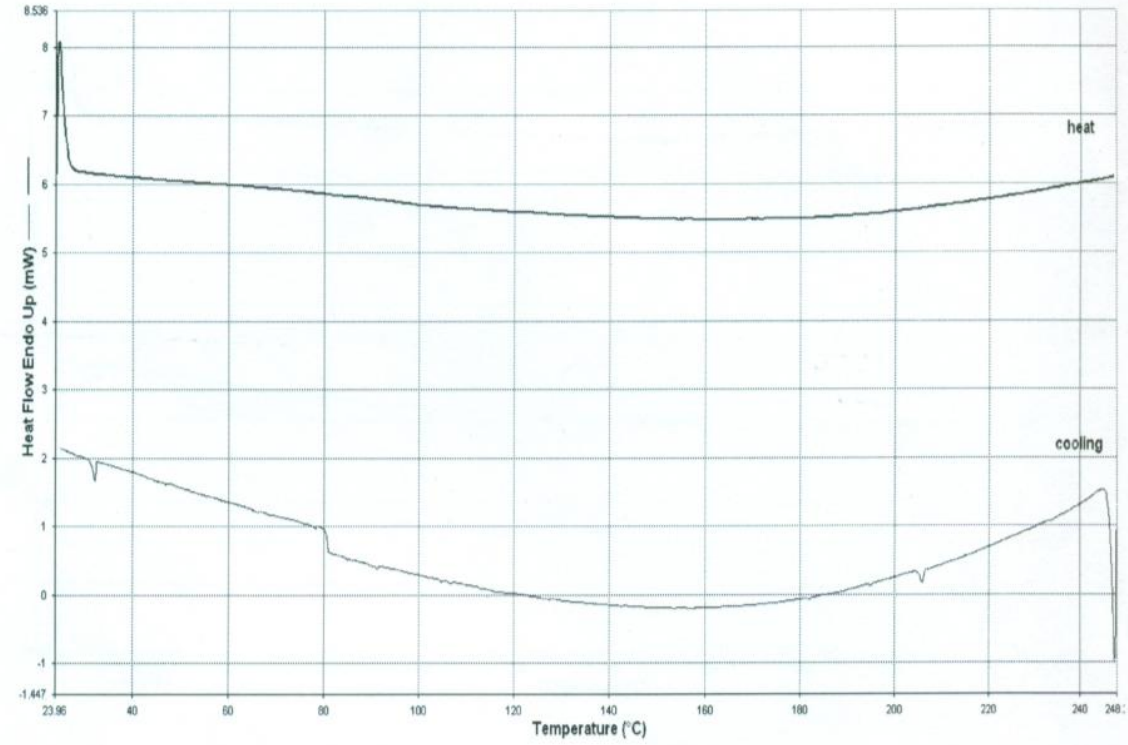

Figure A. 1 DSC Spectra of P1. 


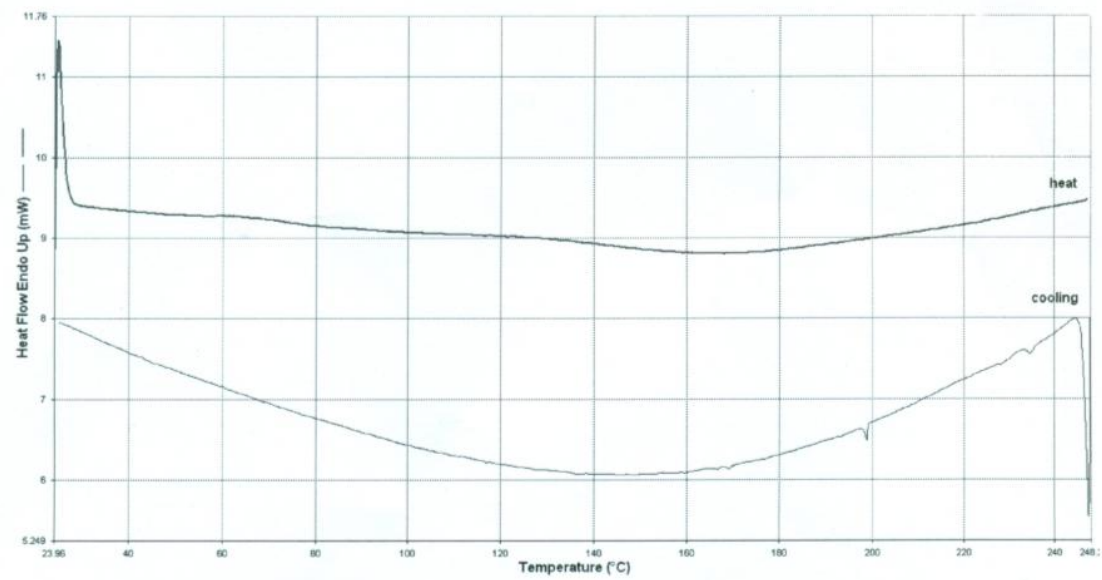

Figure A. 2 DSC Spectra of P2.

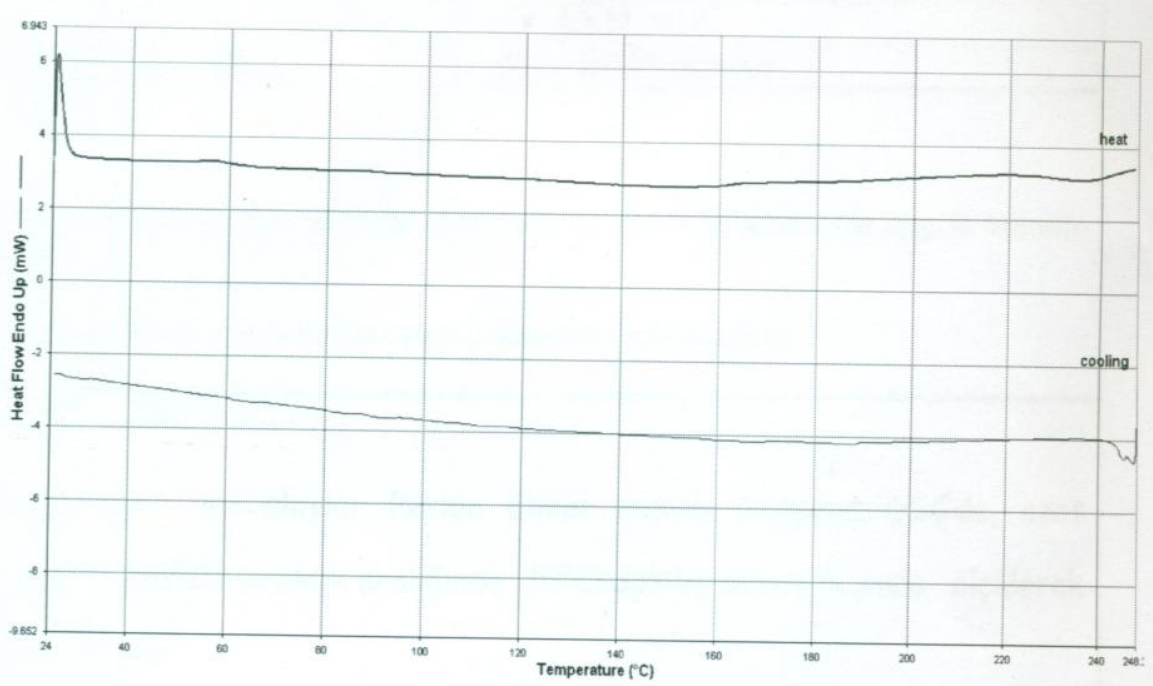

Figure A. 3 DSC Spectra of P3. 
APPENDIX B

\section{TGA DATA}

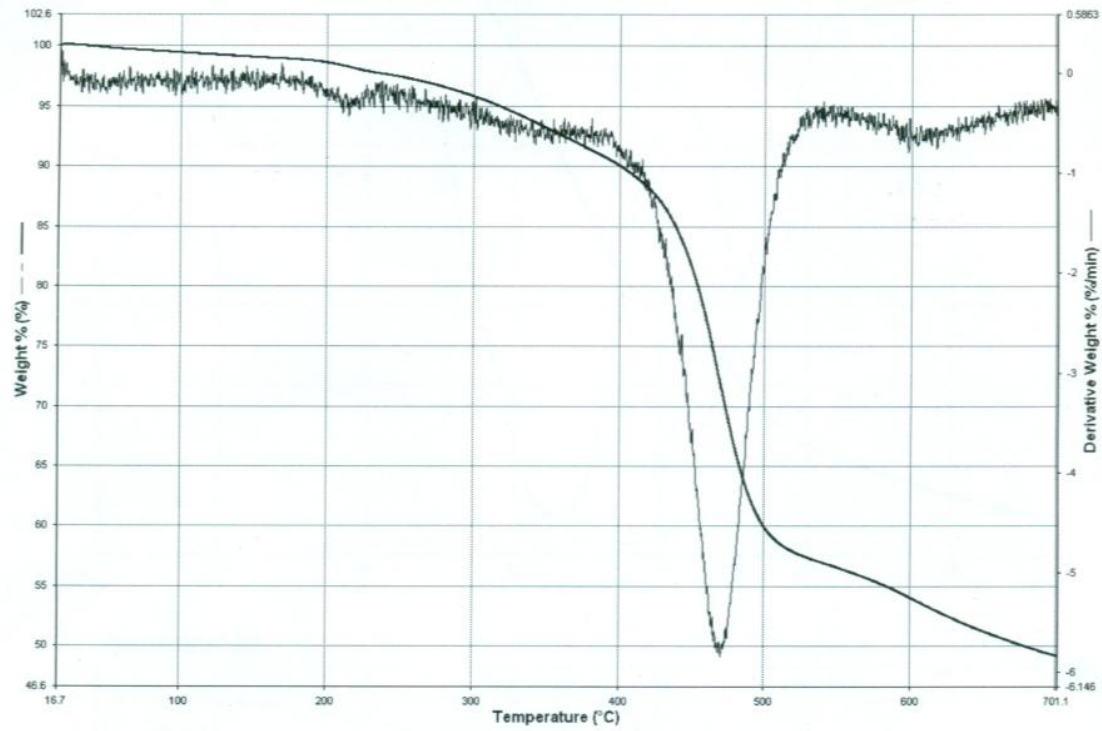

Figure B.1 TGA Spectra of P1. 


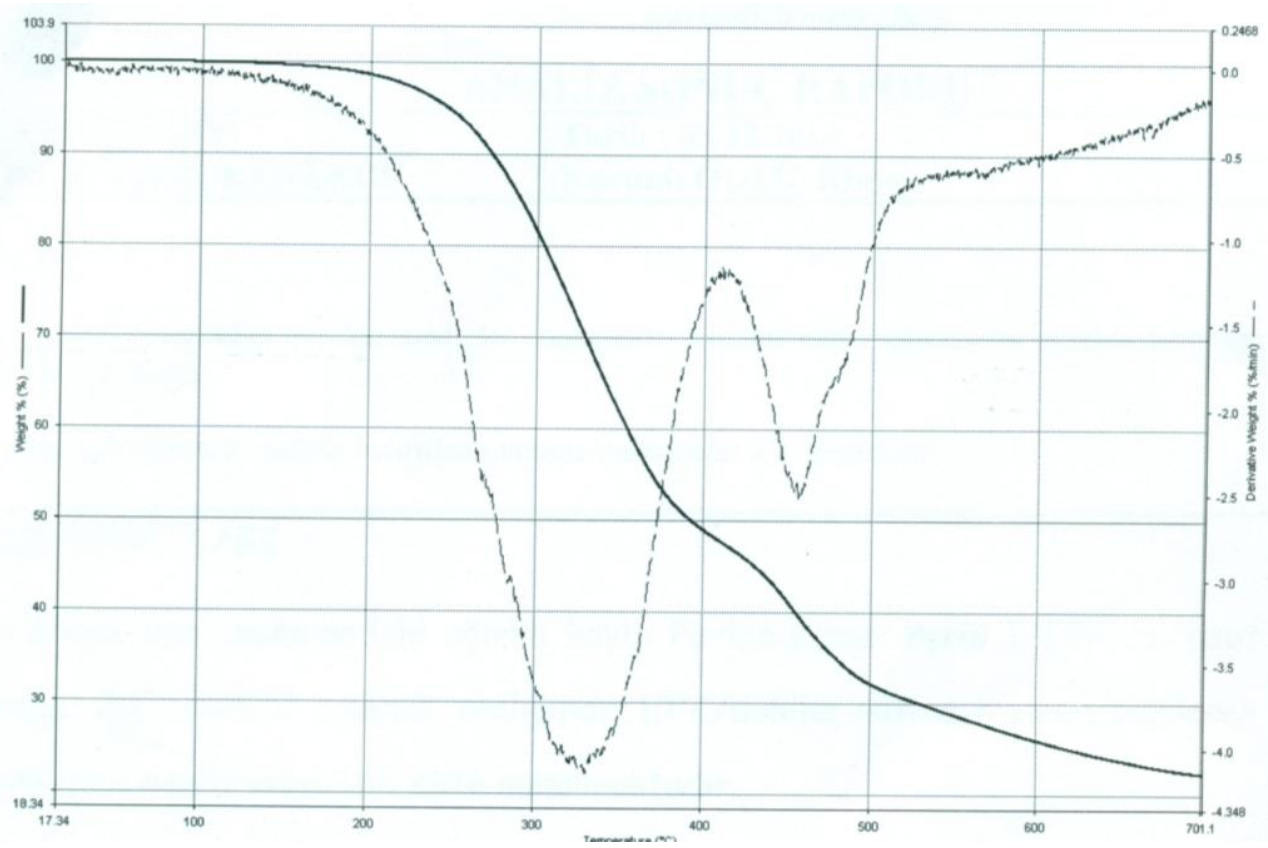

Figure B.2 TGA Spectra of P2.

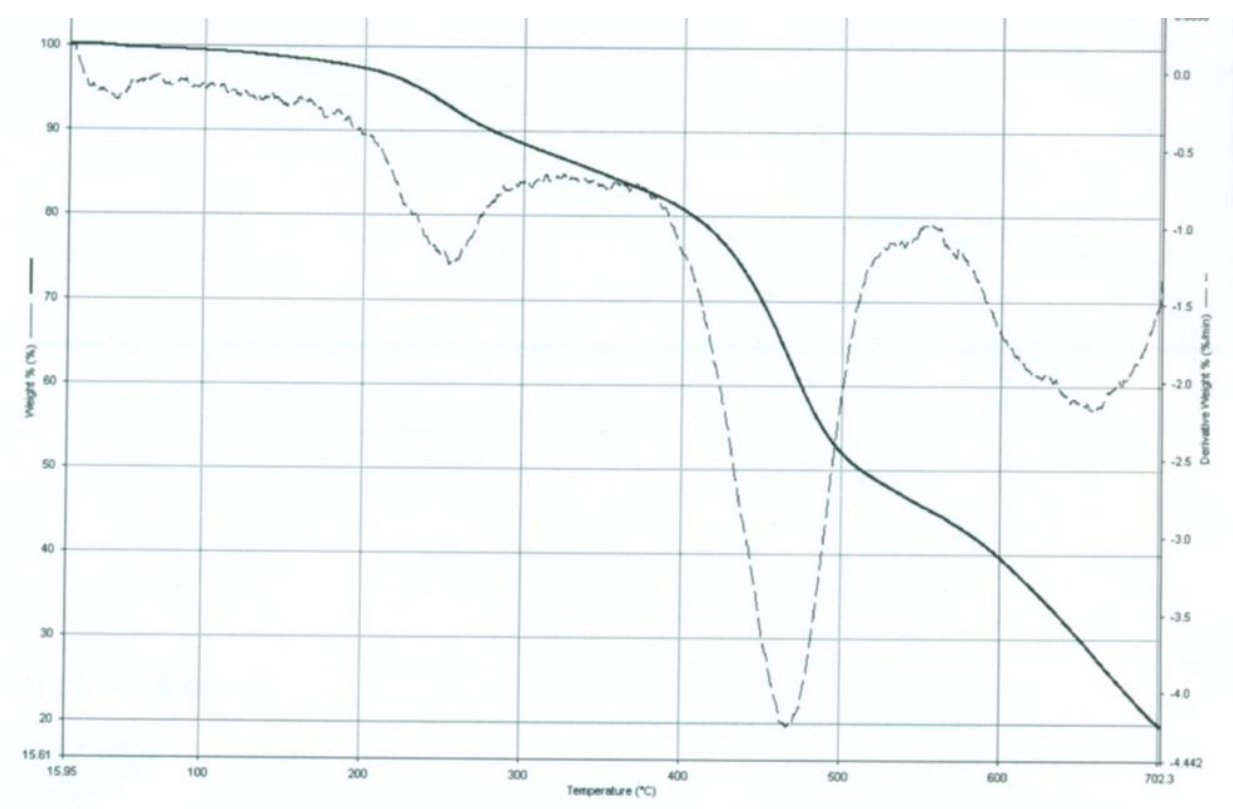

Figure B.3 TGA Spectra of P3. 